\title{
An overview of multimethod imaging approaches in environmental geophysics
}

\author{
Florian M. WAGNER (D) ${ }^{1}$ \& SEBASTIAN UHLEMANN (D) 2 \\ ${ }^{1}$ Institute for Applied Geophysics and Geothermal Energy, RWTH Aachen University, Aachen, Germany \\ ${ }^{2}$ Earth and Environmental Sciences Area, Lawrence Berkeley National Laboratory, Berkeley, United States
}

This is the authors' preprint* of a book chapter published in Advances in Geophysics:

Wagner, F. M. \& Uhlemann, S. (2021). An overview of multimethod imaging approaches in environmental geophysics. Advances in Geophysics, Vol. 62, Chap. 1, pp. 1-72, Elsevier, https://doi.org/10.1016/bs.agph.2021.06.001.

* This preprint is distributed under a CC BY 4.0 license and contains minor differences to the publisher's version.

\begin{abstract}
Quantitative characterization of subsurface properties is critical for many environmental applications and serves as the basis to simulate and better understand dynamic subsurface processes. Geophysical imaging methods allow to image subsurface property distributions and monitor their spatio-temporal changes in a minimally-invasive manner. While it is widely agreed upon that models integrating multiple independent data sources are more reliable, the number of approaches to do so is increasing rapidly and often overwhelming for researchers and, particularly, novices to the field.

With this work, we aim to contribute to the development multi-method imaging through (1) an overview of, and didactic introduction to, existing inversion approaches for the integration of multiple geophysical data sets with other measurement types (e.g., hydrological observations), petrophysical models, and process simulations, (2) a state-of-the-art review on the use and potentials of these approaches in various environmental applications, and (3) a discussion on new frontiers and remaining challenges in the field.

We hope that this chapter provides an entry point to recent developments in multimethod geophysical imaging, clarifies similarities, differences and development potentials of existing approaches, and ultimately helps practitioners to choose the optimum one to integrate their data sets.
\end{abstract}




\section{Contents}

1 Introduction 3

2 Theoretical foundation of multimethod imaging 4

2.1 Overview and terminology $\ldots \ldots \ldots \ldots \ldots \ldots \ldots \ldots \ldots \ldots \ldots \ldots \ldots$

2.2 Independent inversion and joint interpretation $\ldots \ldots \ldots \ldots \ldots$

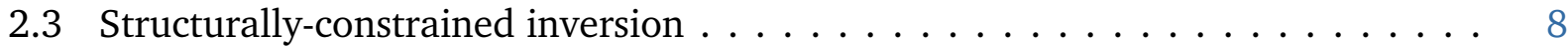

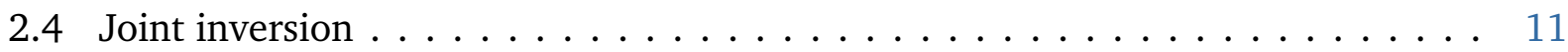

2.4.1 Structurally-coupled joint inversion . . . . . . . . . . . . 11

2.4.2 Structurally-coupled cooperative joint inversion . . . . . . . . . . . . . 12

2.4 .3 Petrophysical joint inversion . . . . . . . . . . . . . . . 13

2.5 Process-based inversion $\ldots \ldots \ldots \ldots \ldots \ldots \ldots \ldots$

3 Environmental applications $\quad 18$

3.1 Estimating vadose and critical zone properties . . . . . . . . . . 18

3.2 Groundwater investigation . . . . . . . . . . . . . . . 23

3.3 Natural hazards . . . . . . . . . . . . . . . . . . . . . 31

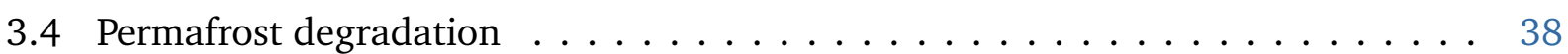

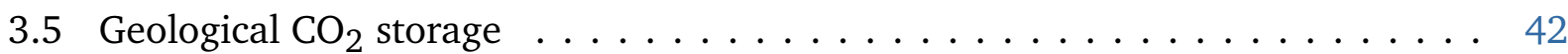

4 Remaining challenges and new frontiers $\quad 44$

4.1 Potential pitfalls in multimethod geophysical imaging . . . . . . . . . . . . . . 44

4.1.1 Structurally-constrained inversion . . . . . . . . . . . . . . 44

4.1 .2 Structural joint inversion . . . . . . . . . . . . . . . . . . 44

4.1 .3 Petrophysical joint inversion . . . . . . . . . . . . . . . . 45

4.1 .4 Process-based inversion . . . . . . . . . . . . . . . . . 46

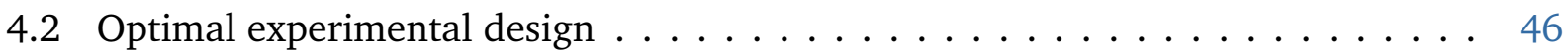

4.3 Incorporation of geological realism $\ldots \ldots \ldots \ldots \ldots$. . . . . . . . . 47

4.4 Uncertainty quantification . . . . . . . . . . . . . . . . . . . . 48

4.5 Machine learning . . . . . . . . . . . . . . . . . . . . . 49

4.6 Opportunities through open-source software developments . . . . . . . . . . 51

5 Concluding remarks $\quad 52$ 


\section{Introduction}

External stressors to our natural systems are increasing both in frequency and severity, causing ever changing and newly developing environmental problems. Geophysical techniques are widely used to characterize these natural systems at scales that are representative of the key processes defining these systems, covering the pore to the catchment scale, and are known to supplement and link conventional local sampling approaches (e.g., by using boreholes) with observations from remote sensing. Applications range from characterizing subsurface hydrological features and critical zone properties (e.g., Holbrook et al., 2014; Thayer et al., 2018; Hausmann et al., 2013; Moravec et al., 2020; Yamakawa et al., 2012), to natural hazards such as landslides (e.g., Capizzi and Martorana, 2014; Sauvin et al., 2013; Sass et al., 2008; Bièvre et al., 2012) or sinkholes (e.g., Carbonel et al., 2014; Gómez-Ortiz and Martín-Crespo, 2012), permafrost degradation (e.g., Parsekian et al., 2019; Mollaret et al., 2020; Steiner et al., 2021), or geological $\mathrm{CO}_{2}$ storage (e.g., Carcione et al., 2012; Bergmann et al., 2016).

A fundamental problem of geophysical measurements made at the Earth's surface is that they commonly can be explained by a multitude of models resulting in interpretational ambiguity. For example, while the onset of subsurface permafrost typically coincides with a considerable increase in seismic velocity and thus a strong signal in refraction data sets (e.g., Hilbich, 2010), its base often represents a velocity inversion leading to the well-known hidden layer problem (Banerjee and Gupta, 1975). Fortunately, this very same transition is likely to be well detectable by electrical methods due to its change from frozen to unfrozen water. These complementary sensitivities are one reason why seismic and electrical techniques are often combined in permafrost research (e.g., Hauck et al., 2011).

The complexity of the subsurface and its dynamic processes that is characteristic for many environmental problems motivates researchers and practitioners to combine multiple data streams at a given site in order to maximize the information for a high-resolution and possibly quantitative characterization. Such endeavors often involve the integration of multiple geophysical techniques, geological data, borehole measurements, as well as petrophysical and process models. Approaches for data integration in combined imaging frameworks are manifold. Coupled inversion, joint inversion, multi-physics inversion, simultaneous inversion - various terms exist in the continuously growing body of literature on multimethod geophysical imaging. Their terminology and functional principle is often overwhelming for researchers and, particularly, novices in the field. This is complicated by the fact that these terms are not always used consistently across studies. The textbook by Moorkamp et al. (2016a) provides a comprehensive review of different integrated imaging approaches covering a wide spectrum of applications 
ranging from near-surface studies over mineral and hydrocarbon exploration to structural investigations of the Earth's lithosphere and mantle. Our contribution is focused on applications in environmental geophysics, as the chapter of Linde and Doetsch (2016), but complementary in the range of inversion approaches and more extensive in the discussed applications and examples shown.

We start this contribution with an overview and didactic introduction to existing imaging approaches for the integration of multiple geophysical and non-geophysical data sets, petrophysical models, and process simulations (section 2). This is followed by a state-of-the-art review on the use and potentials of these approaches in various environmental applications (section 3). We finalize this chapter with a discussion on new frontiers and remaining challenges in the field (section 4) and concluding remarks (section 5).

We hope that this work provides an entry point to recent developments in the emerging and truly interdisciplinary field of multimethod geophysical imaging and clarifies similarities, differences and development potentials of existing approaches for data integration, and ultimately helps practitioners to choose the most suited one for their data sets.

\section{Theoretical foundation of multimethod imaging}

\subsection{Overview and terminology}

In this section, we provide an overview of existing approaches to combine different geophysical methods in environmental geophysics and give recommendations for a clear and coherent terminology.

In an independent inversion, geophysical data (e.g., seismic traveltimes) of one geophysical method (e.g., refraction seismics) are inverted for one set of geophysical parameters (e.g., Pwave slownesses) independently of other geophysical methods (Fig. 1A). A geophysical forward model (e.g., raytracing algorithm) is needed and provides the link between the model parameters and the model response. Multiple independent inversions of different geophysical methods can then be used in a joint interpretation.

A straightforward way of combining two or more geophysical methods is by means of structurally-constrained inversion. Here, the inversion of a data set belonging to geophysical method A is informed about the location of a prominent subsurface boundary identified through independent processing or inversion of observations from geophysical method B (Fig. 1B). An example would be the use of strong reflectors in a ground-penetrating radar survey related to aquifer boundaries to structurally constrain the inversion of electrical resistivity data (Doetsch et al., 


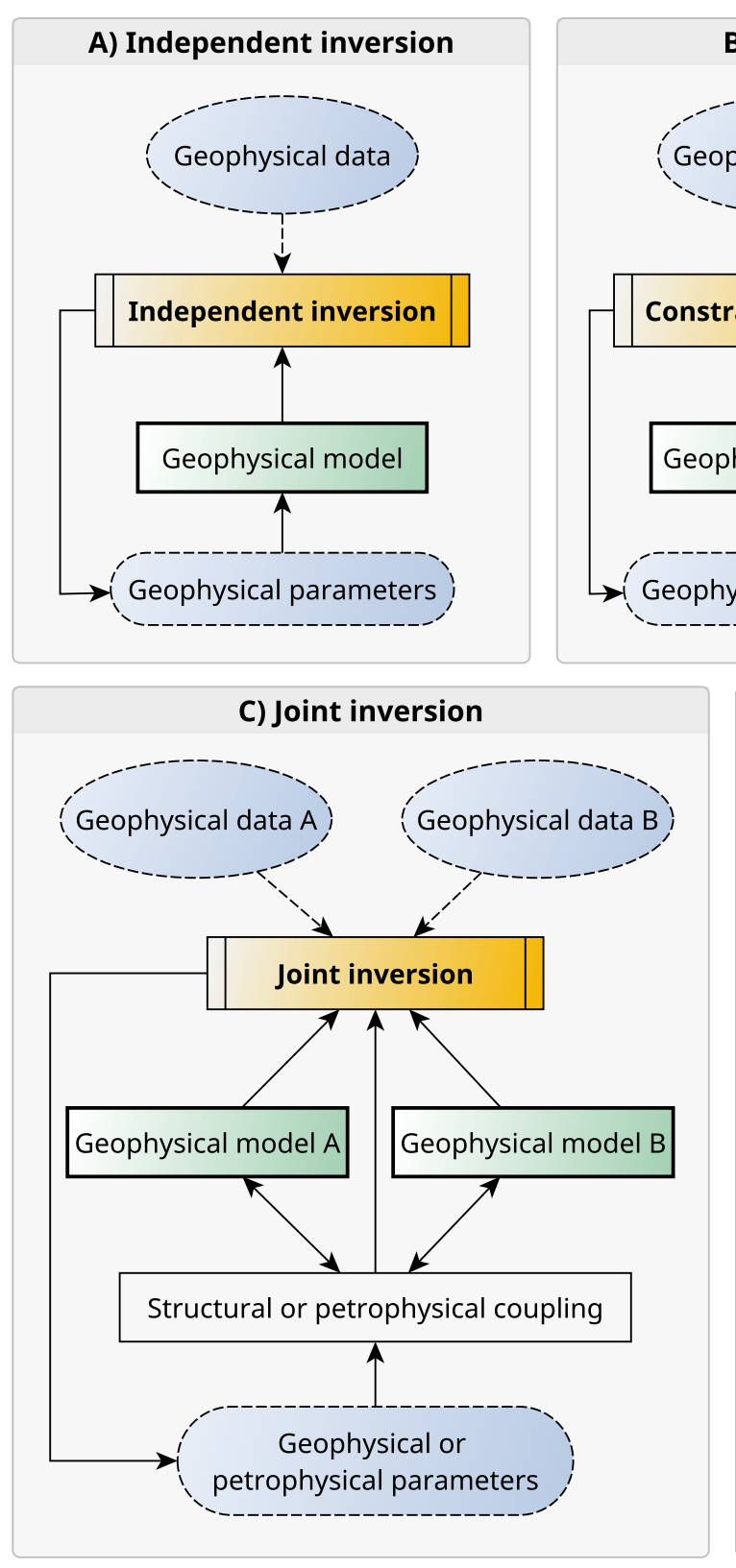

\section{B) Structurally-constrained inversion}

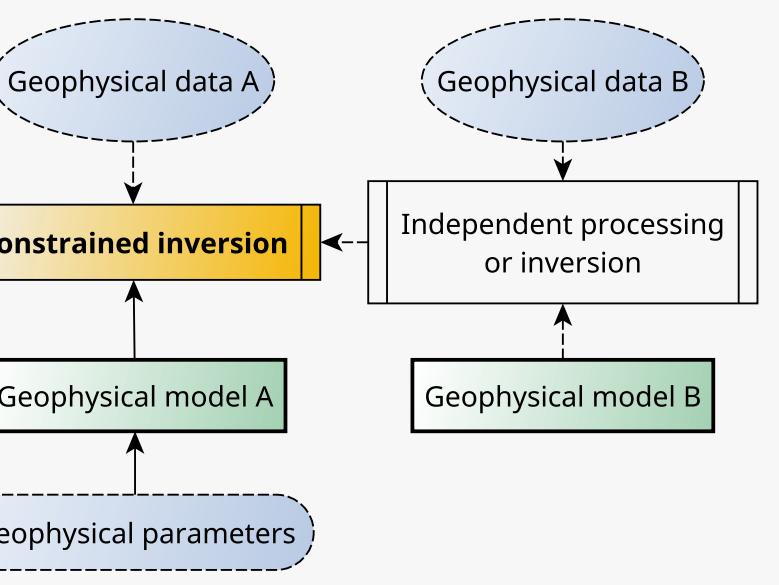

Figure 1: Schematic overview of (A) independent geophysical inversion and various multimethod imaging approaches including (B) structurally-constrained, (C) joint, and (D) process-based inversion.

2012a). This is realized by locally decreasing the regularization strength across the boundaries derived from ground-penetrating radar (GPR) during the otherwise spatially smoothnessconstrained inversion of electrical resistivity data. Since the two geophysical methods can be processed sequentially, we advise against using the term "joint" for these type of inversions.

Joint inversion rather refers to the amalgamation of multiple geophysical methods in one parameter estimation (Fig. 1C). Both data sets are part of a single objective function with concurrent updates of the model parameters within one (joint) inversion. The most straightforward approach of joint inversion is the combined inversion of methods, which are sensitive to the same 
geophysical property. The simplicity of this approach lies in the concatenation of data vectors and forward operators without the need for a mathematical coupling procedure between different model parameters. Although conceptually simple, single-property joint inversions may entail challenges in practice due to different scale, resolution, and convergence properties for example. Moorkamp et al. (2016b) point out that problems can also arise if the jointly inverted geophysical methods have different sensitivities with respect to the anisotropy of the common underlying parameter for example.

Multi-property joint inversions require a mathematical description of the link between these properties, which can either be of structural nature or motivated by the shared sensitivity to one or more petrophysical parameters. In case of the former, a structural joint inversion results in parameter distributions of the involved geophysical methods usually with an improved degree of structural similarity. In a petrophysical joint inversion, the geophysical parameters of methods A and B are translated to a common petrophysical parameter (e.g., porosity or water saturation), which is the parameter estimated during inversion, honoring the defined petrophysical relations.

The aforementioned approaches, illustrated in Fig. 1A-C, have one thing in common - they only depend on geophysical forward simulations (e.g., of electrical current flow or wave propagation), which in turn are solely based on geophysical model parameters. Yet, in many monitoring applications in environmental geophysics, one aims to estimate process-relevant parameters of the studied subsurface dynamics. When a simulation of this investigated process is available, e.g., numerical simulations of flow and transport phenomena, opportunities exist to integrate these simulations into a process-based inversion (Fig. 1D), enabling the estimation of processrelevant parameters such as hydraulic conductivity for example. Parameters of interest are updated, fed into a process model, and the resulting response (e.g., spatio-temporal solute concentration) is translated to geophysical parameters leveraging upon petrophysical relations and passed on to a geophysical forward simulation. The resulting geophysical response is therefore process-based, i.e., it depends on the parameters of the process model, which in turn can be estimated from such a coupled workflow.

In the field of hydrogeophysics, these type of inversions are often termed coupled hydrogeophysical inversions (e.g., Ferré et al., 2009). We prefer the more general term process-based inversion, since it is process-agnostic and may also cover plant physiological models or simulations of freezing and thawing in the emerging fields of biogeophysics and cryogeophysics for example. 
In the following subsections, we discuss the theoretical foundation of the mentioned approaches, their advantages and disadvantages, and provide details on their technical implementations.

\subsection{Independent inversion and joint interpretation}

In geophysical imaging one commonly aims to infer parameters of the subsurface from observations made at the Earth's surface or in boreholes. This endeavor represents an inverse problem commonly solved in a deterministic manner seeking one model that describes the observed data within its error bounds. While we describe this deterministic viewpoint and its extensions to integrate multiple geophysical methods in the following, we note that the described approaches for method combinations are equally applicable to probabilistic inversions.

The physical relationship between the model parameters $\mathbf{m}$ and the observations $\mathbf{d}$ is usually described as a non-linear function $\mathbf{d}=\mathscr{F}(\mathbf{m})$ governed by the forward operator $\mathscr{F}$, which could represent a numerical simulation of seismic wave propagation for example. A geophysical inversion aims to obtain an estimate of $\mathbf{m}$ from $\mathbf{d}$ and can be formulated as a minimization problem using the L2 norm through the following objective function

$$
\left\|\mathbf{W}_{\mathrm{d}}(\mathscr{F}(\mathbf{m})-\mathbf{d})\right\|^{2}+\lambda\left\|\mathbf{W}_{\mathrm{m}} \mathbf{m}\right\|^{2} \rightarrow \min
$$

where the first term quantifies the misfit between the observed data and the predictions made by the model, multiplied by the data weighting matrix $\mathbf{W}_{\mathrm{d}}$. Under the assumption of uncorrelated data errors, $\mathbf{W}_{\mathrm{d}}$ is diagonally occupied with reciprocals of the standard deviation ensuring larger influence of high-quality measurements. Model regularization is implemented in the second term with the model weighting matrix $\mathbf{W}_{\mathrm{m}}$ acting on the model $\mathbf{m}$. In most cases, $\mathbf{W}_{\mathrm{m}}$ is a roughness operator describing the spatial connectivity of model parameters and thereby imposing smoothness constraints based on Occam's principle (deGroot Hedlin and Constable, 1990). The individual contributions of data misfit and model misfit are balanced by the dimensionless regularization factor $\lambda$ commonly chosen to find the smoothest model, which describes the observations within their error bounds.

Application of the Gauss-Newton scheme (e.g., Aster et al., 2013) to the iterative minimization of Eq. 1 leads to an expression of the model update at the $\mathrm{k}^{\text {th }}$ iteration $\Delta \mathbf{m}^{\mathrm{k}}$

$$
\left(\mathbf{J}^{\mathrm{T}} \mathbf{W}_{\mathbf{d}}^{\mathrm{T}} \mathbf{W}_{\mathbf{d}} \mathbf{J}+\lambda \mathbf{W}_{\mathbf{m}}^{\mathrm{T}} \mathbf{W}_{\mathbf{m}}\right) \Delta \mathbf{m}^{\mathrm{k}}=\mathbf{J}^{\mathrm{T}} \mathbf{W}_{\mathbf{d}}^{\mathrm{T}} \mathbf{W}_{\mathbf{d}}\left(\mathbf{d}-\mathscr{F}\left(\mathbf{m}^{\mathrm{k}}\right)\right)-\lambda \mathbf{W}_{\mathbf{m}}^{\mathrm{T}} \mathbf{W}_{\mathbf{m}} \mathbf{m}^{\mathrm{k}}
$$

where $\mathbf{J}$ is the Jacobian matrix holding the sensitivities of the $\mathrm{i}^{\text {th }}$ measurement with respect to a change in the $\mathrm{j}^{\mathrm{t}}$ model parameter, i.e. $\mathrm{J}_{\mathrm{i}, \mathrm{j}}=\partial \mathscr{F}\left(\mathrm{m}^{\mathrm{k}}\right)_{\mathrm{i}} / \partial \mathrm{m}_{\mathrm{j}}^{\mathrm{k}}$. Equation 2 is solved for 
the model update $\mathbf{m}^{\mathrm{k}}$ and the parameter set of the next iteration is calculated by $\mathbf{m}^{\mathrm{k}+1}=$ $\mathbf{m}^{\mathrm{k}}+\Delta \mathbf{m}^{\mathrm{k}}$. This iterative process is usually continued until the target data misfit is reached, i.e., the model describes the measured data within its error bounds, the objective function cannot be reduced further, or a prescribed maximum number of iterations has been reached. The final models of multiple independent inversions of different geophysical methods may be subsequently interpreted structurally or petrophysically.

\subsection{Structurally-constrained inversion}

When structural subsurface information such as the presence and orientation of lithological boundaries or faults is available from prior geological knowledge or conventional processing of a structure-sensitive geophysical method, a relatively straightforward approach to account for this knowledge in a subsequent inversion of another geophysical method is through a structurally-constrained inversion. This is illustrated in Fig. 2, where the upper row schematically shows a reflection seismic and an electrical resistivity survey conducted across an anticlinal structure. On the basis of reflection seismic processing, a prominent horizon is interpreted from the depth-migrated seismogram. Under the assumption that a sharp contrast in the seismic impedance is accompanied by a contrast in electrical properties at the given site, the interpreted reflection may be used as a prior structural constraint during the inversion of electrical resistivity data.

The effect of the integration of this structural boundary is further illustrated in Fig. 3. Fig. 3A shows a $100 \Omega \mathrm{m}$ bedrock overlain by a $50 \Omega \mathrm{m}$ overburden. In an independent inversion with isotropic smoothing (Fig. 3B), the interface is blurred out, in particular towards the edges of image, where the interface dips towards larger depths and the sensitivity of surface acquisitions typically decreases. In Fig. 3C the smoothness-constraint is locally down-weighted across the interface up to $\mathrm{x}=10 \mathrm{~m}$ leading to an improved image of the sharp layer boundary in the left part of the tomogram. Note that not only the interface position is sharpened, but also the amplitudes of the resistivities of each layer are in a better agreement to the true model, since the inversion is no longer forced to produce smooth transitions with intermediate parameter values absent in the true model. Once the structural constraint is no longer present $(x>10 \mathrm{~m}$ in Fig. 3C), the smoothing regularization exerts its influence and produces a smooth transition comparable to the tomogram in Fig. 3B.

The structural decoupling is technically implemented into a smoothness-constrained inversion by manipulation of the roughness operator $\mathbf{W}_{\mathrm{m}}$ (Günther and Rücker, 2006). In its first-order form, the operator approximates the first derivative (i.e., the gradient) of the model. Since this quantity is minimized in the objective function (Eq. 1), the term favors models where adjacent 

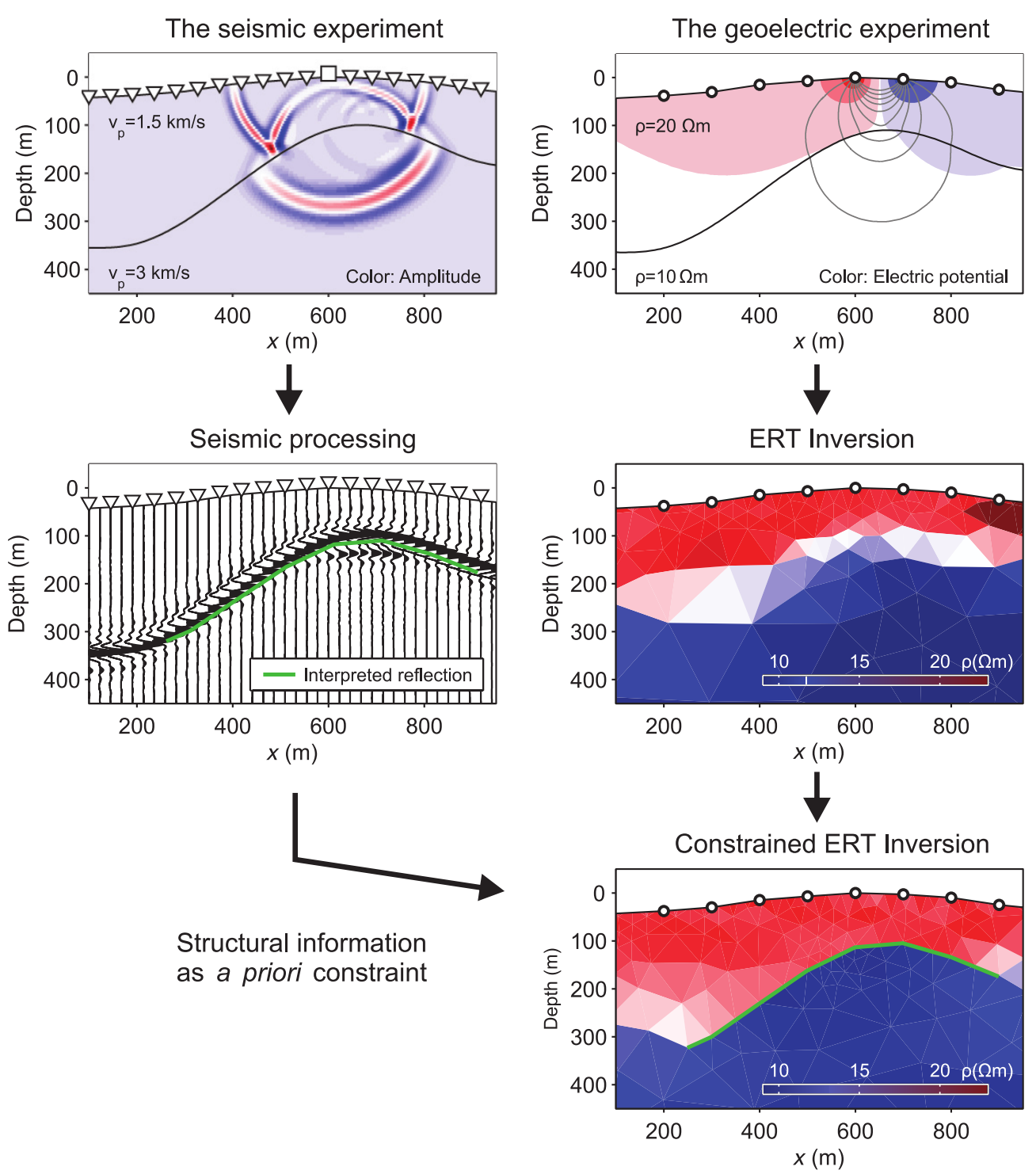

Figure 2: Schematic illustration of structurally-constrained inversion of electrical resistivity data honoring an expected sharp parameter change across a prominent interface derived from reflection seismic processing by means of a synthetic anticline model. The white square indicates the position of the seismic source, whereas white triangles and circles represent geophones and electrodes, respectively (after Bergmann et al., 2014).

parameter values are closer to each other, i.e., do not exhibit strong jumps. Yet in many cases, these strong parameter jumps are deemed more realistic. Examples in near-surface geophysics include, but are not limited to, lithological interfaces, the water table, or the bottom of the seasonal thaw layer (active layer). Structurally-constrained inversion thus aims to down-weigh, or completely remove, the smoothness constraint across known interfaces.

Fig. 3F shows a subset of the mesh at the right edge of the interface and Fig. 3E shows the roughness operator for this part of the mesh, i.e., $\mathbf{W}_{\mathrm{m}}$ in Eq. 1 , with the dimensions $\mathrm{B} \times \mathrm{M}$, 

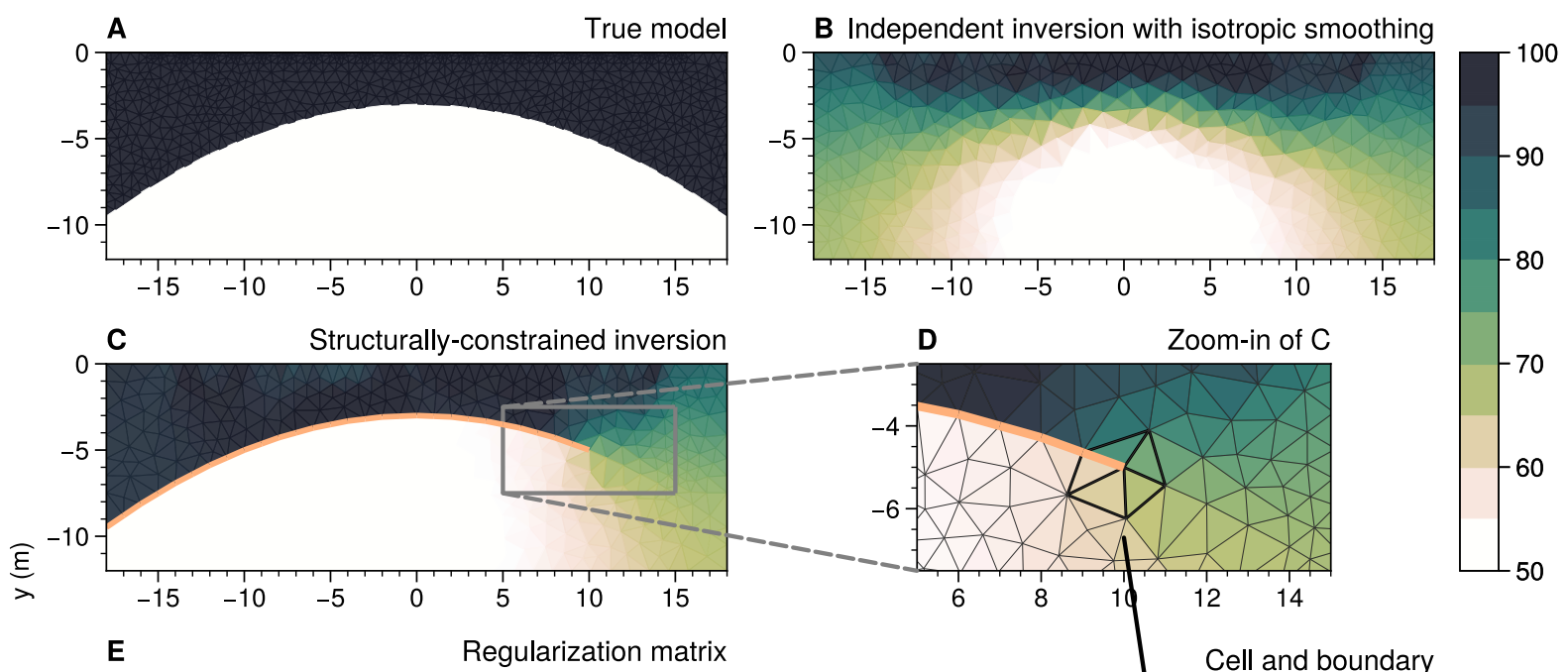

Zoom-in of C

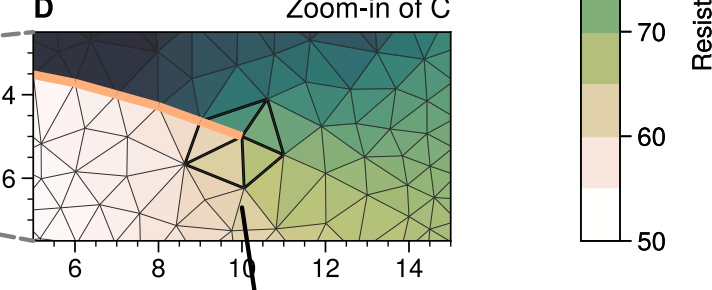

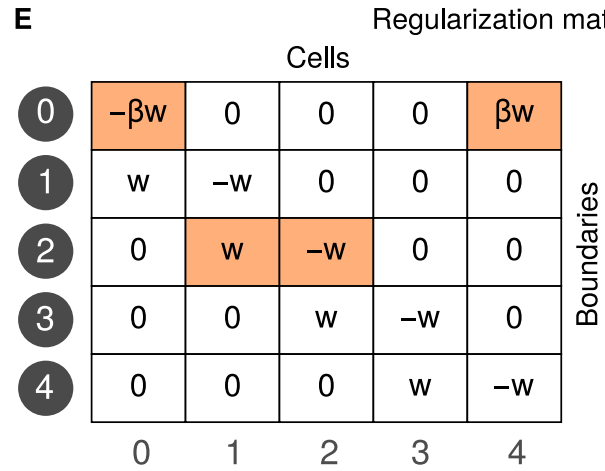

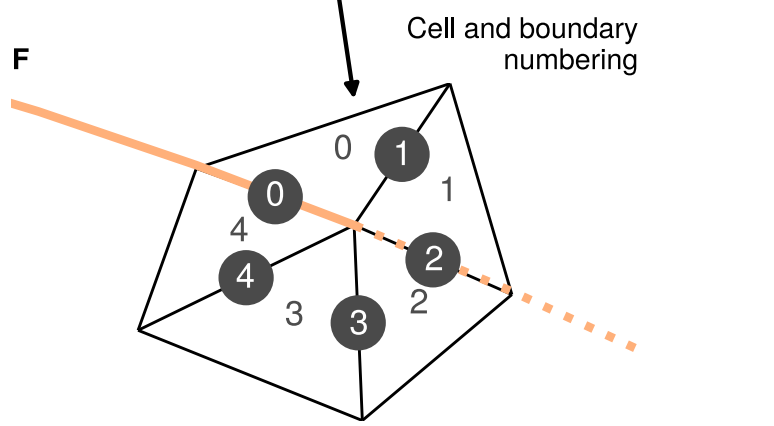

Figure 3: Two-layer model with an anticlinal interface in-between (A), corresponding conventional smoothness-constrained inversion result (B), and a structurallyconstrained inversion result in which the known structural boundary is assumed to be known until $\mathrm{x}=10 \mathrm{~m}$. The latter is realized by down-weighting the corresponding cell connections across the interface (boundaries 0 and 2 shown in panel F) in the regularization matrix (E).

where $B$ is the number of inner mesh boundaries and $M$ is the number of mesh cells. The factor $\mathrm{W}$ may be set to unity on structured grids and would result in subtracting the values of adjacent model cells upon multiplication of $\mathbf{W}_{\mathrm{m}}$ with the model vector. On unstructured grids with strongly varying cell sizes, $\mathrm{w}$ should include normalization by the distance of the respective cell centers (Oldenburg et al., 1993).

The first boundary in Fig. 3F (boundary \#0) is connecting cells \#4 and \#0. The corresponding entries in the roughness operator are scaled with an additional factor $\beta$ (Fig. 3E). If $\beta$ is set to one, no special treatment is given to the boundaries belonging to the interface, leading to an isotropically smoothed model as shown in Fig. 3B. If $\beta$ is set to zero, smoothing constraints are completely omitted across the known boundary resulting in the structurally-constrained inversion result shown in Fig. 3C. 


\subsection{Joint inversion}

\subsubsection{Structurally-coupled joint inversion}

Structural joint inversion approaches rest on the assumption that one geophysical method exhibits spatial changes at similar locations of the subsurface as another geophysical method. In structurally-constrained inversions (see subsection 2.3), these locations are fixed and manifested in the spatial regularization operator leading to a certain rigidity of this approach. Haber and Oldenburg (1997) introduce a structural joint inversion approach, which promotes structural similarity of two geophysical models without prescribing the locations where this structural similarity is expected. Their approach is based on the minimization of the squared difference of a weighted Laplacian operator of both models and is dependent on the magnitudes of changes (Linde et al., 2006). Gallardo and Meju (2003); Gallardo (2004) introduce an alternative approach based on a simple, yet powerful, quantitative measure of structural similarity - the cross-product of two (or more) model gradients.

This cross-gradient functional $\tau(\mathrm{x}, \mathrm{y}, \mathrm{z})$ of two geophysical models $\mathbf{m}_{\mathrm{A}}$ and $\mathbf{m}_{\mathrm{B}}$ is defined as

$$
\tau(\mathrm{x}, \mathrm{y}, \mathrm{z})=\nabla \mathrm{m}_{\mathrm{A}}(\mathrm{x}, \mathrm{y}, \mathrm{z}) \times \nabla \mathrm{m}_{\mathrm{B}}(\mathrm{x}, \mathrm{y}, \mathrm{z})
$$

where $\times$ denotes the cross-product of the two model gradient vectors. This functional (Eq. 3) equates to zero if the two model gradient vectors $\mathbf{m}_{\mathrm{A}}$ and $\mathbf{m}_{\mathrm{B}}$ are parallel or anti-parallel to each other or if one of them is zero implying that the associated model does not change. Translated to the structurally-coupled joint inversion of two geophysical data sets, this means that a minimization of this term penalizes model gradient vectors that point in different directions (with the exception of them being anti-parallel, e.g., electrical resistivity increases while seismic slowness decreases) and thereby promotes models which exhibit spatial changes at similar locations. The characteristic behavior of the cross-gradient term is illustrated in Fig. 4D for two hypothetical geophysical models (shown in Fig. 4B and Fig. 4C).

In regions where $\mathbf{m}_{\mathrm{A}}$ and $\mathbf{m}_{\mathrm{B}}$ change in the same or opposite direction and where $\nabla \mathbf{m}_{\mathrm{B}}$ is small, the normalized cross-gradient product (Fig. 4D) is zero. In the lower right corner of the model domain, the model gradients deviate from each other, coinciding with regions of nonzero values in the cross-gradient image. By minimizing Eq. 3 as an additional term within the objective function, this approach promotes models of structural similarity during the inversion. Gallardo (2007) further develops this approach to multiple geophysical methods (i.e., more than two) and Gallardo and Meju (2011) provide an overview on its multitude of applications. 


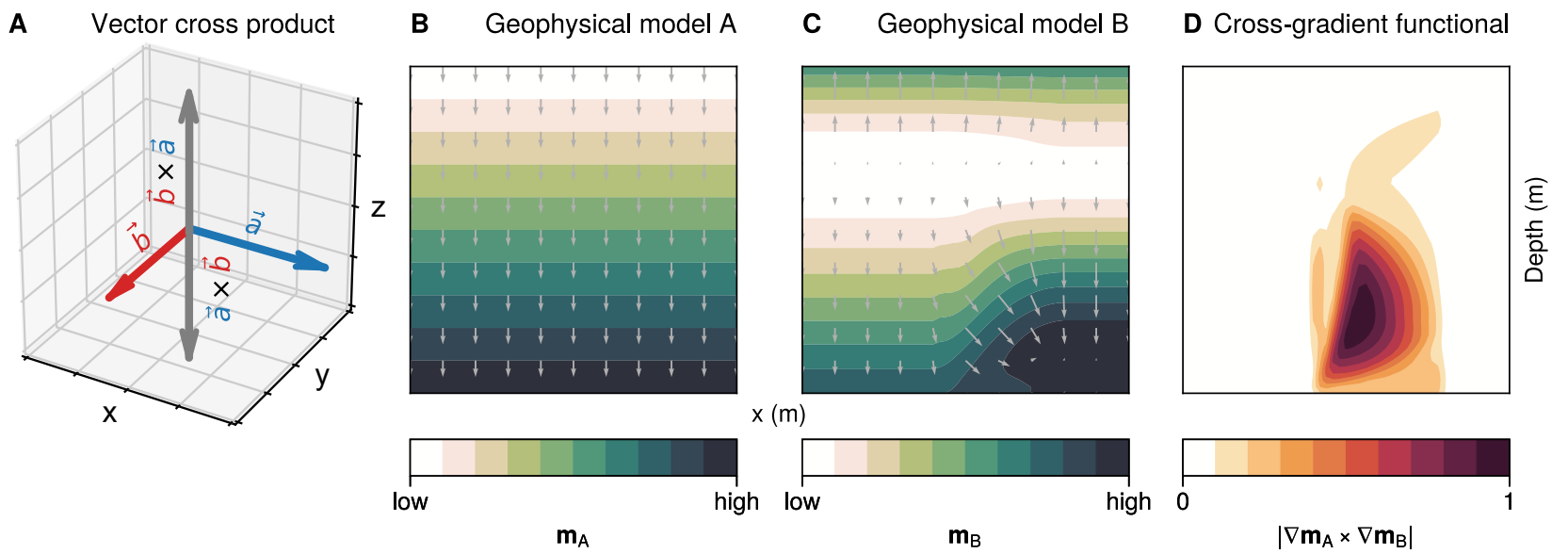

Figure 4: The characteristics of vectors and their cross-product (A) is applied to the gradients of two geophysical models (B and $\mathrm{C}$ ) denoted by the grey arrows. The magnitude of the corresponding cross-gradient functional (D) is zero if the model gradients are parallel or anti-parallel (or one of the models does not change).

\subsubsection{Structurally-coupled cooperative joint inversion}

Based on the principle of robust modeling, i.e., a minimization of the data misfit based on the $\mathrm{L}_{1}$-norm known to be less susceptible to outliers and non-Gaussian noise (Claerbout and Muir, 1973), Günther and Rücker (2008) introduce a joint inversion approach leveraging upon the exchange of structural information between two otherwise independent geophysical inversions. Since the inversions run in parallel and do not rest on the minimization of a common objective function, the approach is termed structurally-coupled cooperative inversion (SCCI). It is independent of the mesh type, but requires the involved geophysical methods to use the same spatial discretization such that the regularization operators have the same dimensions. The approach has successfully been used to invert electrical resistivity and seismic refraction data (Günther and Rücker, 2008; Hellman et al., 2017; Ronczka et al., 2017) as well as magnetic resonance and resistivity data in 1D (Günther et al., 2010; Skibbe et al., 2018) and 2D (Skibbe et al., 2021).

Similar to the structurally-constrained inversion (section 2.3), the approach is implemented via a local decrease of the smoothness constraints in the regularization operator. But in contrast to structurally-constrained inversions, the regularization operator is not manipulated once, but dynamically between iterations. It starts by calculating the roughness vector $\mathbf{r}^{\mathrm{P}}$ for each parameter distribution $\mathrm{m}^{\mathrm{p}}$. The model $\mathrm{m}^{\mathrm{P}}$ is subjected to a method-specific transformation (e.g., logarithmized in most electromagnetic methods) and the roughness is calculated on the basis of this transformed model after each iteration of the independent geophysical inversions:

$$
\mathbf{r}^{\mathrm{p}}=\mathbf{W}_{\mathrm{m}}^{0} \mathbf{m}^{\mathrm{p}}
$$


Here, $\mathbf{w}_{\mathrm{m}}^{0}$ is the initial unmodified roughness operator. Based on these model roughnesses, individual weights are calculated for each of the $\mathrm{n}$ methods according to:

$$
\mathbf{w}^{\mathrm{p}}=\frac{\mathrm{a}}{\mid \mathbf{r}^{\mathrm{P} \mid}+\mathrm{a}}+\mathrm{b}, \text { for } \mathrm{p} \text { in }[1 \ldots \mathrm{n}]
$$

where $\mathrm{a}$ and $\mathrm{b}$ are coupling parameters chosen to satisfy $0 \leq \mathrm{a} / \mathrm{b} \leq 1$. The combined weights $\mathbf{w}_{\mathrm{c}}^{\mathrm{p}}$ for one method are based on the multiplication of the individual weights for all other methods to be coupled:

$$
\mathbf{w}_{\mathrm{c}}^{\mathrm{p}}=\prod_{\mathrm{i}=1}^{\mathrm{i} \neq \mathrm{p}} \mathbf{w}^{\mathrm{i}}, \text { for } \mathrm{p} \text { in }[1 \ldots \mathrm{n}] .
$$

These combined weights are finally used to update the roughness operator for the next iteration:

$$
\mathbf{W}_{\mathrm{m}}^{\mathrm{p}}=\operatorname{diag}\left(\mathbf{w}_{\mathrm{c}}^{\mathrm{p}}\right) \cdot \mathbf{W}_{\mathrm{m}}^{0}
$$

The approach enables the exchange of structural information and the focusing on common boundaries. This is illustrated in Fig. 5, which shows how the models and weighting factors based on Eq. 5 are developing throughout the course of iterations of the SCCI based on the work by Skibbe et al. (2021).

It is applicable to any kind of discretization (e.g., 1D to 3D, structured and unstructured meshes) and geophysical method and is relatively straightforward to implement, since the original inversion algorithms are not modified.

\subsubsection{Petrophysical joint inversion}

In many interdisciplinary applications in environmental geophysics, one is interested in petrophysical subsurface properties such as porosity for example. To study the widespread degradation of permafrost for instance, researchers strive to directly estimate the volumetric fractions of liquid water, ice, and air in partially-frozen systems from multiple geophysical observations (e.g., Hauck et al., 2011; Dafflon et al., 2016; Mollaret et al., 2020; Steiner et al., 2021). An estimate of these quantities is often realized by applying a suitable petrophysical relationship to transform an inverted geophysical tomogram to the parameter distribution of interest. One problem of post-inversion transformation of geophysical models is represented by the fact that physical plausibility of the petrophysical estimate cannot be ensured. When redefining the inversion problem such that the petrophysical parameter is estimated directly, physical constraints can be imposed during the parameter estimation (e.g., keeping porosity between 0-100\%). Furthermore, this petrophysical transformation does not need to be limited to one geophysical method, building the basis for petrophysical joint inversions. Rücker et al. (2017) present a 

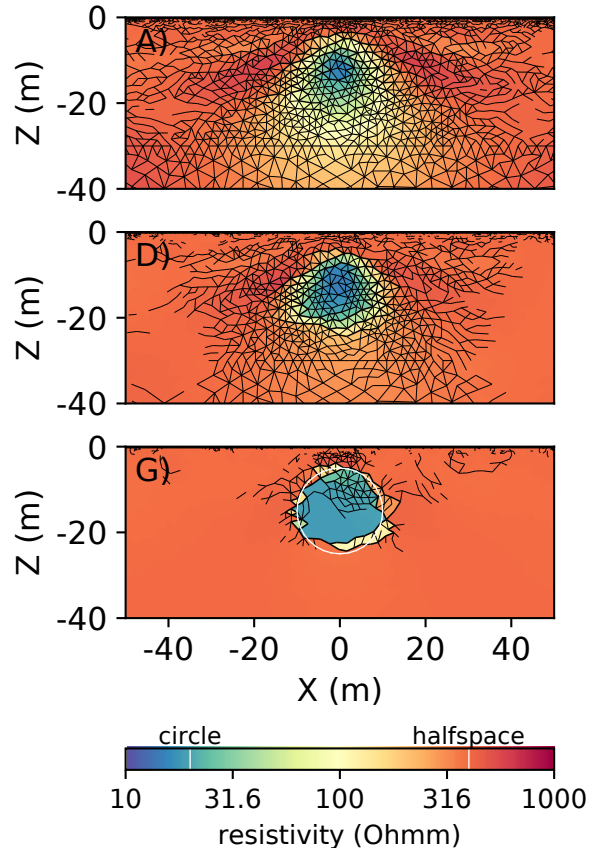
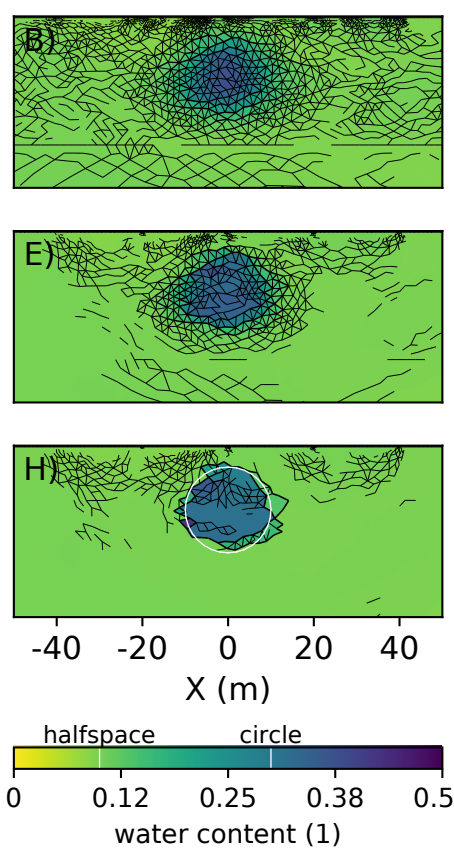
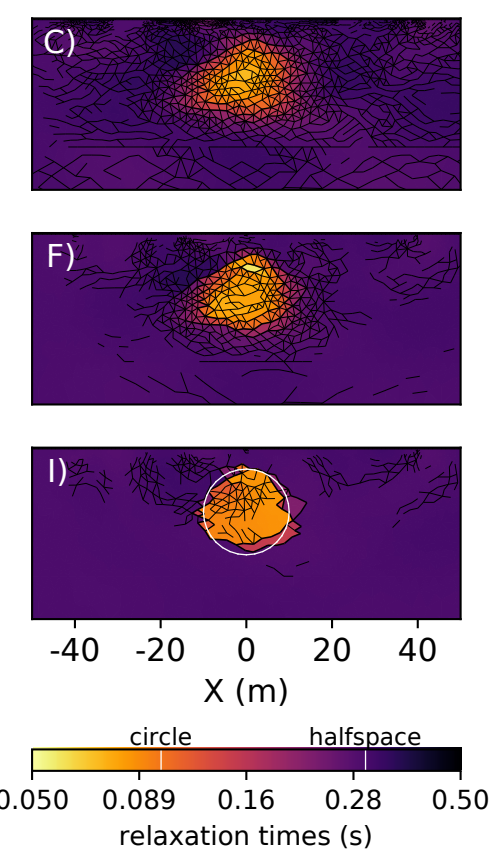

Figure 5: Models and individual weighting factors based on Eq. 5 of three steps of the SCCI: smooth inversion results of the ERT as (A) resistivity and for MRT as (B) water content and (C) relaxation times; (D-F) first iteration; and (G-I) final iteration of the SCCI. Individual weights based on the model roughnesses are shown with the black lines of increasing thickness. Thicker lines represent a stronger gradient of the two adjacent cells. The synthetic model values are marked in the color bar with white lines (modified from Skibbe et al., 2021).

generalized framework for this. The steps of such a workflow are schematically illustrated in Fig. 6.

The petrophysical target properties represent the inversion parameters in the objective function ( $\mathbf{m}$ in Eq. 1). Based on an initial guess of this target parameter distribution (e.g., a porosity gradient model), the parameters of the involved geophysical methods (e.g., electrical resistivity) are calculated on the basis of petrophysical relations $\mathbf{p}(\mathbf{m})$. These geophysical parameter distributions are subsequently used to calculate the geophysical forward responses $\mathscr{F}(\mathbf{p}(\mathbf{m}))$ in order to evaluate their error-weighted misfit to the corresponding field observations. Based on an iterative minimization of the objective function including this misfit and additional model regularization terms, the petrophysical target parameter distribution is being updated. In the calculation of the model update (Eq. 2), the Jacobian matrix needs to hold the sensitivities of the geophysical measurements with respect to the petrophysical target parameter(s). This is realized by an appropriate scaling of the conventional Jacobian matrices of the involved methods on the basis of chain rule splitting

$$
\mathbf{J}=\frac{\partial \mathscr{F}(\mathbf{m})}{\partial \mathbf{m}}=\frac{\partial \mathscr{F}(\mathbf{p})}{\partial \mathbf{p}} \frac{\partial \mathbf{p}}{\partial \mathbf{m}}
$$




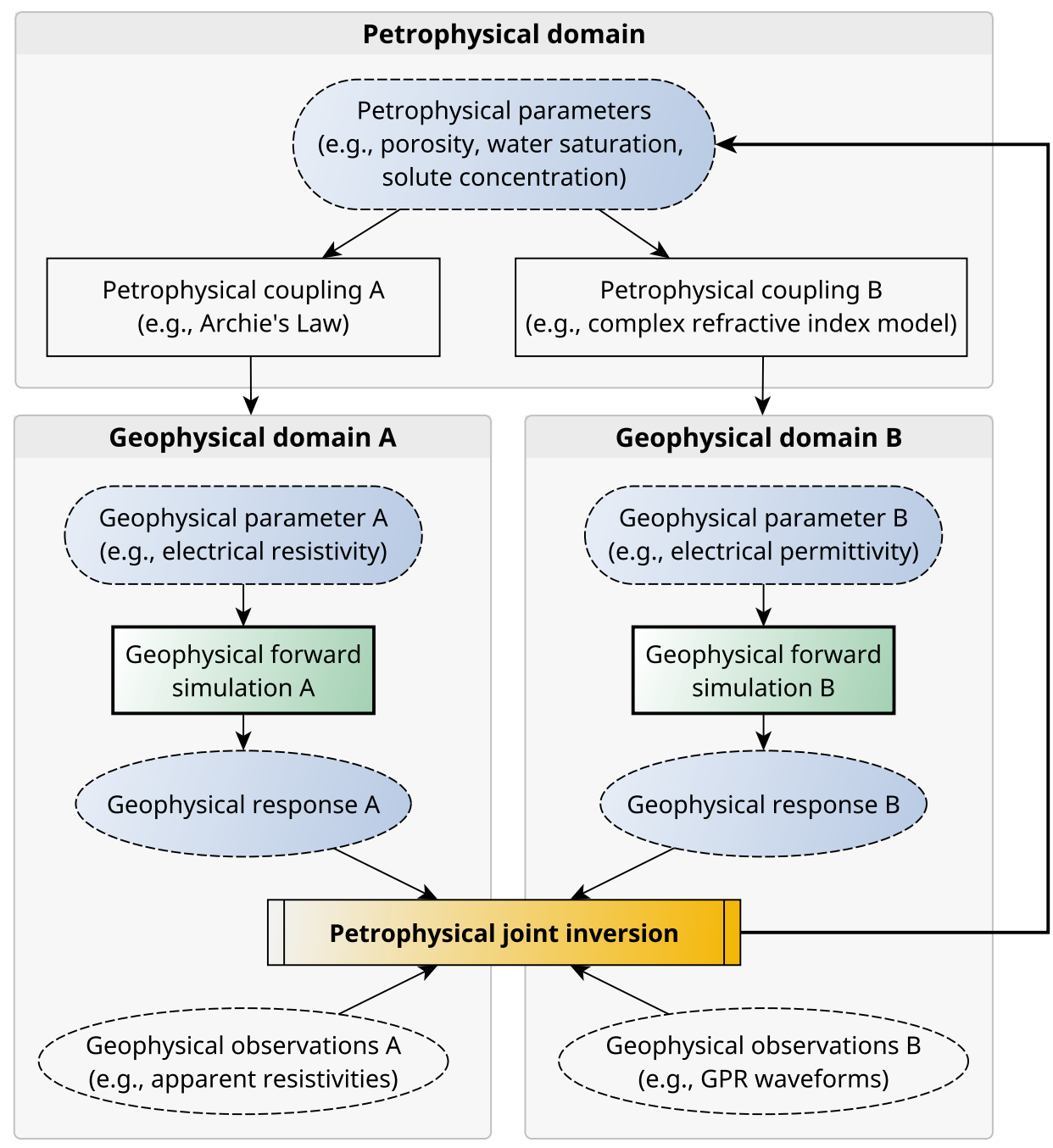

Figure 6: Schematic illustration of a petrophysical joint inversion workflow.

where the outer derivative represents the original Jacobian entries of the geophysical methods scaled by the inner derivatives, i.e., the partial derivatives of the petrophysical relations with respect to the petrophysical target parameters. This concept can be applied to couple multiple geophysical methods sensitive to one or more petrophysical target properties. For petrophysical joint inversions, representative petrophysical models are needed, which are equally important once a process model is involved in the context of process-based inversions.

\subsection{Process-based inversion}

When studying dynamic subsurface processes, field observations are often compared to predictions made by numerical process simulations with the ultimate aim to improve the parametrizations of these process models. Hydrological observations such as soil moisture measurements can often directly be compared to the prediction of a partially-saturated flow simulation for example. The integration of geophysical observations in this context is not straightforward. 
While joint inversions may lead to tomograms with improved structural consistency or estimates of petrophysical parameters, process-based inversions take the dynamic physical process into account and allow the combination of geophysical and non-geophysical observations (e.g., soil moisture or temperature measurements) for an improved imaging of non-geophysical subsurface properties.

Two different approaches to process-based inversion prevail in the literature, the uncoupled (or sometimes referred to as sequential) and the (fully) coupled approach (e.g., Aines et al., 2002; Kowalsky et al., 2005; Hinnell et al., 2010; Camporese et al., 2015). Fig. 7A illustrates the uncoupled approach to use time-lapse geophysical observations for the estimation of parameters of a dynamic subsurface process, which involves three steps (e.g., Camporese et al., 2015):

1. Geophysical field observations are used in a conventional inversion approach to estimate a spatio-temporal distribution of the underlying geophysical parameter (e.g., time-lapse apparent resistivities are inverted for a spatial distribution of electrical resistivity at each time-step).

2. A petrophysical relationship is used to transform the geophysical property into a proxy observation relevant for the studied process (e.g., Archie's law is used to derive a spatiotemporal distribution of saturation from electrical resistivity tomograms).

3. The geophysically-derived observations are used in conjunction with other multi-physical observations to estimate parameters of a process model (e.g., derived salinities from geoelectrical measurements are used together with salinity measurements in boreholes to estimate hydraulic conductivity).

Steps 1 and 2 can be performed with different geophysical methods and are uncoupled from the subsequent inversion of process-relevant parameters, i.e., they can be performed sequentially. Fig. 7B shows the alternative coupled approach involving the following steps (e.g., Camporese et al., 2015):

1. A process model is used to simulate the studied dynamic process and the evolution of state variables (e.g., saturation or temperature) based on process-relevant parameters (e.g., porosity and/or hydraulic conductivity).

2. On the basis of a suitable petrophysical relation, the state variables of the process model are translated to spatio-temporal distributions of geophysical parameters. 


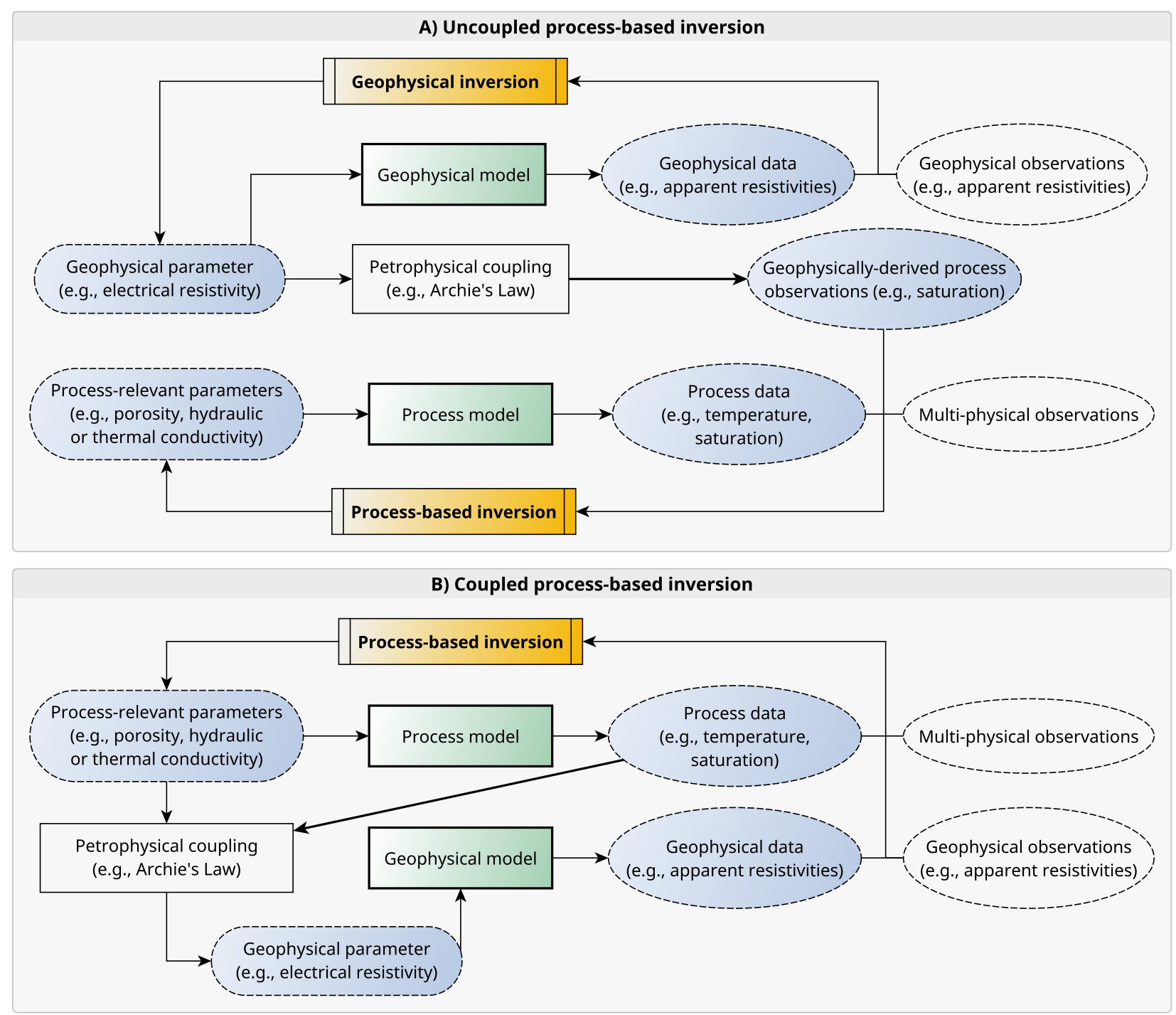

Figure 7: Schematic illustration of (A) coupled and (B) uncoupled process-based inversions.

3. A geophysical forward simulation is carried out and the predicted process-based data is used in conjunction with other multi-physical observations to update the parameters of the underlying process model.

The uncoupled and the coupled approach have several common characteristics: they usually involve time-lapse data, allow to integrate non-geophysical observations, and their success strongly depends on the validity of the petrophysical relation used. Their main difference lies in the fact that the uncoupled approach contains multiple inversions (one for the process model and one for every geophysical method used to constrain it), while the coupled approach consists of a single combined parameter estimation. Didactic examples on coupled process-based inversions are presented by Rücker et al. (2017) and Commer et al. (2020). 


\section{Environmental applications}

The following section gives an overview on the applications of the discussed imaging approaches in various fields of environmental geophysics. Our aim is to highlight the current state and development potential in these different applications without claiming to be exhaustive.

\subsection{Estimating vadose and critical zone properties}

Even though the Earth's shallow subsurface is mostly readily accessible, making direct observations at the spatial and temporal resolutions necessary to capture and characterize processes controlling subsurface flow and transport is difficult. Yet, by controlling storage and release of nutrients, water, or contaminants, these processes are having a direct impact on ecosystems and communities, and hence the zone where these processes are taking place is often referred to as the critical zone (Brantley et al., 2006). Geophysics has been shown to be a valuable tool for upscaling direct observations, which are mostly restricted to a limited number of sampling locations (e.g., boreholes or point sensors), by providing measurements of (mostly) proxies to the variables of interest at the required resolution and scales that can be used to shed light on the processes in this critical zone (Parsekian et al., 2015; Binley et al., 2015). This has been shown to be particularly useful in tracking hydrological dynamics in the critical zone, such as root-water uptake (Mary et al., 2020; Werban et al., 2008), or water infiltration (Looms et al., 2008; Carey et al., 2019; Mawer et al., 2016). Depending on the properties and processes to be imaged, different geophysical methods may provide the best sensitivity and resolution, which has been discussed in detail in various textbooks (Reynolds, 2011; Telford et al., 1990; Knödel et al., 2007). For instance, seismic techniques are well known to be sensitive to bedrock weathering in crystalline environments (e.g., Hayes et al., 2019), while for identifying lithological units in sedimentary environments, geoelectrical methods may be better suited (e.g., Crook et al., 2008; Uhlemann et al., 2017). Many studies have shown that by combining multiple geophysical techniques, the limitations of a single technique can be overcome and their benefits be combined to obtain robust estimates of subsurface properties. In the following, we will discuss some of those studies, particularly regarding their use of multiple geophysical techniques, and we will distinguish them based on the nomenclature used in section 2 . Within this section, we focus on applications that range from the unsaturated to the saturated zone, and mostly consider characterization of the structure and the physical properties of this zone. 


\section{Independent inversion and joint interpretation}

Holbrook et al. (2014) combine seismic refraction and electrical resistivity data to characterize the subsurface of the Southern Sierra Critical Zone Observatory (SSCZO) in California, USA (Fig. 8). While seismic data clearly distinguishes weathered from unweathered bedrock, electrical resistivity data were used to distinguish saturated from dry conditions. Their combined interpretation allowed to go from a purely structural interpretation to a hydrological interpretation of the subsurface, thereby providing means to assess groundwater storage and flow potentials. This study shows the benefit of a combined interpretation; solely from the seismic data, it would have been difficult to distinguish saturated from dry bedrock, whereas if only electrical resistivity data would have been available, estimating weathering fronts would have been challenging. Hence, by combining the two methods, Holbrook et al. (2014) could derive a detailed hydro-geological model of the SSCZO.

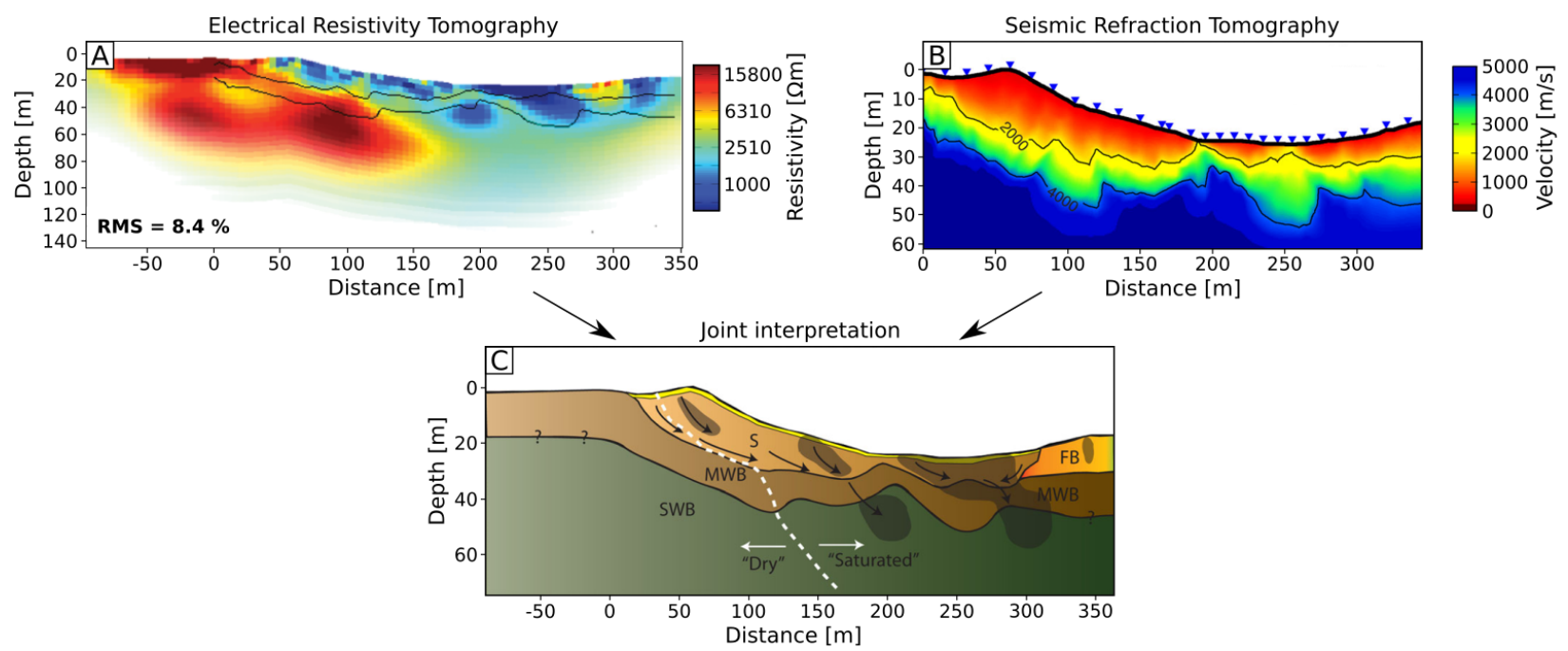

Figure 8: Combined interpretation of (A) electrical resistivity and (B) seismic data to obtain (C) a detailed groundmodel of a critical zone study site in California, USA. Saprolite (S) overlies moderately weathered bedrock (MWB) throughout most of the profile. Fractured bedrock (FB) is outcropping on the northern end (modified from Holbrook et al., 2014).

Many studies use multiple geophysical techniques to characterize the subsurface at a single point in time. Yet, geophysical monitoring has been shown to be able to, e.g., image thermohydrological variability in the subsurface. Combining time-lapse seismic refraction and electrical resistivity tomography (SRT and ERT, respectively) data, Blazevic et al. (2020) show that infiltration pathways through the vadose zone can be imaged using both methods. They were able to identify preferential flowpaths and, while not employed in this study, highlight the opportunity to use co-located, time-lapse seismic and ERT data for joint inversion (e.g., using 
petrophysical coupling) to provide better estimates of the hydrological processes and properties.

\section{Structurally-constrained inversion}

To characterize the vadose and saturated zone at a site close to Heby, Sweden, Mohammadi Vizheh et al. (2020) combine RMT and GPR to estimate the water content within an aquifer. By translating a GPR wave velocity model into estimates of water content and porosity, petrophysical constraints are used to invert RMT data. By updating the petrophysical model and inversion of the RMT data, Mohammadi Vizheh et al. (2020) determine a water content model that fits both the GPR and RMT data. Using this constrained inversion, it was shown that thin $(\sim 3 \mathrm{~m})$ saturated zones could be imaged, which was not possible using an independent inversion of the RMT data. By comparing their results to available hydrogeological data, the authors showed that the results of the constrained inversion were in good agreement with the known subsurface conditions.

\section{Joint inversion}

Within vadose and critical zone studies, joint inversion is often applied using structurally coupled approaches to delineate the geological layering of the subsurface. For example, Bouchedda et al. (2012) use crosshole ERT and GPR travel time tomography to characterize the vadose zone in a sandstone aquifer that is known to be complex and consisting of many different hydrogeological facies, ranging from siltstone, over fine to medium sandstone. While independent inversion of the data provide results that were largely in agreement with borehole records, the structural joint inversion showcased improved results with better delineation of these known boundaries. Their results highlight that the joint inversion can improve the interpretability of geophysical imaging by providing coherent layers that are indicative of different key hydrogeological facies, and variations between sandier and siltier units that may retain water differently. While Bouchedda et al. (2012) show the benefit of joint inversion in delineating thin layers (< $1 \mathrm{~m}$ ) within a small domain $(<10 \mathrm{~m})$, Ronczka et al. (2017) use ERT and seismic refraction tomography data acquired under water along an almost $1 \mathrm{~km}$ long transect to provide subsurface information for nuclear waste disposal at the Äspö Hard Rock Laboratory. They show that despite logistical limitations, which resulted in poor data coverage of the SRT, the joint inversion of resistivity and seismic data enabled the identification of a water-bearing fracture zone, which was not imaged using independent inversions of the data. It is noteworthy that the SRT data did not overlap the ERT data, yet the imposed structural similarity in the rest of 
the model helped in providing a clearer image of this important fracture zone. This shows that joint inversion can provide improved results even in areas where only one method provides better data coverage, but also that joint inversion of multiple geophysical methods can increase the resolution, particularly in complex geological environments.
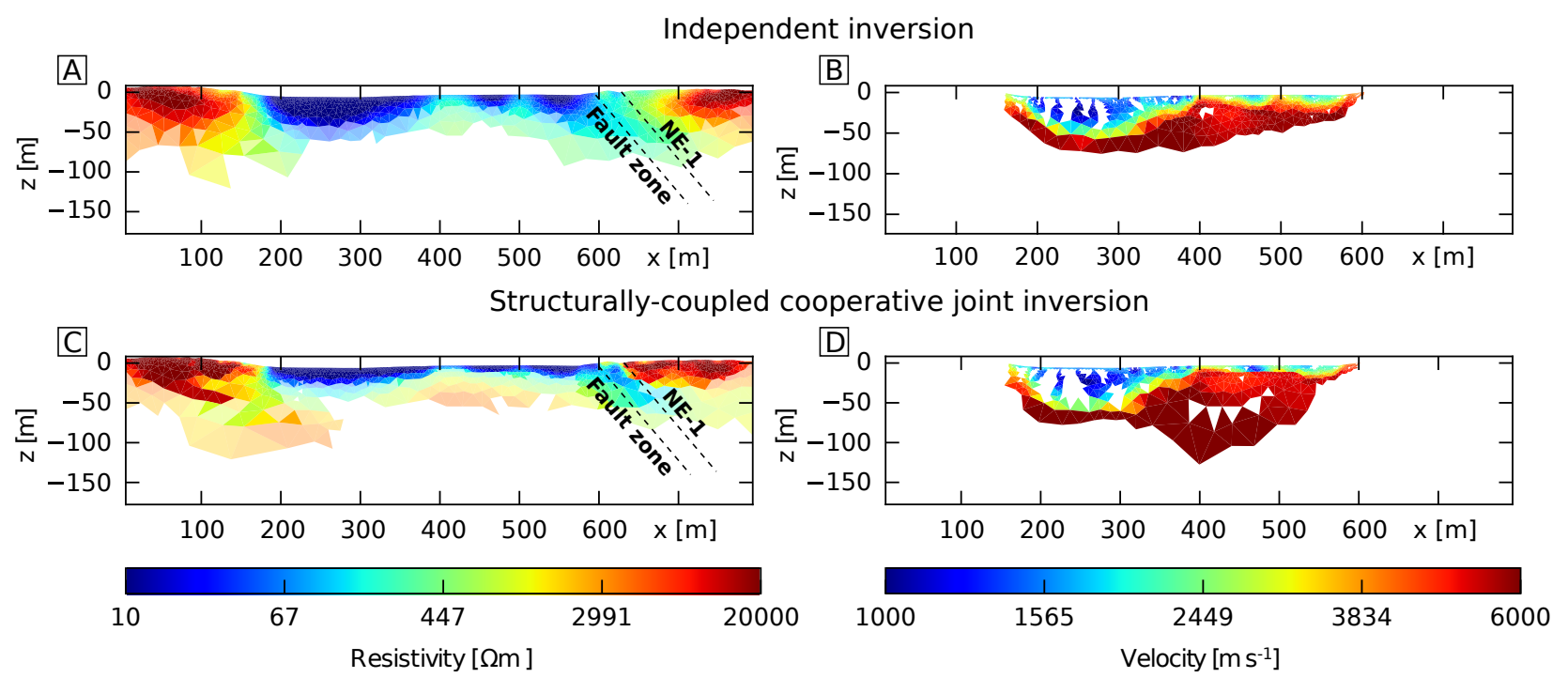

Figure 9: Comparison between independent and joint inversion of underwater ERT and SRT data acquired at the Äspö Hard Rock Laboratory. While the independent inversion (A-B) fails at imaging the known fracture zone NE-1, the joint inversion (C-D), despite having no seismic coverage in that area, clearly images the fracture zone (modified from Ronczka et al., 2017).

\section{Process-based inversion}

Hydrological modeling is well developed within soil science and critical zone applications. This is mainly driven by the common assumption that the subsurface consists of layered facies with predefined properties. Yet, this assumption is often violated due to the inherent heterogeneity of the subsurface caused by, e.g., the depositional regimes. Here, geophysical methods can provide the high-resolution data required to estimate subsurface parameterization for hydrological models to understand and predict hydrological processes of the vadose zone.

Many studies implement inversion approaches linking GPR data with hydrological models to provide detailed estimates of hydrological properties, such as soil water content (Busch et al., 2013; Finsterle and Kowalsky, 2008), hydraulic conductivity or permeability (Hinnell et al., 2010; Kowalsky et al., 2006), but also root parameters like root water uptake (Kuhl et al., 2018). For instance, Finsterle and Kowalsky (2008) developed an approach to estimate soil water content through a process-based inversion linking crosshole GPR data with a hydrological model, TOUGH2. Their proposed inversion methodology jointly estimates hydrological, petrophysical, but also geostatistical parameters, to provide a realistic parameterization of the 
subsurface that explains both the measured hydrological and geophysical data (Fig. 10). Based on a synthetic example, their results show that this approach is successful in recovering a permeability field that is in close agreement with the true permeability distribution, even though the dimensionality of the problem was reduced significantly. This shows that linking geophysical data with process-based models can provide results that go beyond the estimation of geophysical properties, but also provide parameter distributions that can directly be used by, e.g., hydrologists.

Similarly, Tran et al. (2016) used ERT data and the TOUGH2 modeling code for non-isothermal, multiphase flow in porous and fractured media to estimate not only hydrological, but also thermal properties of the subsurface. By including the thermal component, Tran et al. (2016) showed improved estimates of hydrological parameters, compared to approaches neglecting the thermal dependency of electrical resistivity measurements.
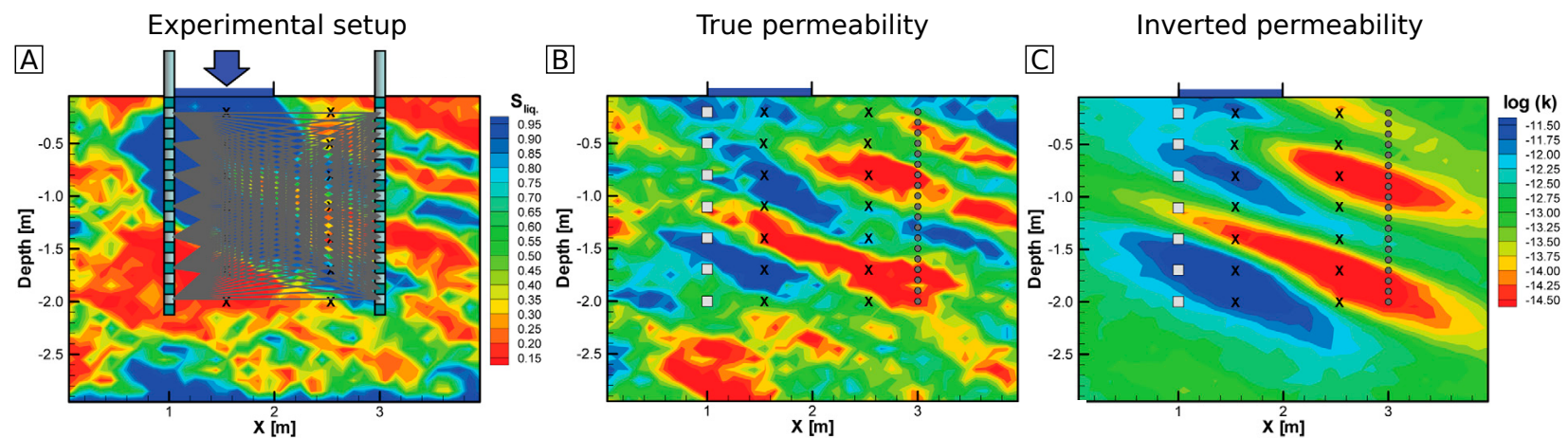

Figure 10: Process-based inversion linking crosshole GPR and TOUGH2 hydrological model to estimate soil water distribution during infiltration experiment. a) Location of neutron probes and GPR ray paths used for the inversion, as well as the spatial distribution of liquid saturation. b) True permeability distribution, c) inverted permeability distribution (modified from Finsterle and Kowalsky, 2008).

Although by no means complete, this review shows that often multiple geophysical methods are used in the study of the critical zone. This is likely due to the complexity and heterogeneity of this shallow part of the Earth. Many studies use independent inversion of multiple geophysical methods, but then jointly interpret their results, and often use additional data, e.g., from boreholes, to provide reliable subsurface models, which can then be used as input to, e.g., Earth system models. Going beyond that, structurally-coupled joint inversion was shown to provide results that pushed the limit in terms of resolution and accuracy than what independent inversion could image, particularly in complex and stratified environments. Process-based inversion can not only produce direct estimates of hydrological properties, but also improve the understanding of hydrological processes in the critical zone. 
So far, we discussed studies that focus on providing detailed information mostly on a site scale. Yet, to enable process understanding in cascading systems (e.g., linking site to hillslope processes and river corridors), approaches that are capable of spanning across scales are needed. Some recent work by von Hebel et al. (2018) and Falco et al. (2019) combine near-surface geophysical methods with remote sensing data to integrate subsurface information with aboveground observations, thereby providing actionable information on the ecosystem as a whole. Similarly, Shailaja et al. (2019) use remote sensing and geophysical data to estimate groundwater potential in western India. Although these studies link near-surface geophysical and remote sensing data, there is a lack of a integrated inversion of those approaches. In seismology, similar efforts have shown to be successful in combining remote sensing and ground-based measurements to define slip movements of earthquakes (Delouis et al., 2002). Such approaches could also be developed for environmental problems, where a combination of remote sensing data and near surface geophysics could be used to, e.g., track changes in soil moisture content for agricultural applications.

\subsection{Groundwater investigation}

Many communities worldwide rely on groundwater for their water supply. Yet, climate change, pollution, and changing water demands are increasing the stress on these aquifers, and hence are changing groundwater security (MacDonald et al., 2021). Over-exploitation, e.g., in the Central Valley of California, ultimately leads to a decrease not only in communal water supply but also in crop production (Scanlon et al., 2012). Hence, developing novel groundwater management approaches, supported by scale-appropriate technologies, is critical to achieve sustainable exploitation of this critical resource, and many questions still remain on how to achieve this goal (Blöschl et al., 2019). To date, subsurface structure and property distributions remain the biggest uncertainty in hydrology and watershed sciences (Fan et al., 2019). Geophysical techniques, as shown in the previous section, can be used to define these important components. The previous chapter focused on applications that covered the unsaturated to saturated zone, with most of the presented studies aiming at characterizing the static conditions. Here we focus on applications that either target structural control on particular groundwater dynamics, such as preferential flow, or use multi-geophysical studies to image the temporal evolution of groundwater systems.

\section{Independent inversion and joint interpretation}

Many groundwater exploration projects are still making use of single geophysical techniques, geoelectrical methods in particular, to provide guidance in siting of groundwater wells, espe- 
cially in developing countries (Boucher et al., 2009). While these techniques have been shown to be quick and reliable, in complex geological or hydrological settings, a single technique may not provide the information required to estimate groundwater resource and flow dynamics.

McClymont et al. (2011) use ERT, GPR, and seismic P-wave refraction data to investigate subsurface flow in alpine moraine deposits, which are characterized by complex hydrological systems due to their formation. While the GPR and SRT data proved essential in delineating the interface between the moraine deposits and the underlying bedrock, the ERT data delineated impermeable barriers to groundwater flow that correlate with spring locations where groundwater emerged at the surface. Low resistivity and P-wave velocity anomalies showed preferential groundwater flow through a network of fractures in the shallow bedrock, while high resistivity and velocity anomalies indicated barriers that confined the groundwater flow to shallow depths in other parts of the studied area. This highlights that by jointly interpreting ERT, GPR, and SRT, a detailed model of the complex flow of groundwater through a moraine deposit and its underlying bedrock could be obtained. Some details, like the flow pattern in the shallow bedrock may have been missed when interpreting the ERT data only, as the interface between the moraine deposit and the bedrock was not as well defined as imaged from the GPR and SRT data.

Focusing on imaging the interface between glacial and alluvial deposits and a Gneiss bedrock, Busato et al. (2019) use ERT and GPR data that spanned across the hyporheic and riparian zones of the Vermigliana Creek, Italy. While the ERT could be used to delineate the interface along a longer transect, the GPR data confirmed the shape of the interface and was used in a hydrogeophysical monitoring study, which showed that water exchanges between the river and the hyporheic zone were happening at very short timescales.

By employing time-lapse GPR and ERT, Steelman et al. (2017) were able to image the 3D migration of a $\mathrm{CH}_{4}$ plume within a shallow aquifer (Fig. 11). While the ERT results imaged the formation of an isolated $\mathrm{CH}_{4}$ bulb around a shallow injector and showed a lateral extension of the $\mathrm{CH}_{4}$ plume, further along the groundwater flow gradient the $\mathrm{CH}_{4}$ did not cause a significant desaturation of the porespace, to which ERT would have been most sensitive, and hence imaging the migration of the plume was not possible. This limitation could be overcome using GPR data, which due to the change in dielectric properties related to the migrating $\mathrm{CH}_{4}$ plume, showed distinct time-varying reflections that could be used to track the migration of the plume. This shows an exemplary case of the complementary nature of multiple geophysical measurements. While using ERT would have allowed to image the built-up of a gas bulb around the injection borehole, the migration of the $\mathrm{CH}_{4}$ plume downgradient would have been missed. Yet, the GPR data was not sensitive to the increasing gas concentration in the vicinity of the 
injection, but successfully imaged the migrating plume. Hence, the integrated interpretation of both techniques could successfully image the entire evolution of the $\mathrm{CH}_{4}$ plume.
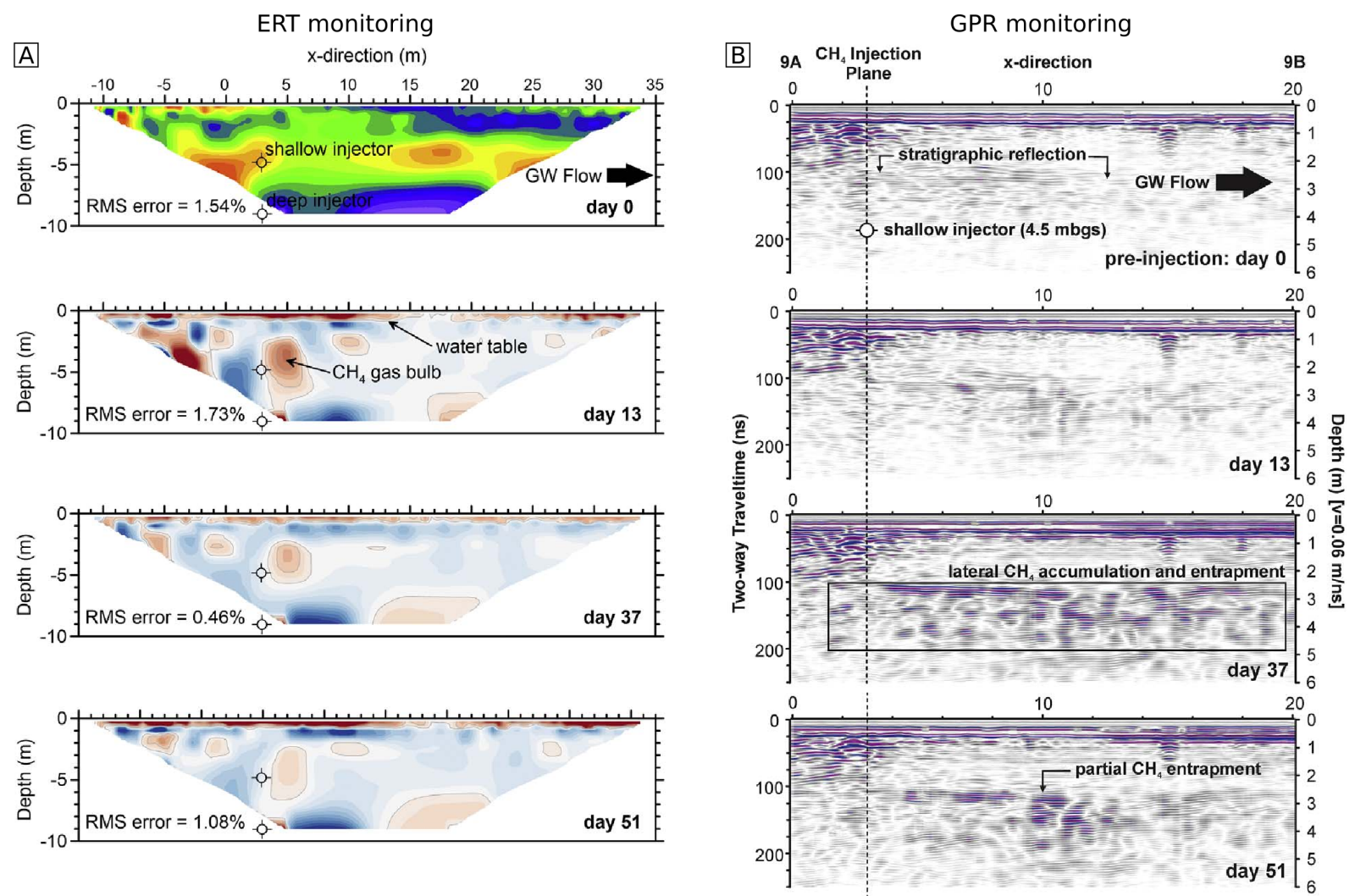

Figure 11: Tracking of $\mathrm{CH}_{4}$ migration using independent time-lapse inversion of ERT data and GPR reflection imaging (modified from Steelman et al., 2017). The results show that ERT is sensitive to the built up of a $\mathrm{CH}_{4}$ gas bulb around the injection location, while a change in dielectric properties is used to image the migrating plume using GPR.

\section{Constrained inversion}

To provide a detailed image of aquifer geometry, geophysical techniques that are known to provide well defined boundaries, such as GPR or seismics, are often used to constrain the inversion of other methods, such as ERT or magnetic resonance tomography (Doetsch et al., 2012a; Jiang et al., 2020; Vouillamoz et al., 2012).

For instance, Doetsch et al. (2012a) identify layers within an aquifer based on 3D GPR reflection data, and use these layers to constrain a 3D ERT inversion (Fig. 12). They apply this approach on a gravel bank of the river Thur in northeastern Switzerland at a location of a recent river restoration. To recover the distinct reflectors observed in the GPR data, regularization is disconnected above and below the picked interfaces, while across the identified groundwater table, even though included in the mesh generation, regularization is still enforced. This approach 
clearly combines the strength of the two techniques. Without the GPR constraints, the layers could be identified from the ERT resistivity model, but as it is common for geoelectrical imaging, layer boundaries are smooth and difficult to decipher. By including the information from the GPR data, the layer boundaries are integrated in the inversion and more detail within the layers could be obtained. This detailed characterization of the aquifer was subsequently used to inform the design of a salt tracer experiment, which was monitored using 3D ERT (Doetsch et al., 2012b). The results highlighted preferential flow paths within the aquifer. While conventional hydrological monitoring equipment (deployed in a set of monitoring boreholes) failed in coherently detecting the tracer movements, the imaged changes in resistivity showed complex movement patterns of the salt tracer, and allowed to estimate plume movement velocities and directions.
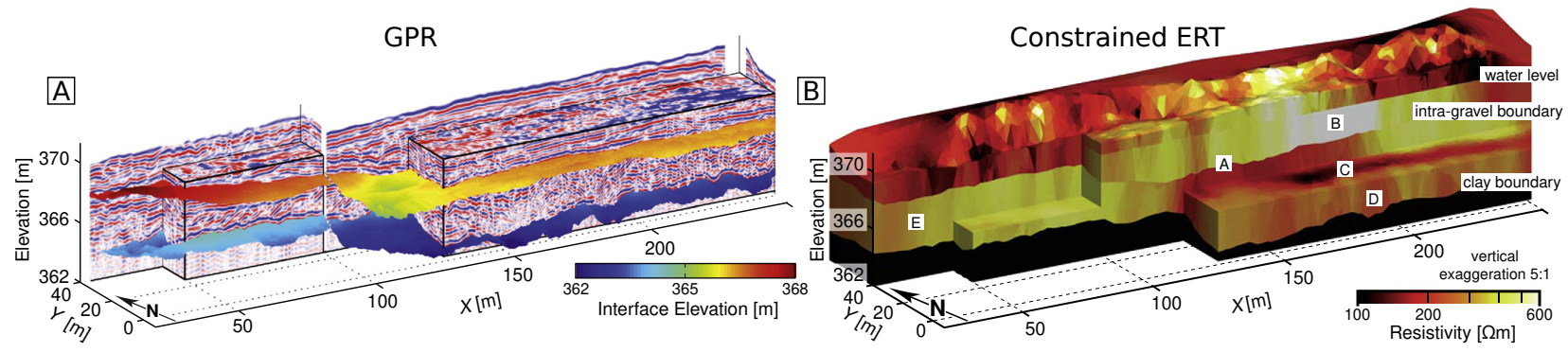

Figure 12: Detailed imaging of an aquifer using ERT constrained by GPR reflection data (modified from Doetsch et al., 2012a). GPR reflection data (A) were used to pick reflectors associated with lithological changes within the aquifer and used to constrain the ERT inversion (B). Note that regularization was disconnected across the intra-gravel and clay boundary, while across the groundwater interface regularization was maintained (even though the interface was included in the mesh generation).

By constraining magnetic resonance tomography (MRT) and ERT data using lithological layers derived from GPR reflection data, Jiang et al. (2020) obtained similar results that also highlight that including structural constraints improved the resolution of variability within units and at larger depths, but also provided hydrological properties that were in closer agreement with borehole data than obtained from smoothness-constrained MRT inversions.

These examples show that constraining one geophysical technique with the results of another, particularly a method with higher spatial resolution or better performance in delineating layer boundaries, can improve hydrogeophysical characterization of hydrologically important units, and allow to image complex aquifer structures and groundwater flow dynamics. 


\section{Joint inversion}

Often, geophysical data are used to parameterize hydrological models, which usually consist of a number of distinct hydrological facies with well defined boundaries. Yet, geophysical imaging usually provides smooth and ambiguous images of these boundaries. Similar to the incorporation of structural constraints, joint inversion of multiple geophysical methods can help to overcome this limitation and to better resolve the boundaries of the hydrological facies (Linde and Doetsch, 2016). Some of the early approaches have focused on combining different types of geophysical data to provide well-defined hydrological facies within a domain bounded by a set of boreholes. In particular, borehole GPR and ERT have been used quite intensively to achieve this goal. Linde et al. (2006) use structural coupling based on cross-gradients to jointly invert ERT and multi-offset gather GPR traveltimes to reconstruct the structural and hydrological properties in 3D within the Sherwood Sandstone formation close to Eggborough, UK. They make use of stochastic regularization operators that are based on geostatistical models estimated from the additional borehole data available at this site, which above the saturated zone are a function of the geology and the water content, and below just a function of the geology. Hence, by using these stochastic regularization operators, Linde et al. (2006) include prior information about the sandstone unit into their structurally-coupled joint inversion and obtain geologically realistic models, even though the independently inverted GPR and ERT data did not show apparent structural correlation. In their work, Linde et al. (2006) did not assume a petrophysical relationship between electrical conductivity and electrical permittivity, but rather obtain such a relation as a by-product of the joint inversion. Based on the analysis of scatterplots of electrical conductivity vs. relative permittivity, a zonation of the hydrostratigraphy could be achieved. Using a similar approach, but applying it to 3D time-lapse inversion of GPR traveltime and ERT data, Doetsch et al. (2010) could significantly improve the imaging of subsurface plume migration, including its lateral spreading and the movement of the center of mass, compared to results from independent inversion of the data sets. Incorporating recent advances in GPR full-waveform inversion, Domenzain et al. (2020b,a) developed a structurally-cooperative joint inversion approach that, by coupling GPR full-waveform and ERT data, can reconstruct significant details from both datasets. By comparing the joint inversion to the independent inversion results, they conclude that for the joint inversion, the ERT method complements the GPR data, particularly in regions of high attenuation, whereas the GPR data support the ERT measurements in areas of low conductivity. They apply their code to a synthetic aquifer model and show that by using the joint inversion, boundaries in the permittivity and conductivity fields can be resolved with high accuracy, and even smaller contrasts within potential aquifer subunits can be imaged (Fig. 13). 

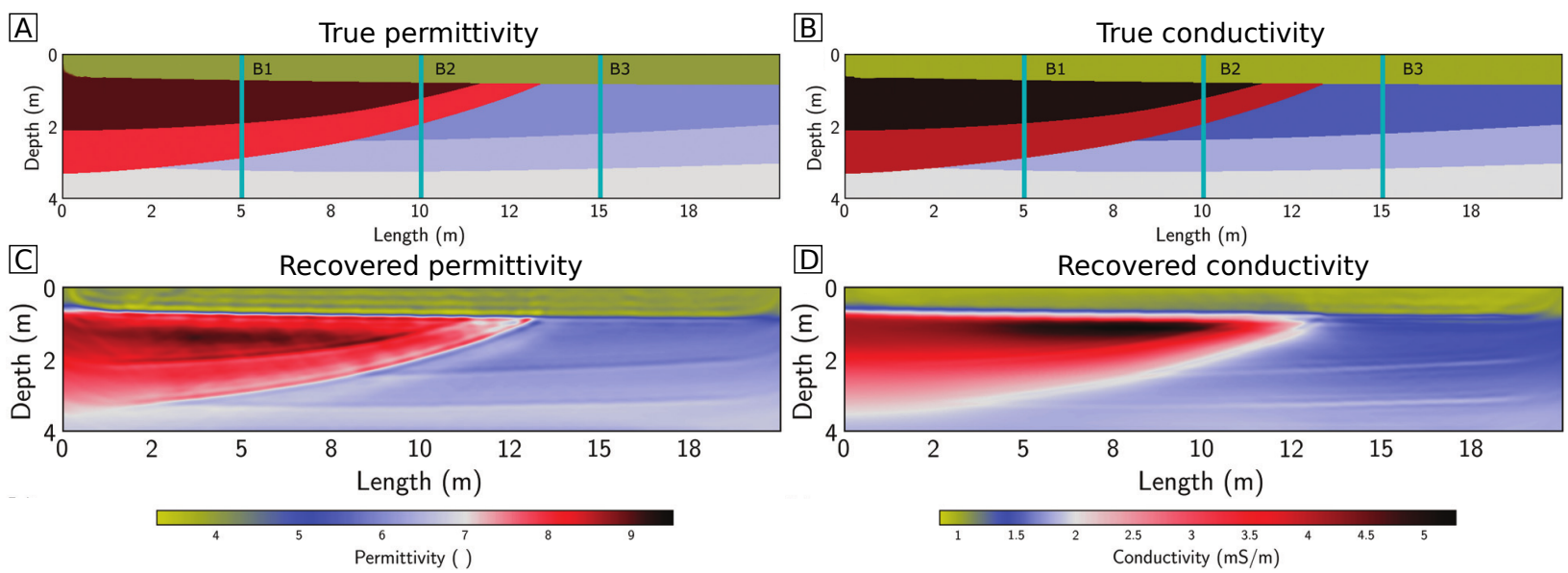

Figure 13: Imaging of a synthetic aquifer using full-waveform GPR and ERT data. (A-B) show the synthetic aquifer model in terms of its permittivity and electrical conductivity. (C-D) the recovered permittivity and electrical conductivity fields obtained from the joint inversion of full wave-form GPR and ERT data (modified from Domenzain et al., 2020a).

Based on the joint inversion of vertical electrical and magnetic resonance soundings, Günther and Müller-Petke (2012) estimate the hydraulic properties of a layered groundwater system on the North Sea island of Borkum, Germany. By solving for the water content, the relaxation time $\mathrm{T}_{2}$, and the electrical resistivity of a 1D layered earth, they are able to distinguish lithological units in a complex freshwater/saltwater system that otherwise would have been hidden by the ambiguity of the results of independent inversions. They also show that by applying petrophysical relationships to these inverted parameters, they can provide important hydrological parameters such as hydraulic conductivity, porosity, and salt concentration, which are all critical for density-driven flow and transport modeling of this coastal aquifer. Developing this methodology for 2D applications, Skibbe et al. (2021) show that the joint inversion of magnetic resonance and electrical resistivity tomography data yield improved aquifer zonation and property estimates, particularly with regard to imaging the hydraulic conductivity distribution, even in a complex environment.

\section{Process-based inversion}

In groundwater-focused applications, and in hydrogeophysics in general, geophysical data are often used to constrain hydrological models, either by providing structural characteristics, or by providing data on temporal dynamics (Binley et al., 2015). Given this well-developed link to hydrological flow and transport models, process-based inversions have been adapted relatively early on in groundwater applications, similarly to the many developments in vadose zone applications. The first example of an uncoupled process-based inversion was achieved through a 
thorough hydrogeophysical characterization of the South Oyster Bacterial Transport Site (Hubbard et al., 2001) that eventually enabled detailed modeling of solute transport by Scheibe and Chien (2003). Scheibe and Chien (2003) constrained their transport model using both the hydraulic property estimates from borehole flow meters, in addition to the cross-sectional estimates of hydraulic conductivity derived from cross-borehole measurements of Hubbard et al. (2001). They show that by just constraining the model with the borehole flow meter data, the estimated model predictions did not significantly improve and were overly confident. Yet, when incorporating the hydraulic conductivity estimates from the cross-borehole GPR data, considerable improvements in both the accuracy and precision of the model predictions were observed.

Using a fully coupled approach, Johnson et al. (2009) use time-lapse ERT data and hydrological observations to invert for the hydraulic conductivity field. Rather than using specific petrophysical relationships, which depending on the subsurface heterogeneity may not be spatially continuous, their approach only assumes the form of the petrophysical relationship, e.g., whether it is linear or exponential, and include this into the objective function of the inversion. While this should be applicable to various geophysical properties, Johnson et al. (2009) use this approach to link changes in observed bulk resistivity to changes in the fluid conductivity. The changes in the fluid conductivity are then linked to the results of a MODFLOW-based flow and transport model to jointly invert the ERT data with observed measurements of hydraulic head and fluid conductivity. Their results, based on a synthetic example, show that this approach provides a detailed image of the true hydraulic conductivity field that is superior to both the estimated hydraulic conductivity field from the hydraulic and geophysical observations alone (Fig. 14).

Avoiding potentially poorly defined petrophysical relationships altogether, Lochbühler et al. (2013) propose a methodology that, similar to structurally-coupled joint inversion of multiple geophysical data sets, uses spatial gradients in both the geophysical and hydrological data to jointly invert these data sets assuming structural similarity. Using an alternating direction method of multipliers (known as ADMM), Steklova and Haber (2017) break down the complex joint inversion problem and solve the geophysical and hydrological problem separately, while still minimizing the misfit for both problems simultaneously. This approach allows to combine two inverse problems that potentially have different convergence properties, and generally reduces the computational effort and allows for flexibility in the choice of forward modeling and inversion codes. Applied to a seawater intrusion problem, Steklova and Haber (2017) show that using ADMM time-lapse ERT and groundwater sampling data can be jointly inverted to 


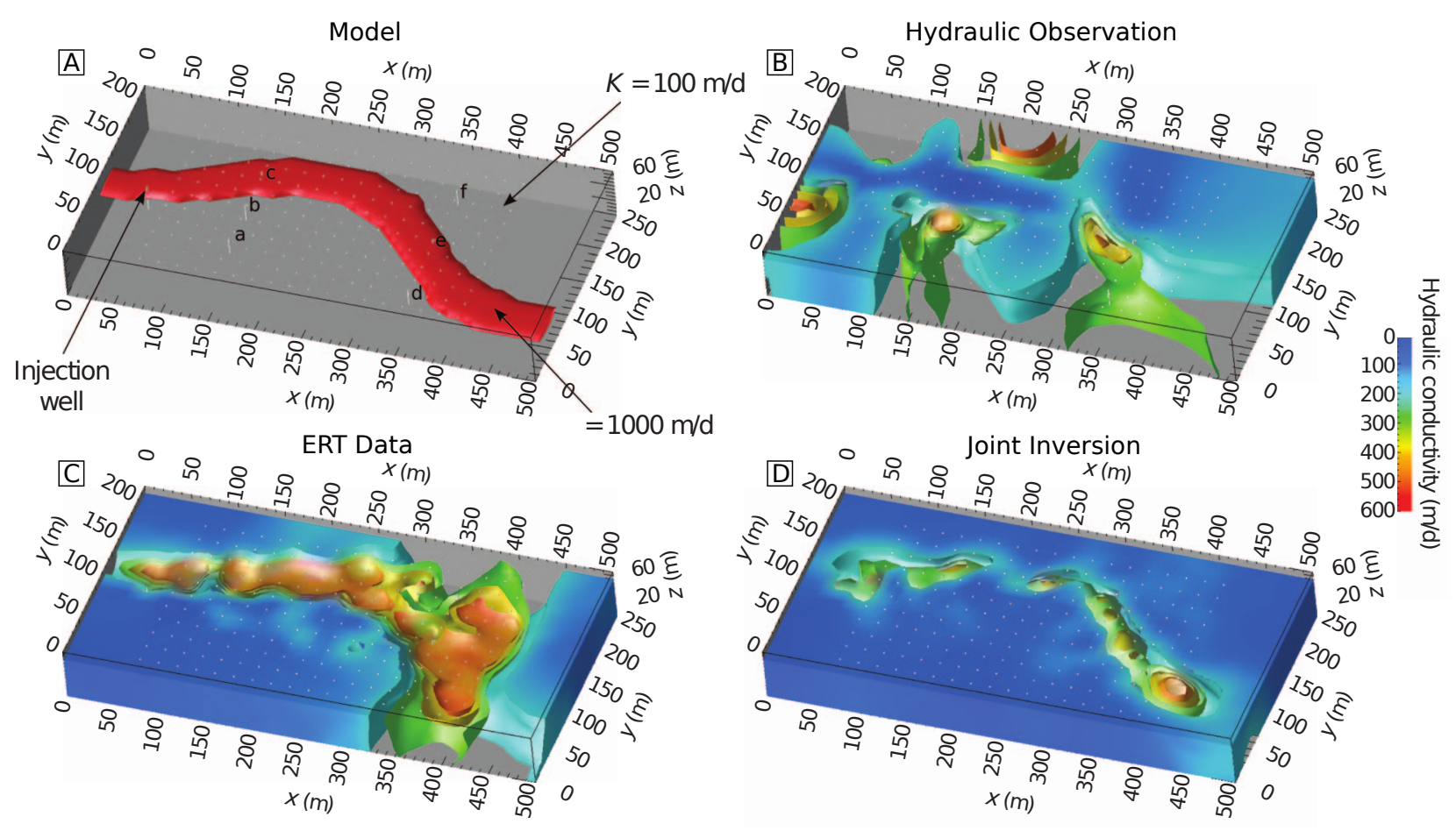

Figure 14: Inversion results of synthetic hydraulic conductivity field (A), using only hydraulic head and fluid conductivity observations (B), only time-lapse ERT data (C), and a joint inversion of both hydraulic and geophysical observations (D) (modified from Johnson et al., 2009).

provide accurate estimates of the 4D solute concentration distribution throughout the studied aquifer.

Going beyond providing physical parameter distributions, Tso et al. (2020) show that processbased models can also be used to estimate parameters important for contaminant release, such as leak location, time of leak onset, and contaminant discharge. Their results show that particularly the leak parameters, such as location, time of leakage, and duration can be estimated to a high accuracy, whereas estimating hydrological parameters and contaminant discharge showed large uncertainties. While this work required a good parameterization of the hydrological model, it shows that parameters critical for understanding complex contaminated sites can be gained from such methods, which can be crucial for a reliable long-term monitoring strategy.

These examples show the benefit of applying multimethod investigations to groundwater problems. Not only can joint investigations improve the structural characterization of aquifers, many studies also showed that detailed images of complex hydrological processes can be obtained by considering multiple geophysical methods or by integrating geophysical and hydrological models. Given the rising stress of aquifers around the globe, geophysical investigations used to characterize and assess groundwater resources for their sustainable use will become increasingly important in the future. These studies show that combined geophysical/hydrological 
approaches are able to address this need and that they will play a decisive role in sustainable groundwater management, since direct hydrological observations are (1) often expensive to obtain, and (2) only provide estimates at sparse borehole/sampling locations. However, there is a need to further develop geophysical methods to provide accurate and rapid estimates of groundwater potential, particularly for deep and fractured aquifers, which may be overlain by conductive formations, and hence "hidden" to many geophysical imaging techniques.

\subsection{Natural hazards}

Urban areas and infrastructure networks are progressively moving into regions prone to natural hazards, such as earthquakes, landslides, sinkholes, flooding, or wildfires. With climate change causing an increasing frequency of extreme weather events, the triggering conditions for some of those natural hazards are becoming more frequent and severe. Hence, it is becoming increasingly important to investigate the subsurface characteristics and processes linked to these hazards to assess the risk that they pose. As for previous applications, natural hazards studies also use multiple geophysical techniques to image and characterize the subsurface conditions and processes triggering these natural hazards. Since these processes are known to be complex, combining the sensitivity of multiple geophysical methods has shown to be very beneficial in distinguishing subsurface features related to earthquake ground displacements and liquefaction (Khan et al., 2021), landslide slip surfaces (Zarroca et al., 2014; Schmutz et al., 2009), and sinkhole features (Carbonel et al., 2014). Such methods can overcome the inherent limitations of conventional studies, which are often based on visual observations or remote sensing, which commonly provide information about ongoing effects related to the hazards, such as ground displacements, rather than providing data that can be used for early warning of natural hazards.

\section{Independent inversion and joint interpretation}

Due to the complexity of the ground conditions associated with natural hazards, multiple methods are frequently used to assess various features and to improve the robustness of the developed ground-model. Depending on the hazard, subsurface targets include stratigraphy, location of the groundwater table, or imaging the response of the subsurface to the hazards. In any of those cases, single geophysical techniques may not be able to provide the information that is needed to identify the subsurface features that are controlling the severity of the hazard, and often geophysical techniques are complemented with engineering geological or geotechnical studies (e.g., Merritt et al., 2014; Sass et al., 2008; Bekler et al., 2011; Malehmir et al., 2013). For example, Bichler et al. (2004) use seismic, GPR and ERT data, combined with stratigraphic 
and geomorphological analysis to provide a 3D model of the Quesnel Forks landslide, British Columbia, Canada. Using this combined approach Bichler et al. (2004) were able to image rupture surfaces and other displacement features, and were able to identify possible triggering factors for this landslide, allowing them to assess the risk of this landslide. They highlight that "the multi-geophysical survey approach resulted in a more detailed and less ambiguous interpretation of the 3-dimensional structure of the landslide and terrace than if any one geophysical method were used in isolation", and hence provide an excellent example on how the use of multiple geophysical techniques can overcome the limitations of single techniques. In their case, because of the range of scales and the required depth-of-investigation, no one method would have been ideal to characterize this landslide.

Similarly, Heincke et al. (2010) and Socco et al. (2010) use a combination of seismic and electrical methods to characterize rockslide and rock avalanche deposits. The combined use of multiple geophysical techniques enabled the identification of fracture zones and the determination of the thickness of these deposits across a range of depths and contrasts in geophysical properties.

For sinkhole applications, Carbonel et al. (2014) combine GPR, ERT, and trenching to image the characteristics of sinkholes impacting upon urban areas of Zaragoza, Spain (Fig 15). They show that trenching can provide reliable information on the extend of sinkholes and their internal structure. Trenching across large areas is prohibitive, therefore, geophysical surveys can be used to provide detailed images of the sinkholes features both in 2D and 3D. While GPR is highlighted as the most appropriate technique, mostly due to its sensitivity and resolution to distinguish sinkhole fill from the host rock, the applicability of GPR is limited in the case of electrically highly conductive fill, or deep features. Carbonel et al. (2014) show that this limitation can be overcome by combining GPR with ERT measurements, which although do not provide data at the required resolution to image detailed sinkhole fill, this approach can be used to investigate the deeper features and perhaps controlling conditions of sinkholes that cannot be reached using GPR.

Similarly, Samyn et al. (2014) use ERT and multi-channel analysis of seismic surface waves (MASW) combined with geotechnical investigations to assess the risk of seepage through river dams. By determining anomalies from the ERT and seismic data, they were able to define a failure susceptibility index, which they could use to map seepage risk at high spatial resolution (10 $\mathrm{m}$ ) across the studied area comprising $90 \mathrm{~km}$ of dams along the Loire river. Samyn et al. (2014) highlight that conventional studies, e.g. using borehole investigations, only provide data at a spatial resolution usually of about $500 \mathrm{~m}$. In many cases where the features of interest are of small scale, such as identifying seepage or karst feature, this resolution may be inappropriate, 
A

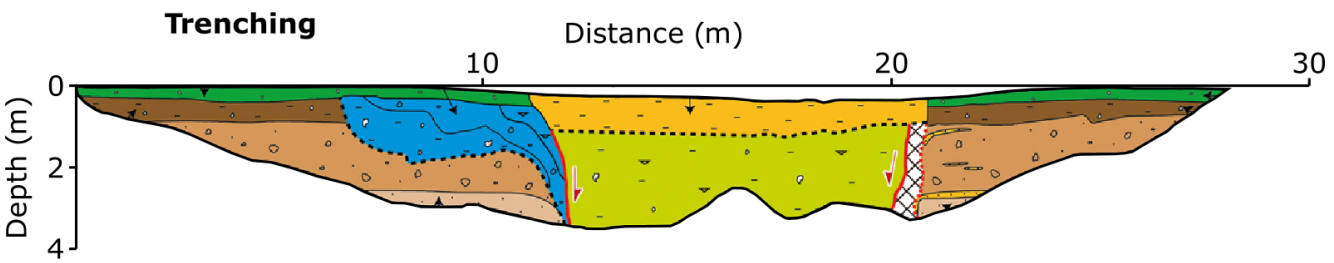

B

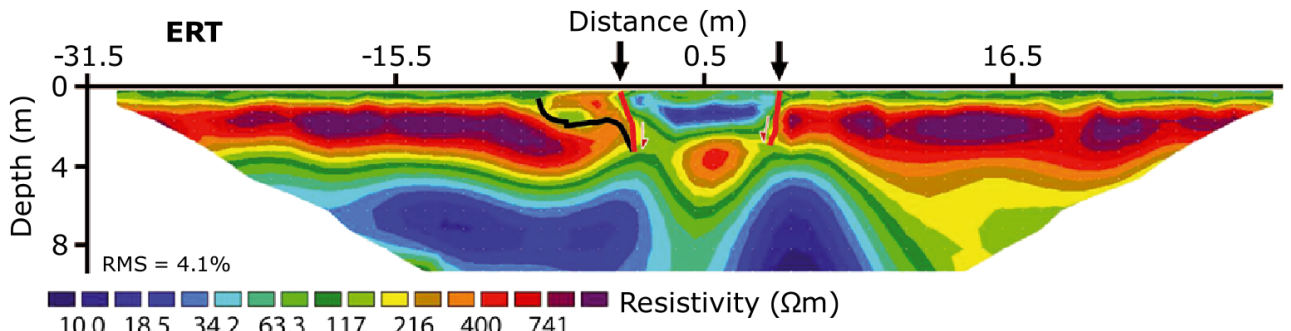
$\begin{array}{llllllll}10.0 & 18.5 & 34.2 & 63.3 & 117 & 216 & 400 & 741\end{array}$

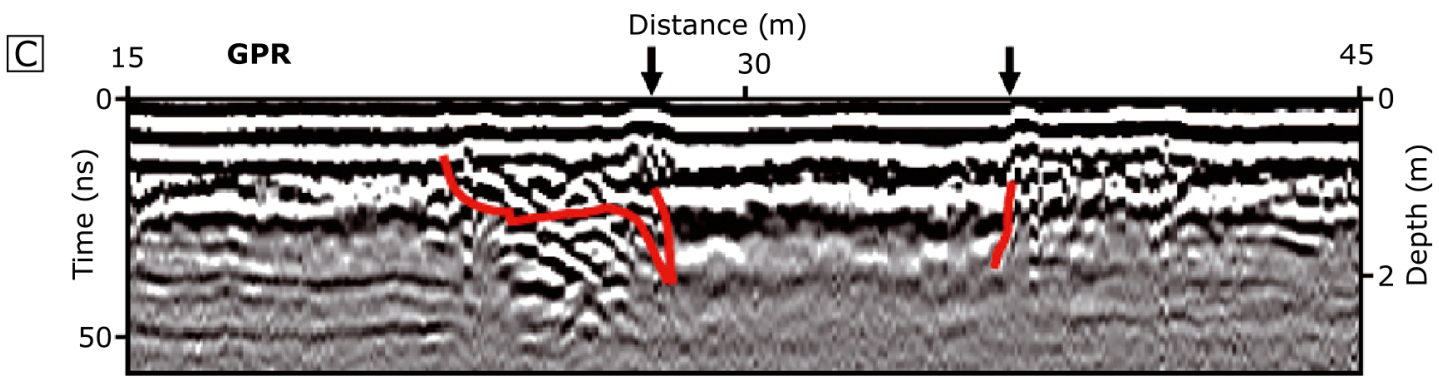

Figure 15: Integrated investigation of sinkholes close to Zaragoza, Spain. Trenching (A), ERT (B), and GPR (C) are used to provide a detailed image of the sinkhole stratigraphy, elucidating the forming mechanism of this sinkhole (modified from Carbonel et al., 2014).

but can be overcome by using a combined acquisition and interpretation of geophysical imaging techniques and conventional investigations.

\section{Constrained inversion}

The subsurface conditions related to natural hazards are often complex. For the example of landslides, the movement of soils or rocks are creating intricate subsurface features including cracks, fissures, and mixtures of materials, next to complex hydrogeological conditions, with perched groundwater tables and preferential flow. Landslides are commonly investigated using geotechnical and geomorphological approaches, which can provide detailed data representative of small volumes, but may fail in providing data representative for these heterogeneous conditions. Geophysics has been proven a valuable tool in the characterization and monitoring of landslides, particularly when combined with standard geotechnical and geomorphological investigations (Jongmans and Garambois, 2007). By combining the results of different geophysical methods, detailed images of the complex subsurface conditions commonly related to natural hazards can be obtained. For instance, Uhlemann et al. (2017) use results from seismic refraction surveys (P- and S-wave) to define a lithological boundary based on the derived 
Poisson's ratio. This interface is used to constrain the inversion of ERT monitoring data and eventually to assign petrophysical relationships to translate the obtained electrical resistivity distribution into distributions of gravimetric moisture content. By doing so, they not only obtain more reasonable images of the lithological interfaces, but also improved the estimates of moisture content in the shallow subsurface, which were shown to be in agreement with independent soil moisture measurements and variations in groundwater table.
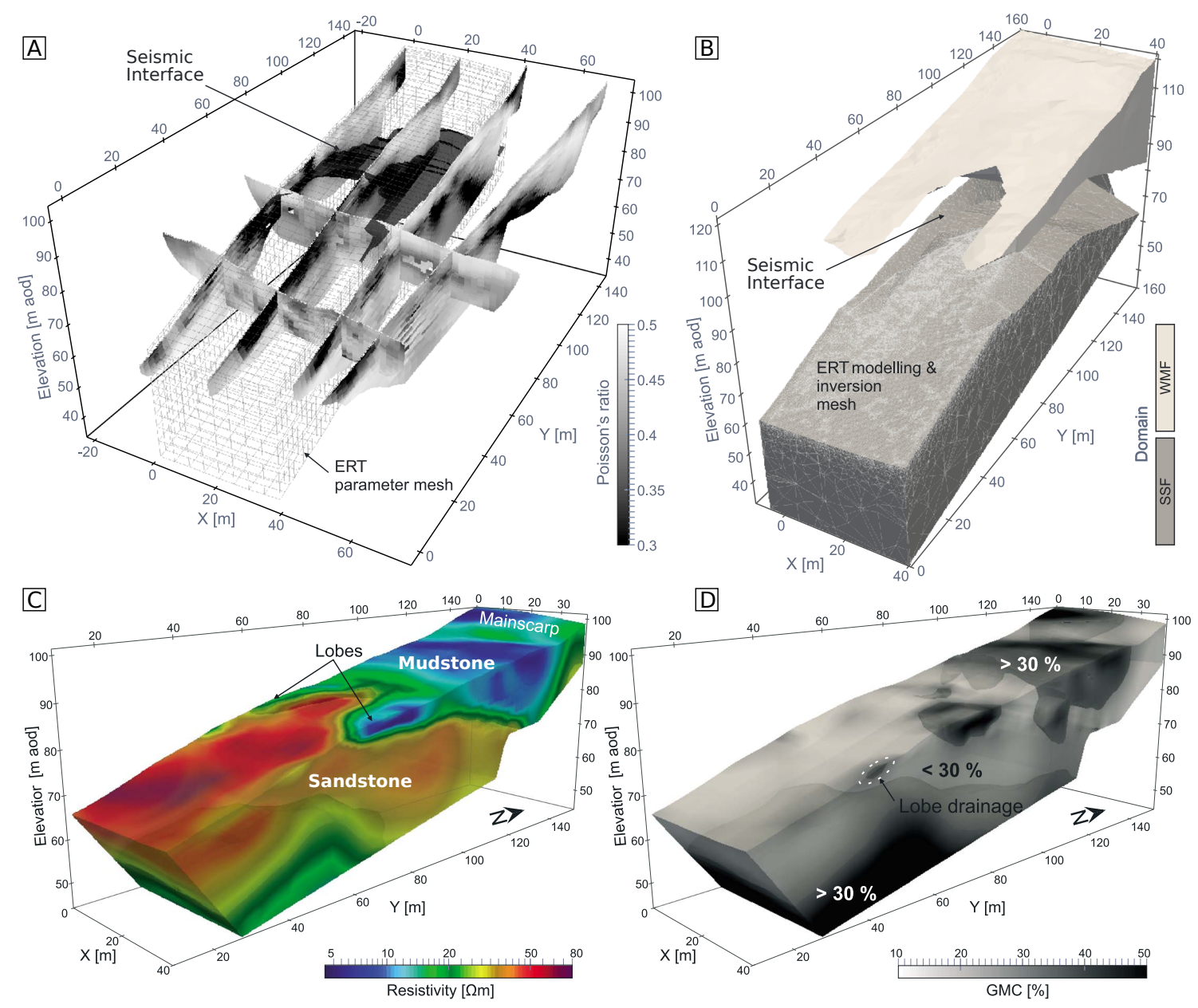

Figure 16: Constrained inversion applied to landslide investigations (modified from Uhlemann et al., 2017). (A) Interface between the mudstone and the sandstone, as defined from the Poisson's ratio, which was determined from Pand S-wave seismic refraction tomography. (B) Inversion mesh, showing how the two different domains for the mudstone and sandstone. (C) Inverted resistivity model highlighting the difference between the lithological units and landslide features. (D) Gravimetric moisture content derived from the ERT data by applying separate petrophysical relationships to the mudstone and sandstone units, as distinguished from the seismic data. 


\section{Joint inversion}

To fully exploit the sensitivity of multiple geophysical methods, Hellman et al. (2017) use a structurally-coupled cooperative inversion approach to jointly invert seismic and ERT data to investigate a landslide setting in Vagnhärad, Sweden (Fig. 17). In their study, they highlight that jointly inverting multiple geophysical data addresses the equivalence problem, common to geophysical inversion, and that the structurally-coupled cooperative inversion aids in enhancing subsurface contrasts that are common in the geophysical methods used. In this case, the subsurface could be divided into 3 layers, with clay overlying a glacial till, which is underlain by bedrock. The investigated landslide was triggered by a rise in pore pressure at the interface between the till and the clay. A joint use of ERT and seismic is beneficial in this case. While there is a large electrical resistivity contrast between the till and clay, the contrast between till and bedrock is small, yet the contrast in seismic velocity of this lower interface is large. Hence, by jointly inverting the data of the two methods, more pronounced interfaces between both clay and till, and till and bedrock were obtained compared to independent inversion of the data.
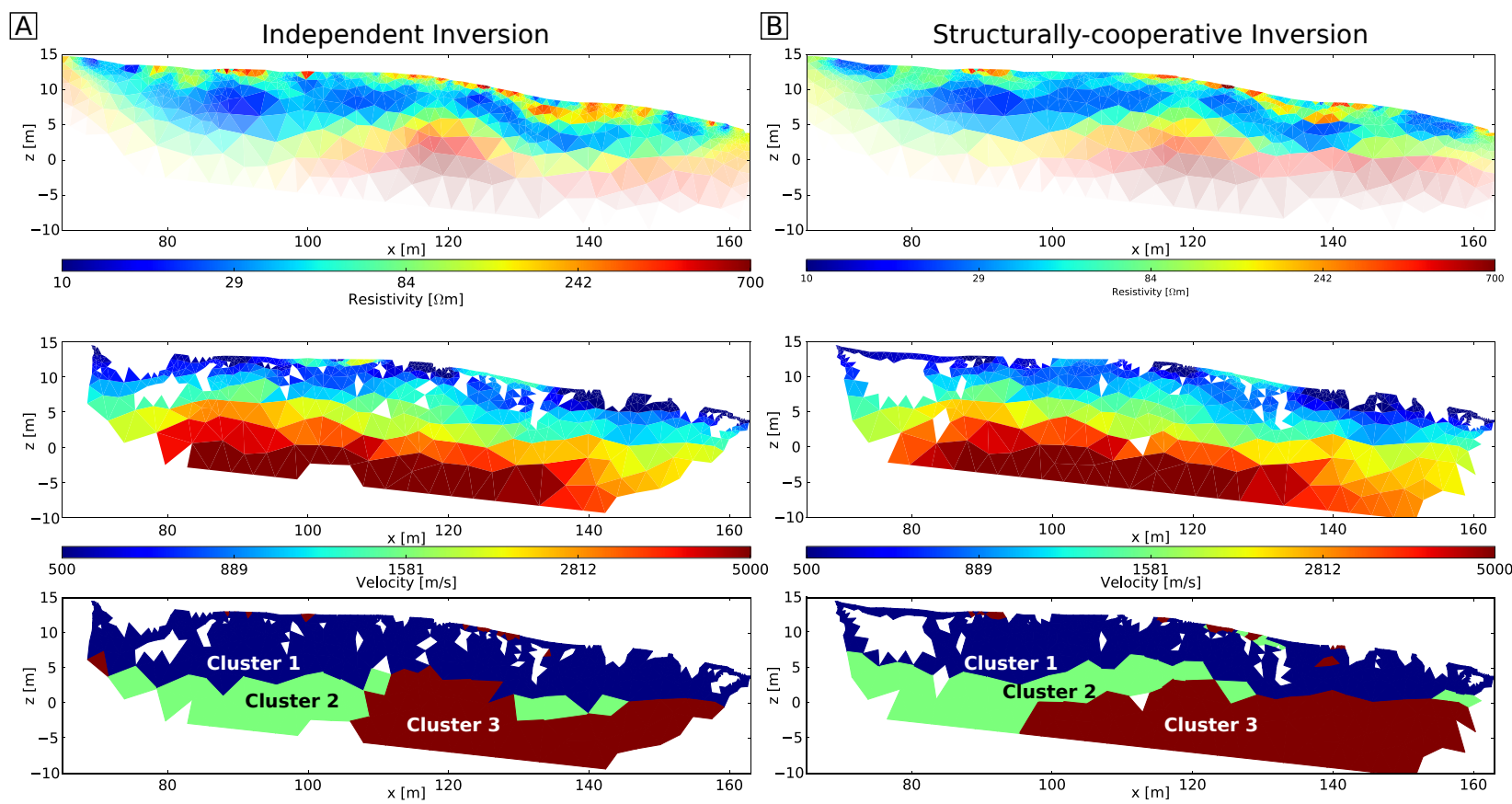

Figure 17: Results of independent (left) and structurally-cooperative joint inversion of ERT and seismic P-wave refraction data, acquired on a landslide in Vagnhärad, Sweden (modified from Hellman et al., 2017). The top two panels show the ERT and seismic inversion results, the bottom panel shows a cluster analysis of the resistivity and P-wave velocity models. The structurallycooperative joint inversion enables a better delineation of the interface between the clay (cluster 1 ) and the glacial till (cluster 2), as well as between the till and the bedrock (cluster 3). 
To investigate sinkholes in northern France, Jardani et al. (2007) jointly invert SP and EM data, using a simulated annealing approach. The two methods are linked under the assumption that the thickness of the vadose zone is determining both the EM and SP response. Their results show distinct variations in the thickness of the vadose zone that correspond with the location of known sinkholes, however, they were also able to identify anomalies that could be linked to previously unknown sinkholes. The depressions of the base of the vadose zone are linked to preferential groundwater flow towards the underlying aquifer. While both methods are sensitive to these variations in flow and soil moisture content, their joint inversion provided robust estimates of anomalous locations that correlated with known sinkhole locations, and highlighted the hydrological conditions governing these systems.

To image potential piping in a test embankment, Rittgers et al. (2016) jointly invert time-lapse P-wave refraction and ERT data. By comparing independent, structural cross-gradients (SCG), and time-lapse SCG, and an iteratively reweighted SCG, it is shown that the small scale, targeted piping feature could only be imaged using time-lapse SCG and the time-lapse reweigthed SCG constraints. This highlights the use of joint inversion approaches to increase contrasts and hence resolution to image even small scale features, which can be very difficult to image using a single geophysical technique.

\section{Process-based inversion}

To progress from monitoring proxies to the factors triggering natural hazards to eventually predict the hazard, linking geophysical data with the appropriate mechanistic model is necessary. Yet, in contrast to vadose zone or groundwater studies, where many process-based inversion approaches have been developed and used, in the field of natural hazards this is only now starting to emerge. Some recent studies have combined subsurface structures identified from airborne EM data with hydro-geomechanical models to assess the stability of volcano flanks (Peterson et al., 2021; Finn et al., 2018). By incorporating subsurface features into the slope stability model, Finn et al. (2018) could improve the hazards assessment for slope failure of Mt. Baker, Alaska, US, which showed reduced stability due to hydro-thermal alteration of the rocks forming the flanks of this volcano. When modeling a homogeneous subsurface property distribution the most likely flank to collapse was estimated to be the north-western flank, however, when incorporating rock alterations mapped by the AEM data, the south-eastern flank was estimated to having a higher susceptibility to failure. Similar results where also obtained by Peterson et al. (2021), which show that particularly deep hydro-thermal alteration of the Iliamna Volcano considerably increases the susceptibility of slope failure, but also increases the potential volume of material that could be released during failure (Fig. 18). 

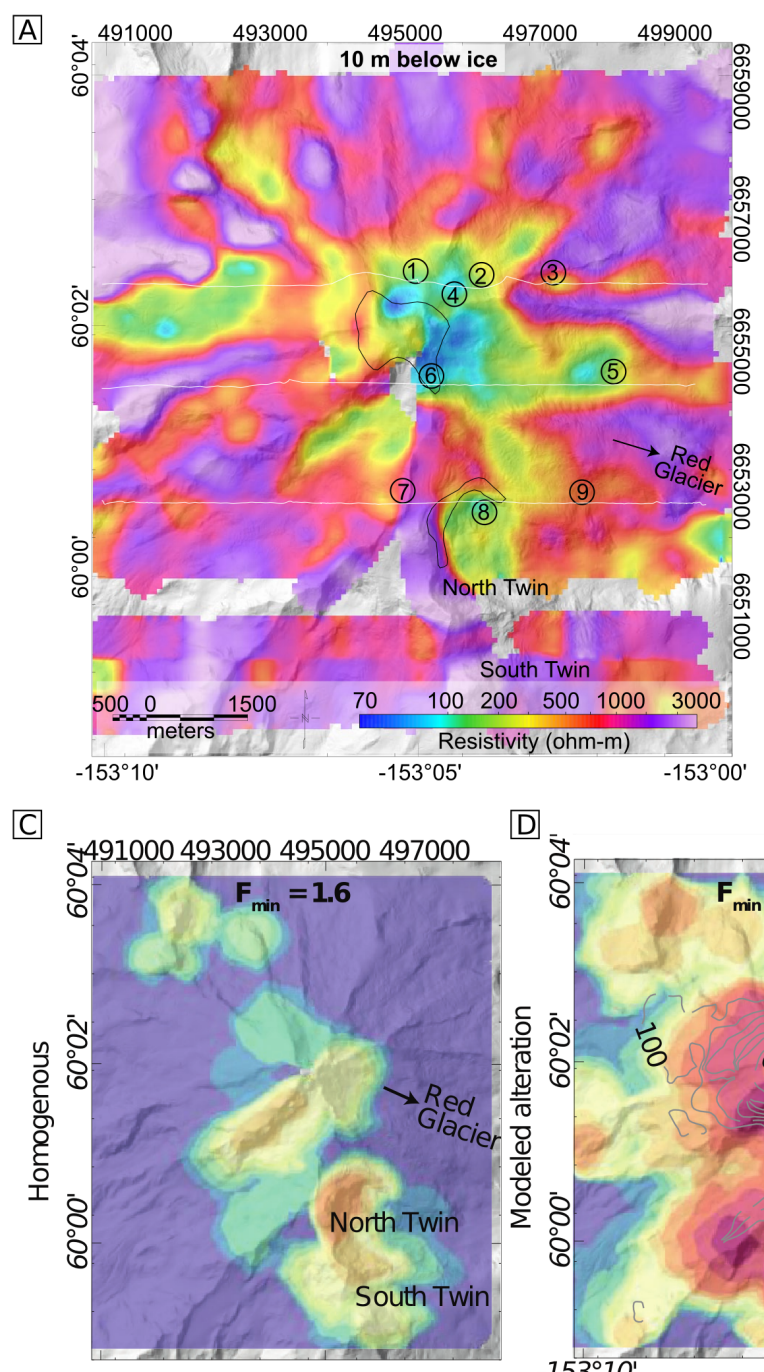

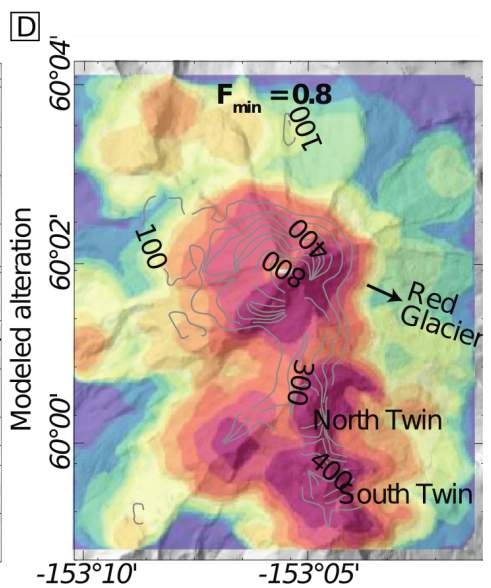

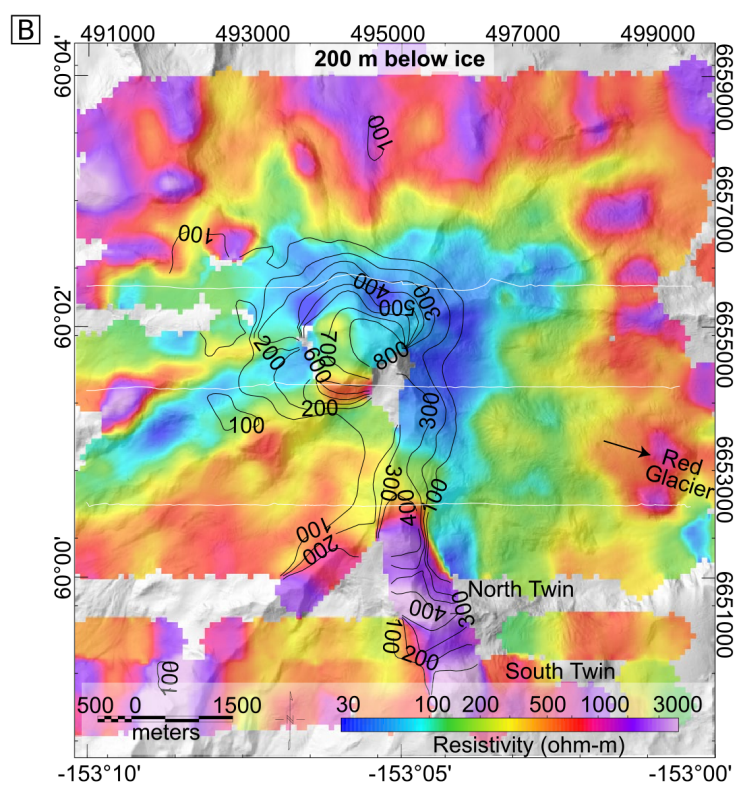

国

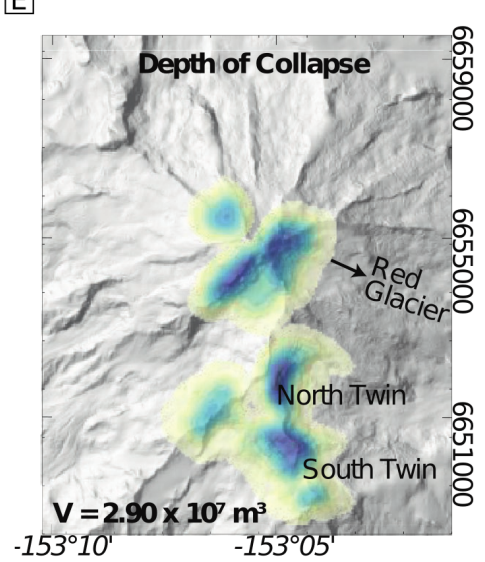

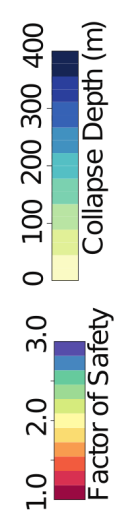

Figure 18: Incorporating subsurface rock alteration identified from airborne EM data into hydro-geomechanical models to assess the stability of the flanks of Iliamna Volcano (modified from Peterson et al., 2021). (A)-(B) Depth slices at 10 and $200 \mathrm{~m}$ below the ice covered volcano surface, with low values indicating hydrothermally altered rock. (C) Slope stability estimated using a homogeneous subsurface model, and using the imaged alterations (D). (E) Depth of the most likely flank failure scenario.

Incorporating time-varying subsurface features, Uhlemann et al. (2021a) propose a processbased joint inversion scheme that extracts the groundwater table from time-lapse ERT data, and uses this information in a hydro-geomechanical model to assess the stability of a landslide. They show that by incorporating the geophysical data, and simulating future storm events, the hazard can be assessed and predicted. These developments of integrating subsurface information obtained from geophysical data into slope stability models are showing encouraging results, and due to improving capabilities with regards to data telemetry and modeling capabil- 
ities, such joint approaches are likely to provide a paradigm change for early warning of natural hazards.

While many studies have shown that geophysics can delineate subsurface features critical to assessing various natural hazards, often there is a disconnect between geophysical and geotechnical or civil engineering investigations. This is mainly due to the different physical properties that are of concern to the various disciplines. As for other fields, the focus of the geophysicists should be to translate geophysical proxies into parameters that are used in geotechnical and civil engineering. Applied to landslide problems, such an approach has been developed by, e.g., Crawford and Bryson (2018). Developing these relationships between geophysical and geotechnical properties is still a pressing issue, but will provide a means of more easily integrating geophysical data into geotechnical and geomechanical models.

\subsection{Permafrost degradation}

Arctic environments present massive storage units for $\mathrm{CO}_{2}$ and hence are pivotal elements to assess the impact of climate warming on the Arctic feedback loop that has the potential to accelerate climate change (e.g., Schuur et al., 2015). In addition, permafrost degradation can increase the probability of slope failures in Alpine regions (e.g., Huggel et al., 2011). Yet, measuring the geological and hydrological properties and processes of those permafrost environments, both in the Arctic and in Alpine settings, is difficult due to inaccessibility, sensitive ecosystems, and the harsh environmental conditions, which is causing a data gap associated with those properties and processes. Geophysical techniques are known to complement point observations and to assess the intermediate depths (1 - 10's of $\mathrm{m}$ ) at spatial and temporal resolutions critical to understanding the impact of climate change on permafrost hydrological dynamics (Kneisel et al., 2008; Dafflon et al., 2017; Minsley et al., 2012; Farzamian et al., 2020). This is because electrical and seismic properties of soils and rocks, particularly at temperatures below freezing, are highly sensitive to variations in temperature and thus ice content (Wu et al., 2017; Dou et al., 2016). Hence, in frozen environments, seismic and electrical methods are often used to image the geological variation, but also the temporal dynamics of permafrost systems. (Hilbich, 2010; Uhlemann et al., 2021b; Buchli et al., 2013; Scandroglio et al., 2021). GPR and magnetic resonance techniques are also used frequently due to their sensitivity to the unfrozen water content in such environments (Parsekian et al., 2019; Campbell et al., 2018). 


\section{Independent inversion and joint interpretation}

Many studies have employed multiple geophysical methods to image the characteristics, and derive the formation and thermo-hydrological functioning of permafrost environments. For instance, Emmert and Kneisel (2021) combine ERT and GPR data to investigate the internal structure of palsas, i.e., peat mounds underlain by permafrost, in central Iceland. Based on their data they could assign the studied palsas to different development stages, highlighting recent changes in environmental conditions that impacted and changed the trajectory of palsa development. To investigate the controls of thermal degradation of a rock glacier in the Turtmann valley, Switzerland, Buchli et al. (2013) use a combination of seismic and GPR data, together with geotechnical investigations and multi-level temperature measurements. While the seismic data were used to identify the top of permafrost, and confirmed by borehole temperature measurements, GPR data proved useful in identifying the active shear zone of the rock glacier, which was validated through depth-resolved deformation measurements. This integrated study shows that using a combination of geophysical measurements, detailed geotechnical and thermo-hydrological investigations the thermo-hydromechanical dynamics within a degrading, creeping rock glacier could be imaged, thereby providing insights into the factors influencing the stability of the rock glacier.

\section{Joint inversion}

Formulating a petrophysical link between electrical and seismic properties of rocks, Hauck et al. (2011) built the basis for a number of recent studies employing petrophysical joint inversion of ERT and SRT data sets (e.g., Wagner et al., 2019; Mollaret et al., 2020; Steiner et al., 2021). In their model, Hauck et al. (2011) define the frozen subsurface to consist of four phases: rock, air, and unfrozen and frozen water (i.e., the four-phase model - 4PM). Employing Archie's law and an extension of Timur's time-averaging equation, both independently inverted geophysical data sets can be linked to provide estimates of the volumetric fraction of each phase in the subsurface. While it is shown to provide robust estimates of air and water content, distinguishing between rock and ice proved difficult because of their similar electrical and seismic properties. Since the electrical and seismic data were inverted independently, the 4PM model applied to these tomographic images can return nonphysical values, like negative volume fractions, and does not account for other constraints such as mass-conservation laws. To overcome this limitation, Wagner et al. (2019) developed this approach further and used the 4PM model as the petrophysical link for a joint inversion of ERT and SRT data (Fig. 19). Rather than solving for the geophysical property distribution, i.e., electrical resistivity and seismic slowness, this approach solves directly for the distribution of the four phases. Doing so, Wagner et al. (2019) 
could include other constraints such as the mass-conservation law, and could show that only physical values were obtained. They also demonstrated that for petrophysical joint inversion, if the porosity distribution is known, it can result in more accurate estimates, in particular for the ice content. Although the petrophysical joint inversion provides more robust estimates of the ice/air/water/rock content of the subsurface, the pronounced sensitivity to the subsurface porosity distribution has yet to be overcome. This has also been shown by Steiner et al. (2021), who compare the two approaches in detail based on data from the summit of Hoher Sonnblick, Austria. Using GPR data as structural constraints within the petrophysical joint inversion (i.e., a combination of the workflows illustrated in Fig. 1B and Fig. 1C), Steiner et al. (2021) can provide an independent estimate of the subsurface structure, limiting the non-uniqueness of the approach. Applying this framework to time-lapse data, they can show that variations derived from the petrophysical joint inversion are in agreement with auxiliary data streams indicating infiltration of snow melt.

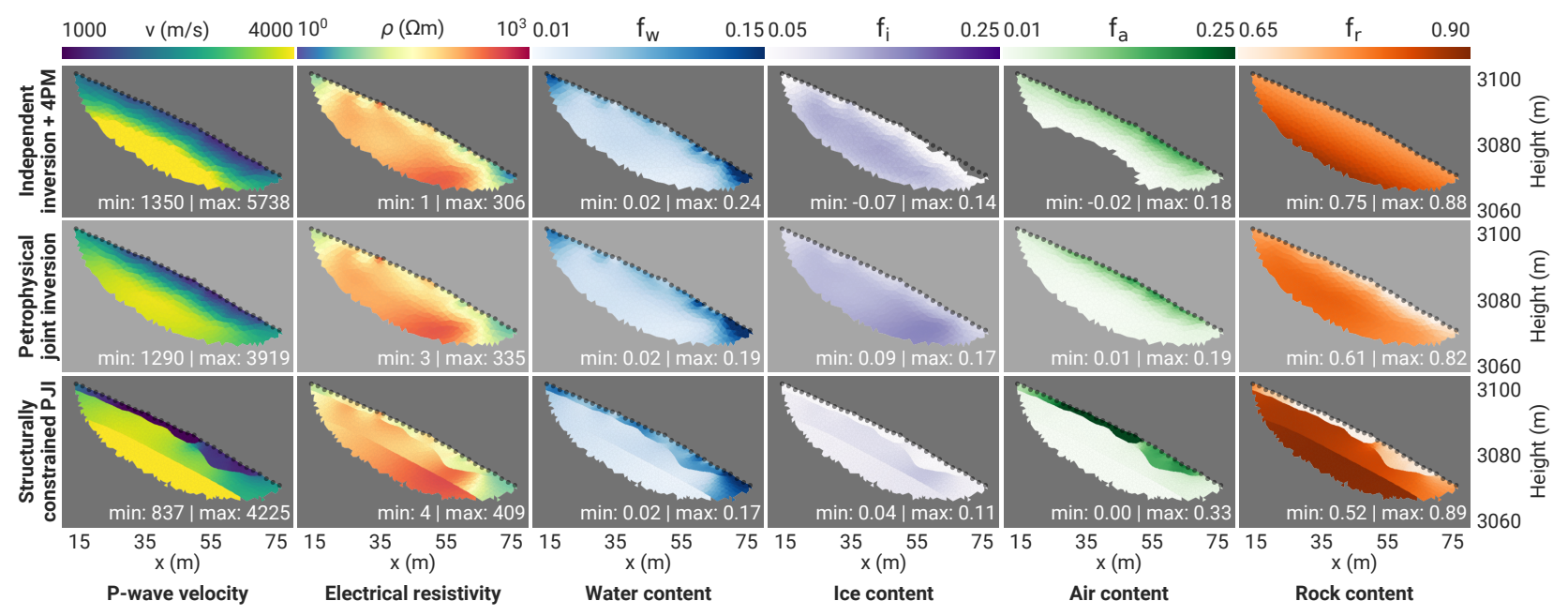

Figure 19: Quantitative imaging of an alpine permafrost site using different inversion approaches. (Top) Independent inversion of both ERT and SRT data and subsequent application of the 4PM model after Hauck et al. (2011), (Center) Petrophysical joint inversion (PJI) after Wagner et al. (2019), (Bottom) Structurally-constrained PJI after Steiner et al. (2021). The columns show P-wave velocity, electrical resistivity, and the volumetric fractions of water $\left(f_{\mathrm{w}}\right)$, ice $\left(\mathrm{f}_{\mathrm{i}}\right)$, air $\left(\mathrm{f}_{\mathrm{a}}\right)$, and rock matrix content $\left(\mathrm{f}_{\mathrm{r}}\right)$ (modified from Steiner et al., 2021).

\section{Process-based inversion}

Earth system models are widely used in Arctic and permafrost research to investigate feedback of climate warming to the release and storage of greenhouse gases, and to assess related changes in hydrology and vegetation dynamics (McGuire et al., 2018; Mekonnen et al., 2021; Jafarov et al., 2018). These models are becoming increasingly sophisticated, being able to 
model important parameters such as snow redistribution, lateral groundwater flow, and dynamic plant distributions (e.g., Coon et al., 2020; Grant and Roulet, 2002; Lawrence et al., 2019). These models have recently been coupled with geophysical data in process-based inversions to estimate soil organic carbon, porosity, and thermal conductivity of permafrost environments (Tran et al., 2016; Jafarov et al., 2020). Tran et al. (2016) develop a coupled hydrological-thermal-geophysical forward model, by linking the Community Land Model (hydrological and thermal modeling, Lawrence et al., 2019) through petrophysical relationships with the geoelectrical modeling code BERT (Rücker et al., 2006). By using a Markov chain Monte Carlo approach, Tran et al. (2016) can estimate the 1D distribution of organic carbon sand content, and estimate the petrophysical parameters linking the thermo-hydrological estimates to the geophysical data. They show that compared to separate inversion of the various input parameters, i.e., temperature, soil moisture, and electrical resistivity, the process-based inversion significantly reduced the uncertainty of the estimated parameters, particularly for shallow depths. Building on this work, Jafarov et al. (2020) use the Advanced Terrestrial Simulator (ATS, Coon et al., 2020) to estimate the 2D distribution of porosity and thermal conductivity. Including monthly ERT monitoring data led to better defined minima of the cost function, thereby providing more accurate estimates of the inverted parameters. They highlight the importance of including time-lapse ERT data, and acknowledge the importance of optimally distributing sensors to capture the dynamics and heterogeneities that are needed for accurate parameter estimations.

These studies show an increasing trend of multimethod geophysical applications in permafrost environments that are often linked to thermo-hydrological models. Due to the inaccessibility of many Arctic, Antarctic, and mountainous permafrost regions, direct observations of these processes that are critical to understand the impact of climate change are often missing. Hence, geophysical methods have frequently been used to image those processes, and these studies highlight the potential of geophysical investigations to provide critical parameter estimates, but also subsurface trends, e.g., related to deep temperature variations. Some questions still remain in this field, e.g., imaging the base of permafrost is still challenging due to the physical similarities with bedrock properties, as well as disentangling hydrological from thermal dynamics in these complex environments. Using multimethod geophysical investigations and petrophysical joint inversion approaches are likely to aid in addressing and answering these questions. 


\subsection{Geological $\mathrm{CO}_{2}$ storage}

Recent observations of increasing temperatures and more frequently occurring weather extremes provide evidence for climate warming and global climate change. The increasing volume of $\mathrm{CO}_{2}$ in the atmosphere is known to be one of the driving forces of this change. Hence, technologies are being developed that can reduce $\mathrm{CO}_{2}$ emissions, or capture $\mathrm{CO}_{2}$ and store it in geological formations. Often, similar geological units than exploited for oil and gas production are used to store $\mathrm{CO}_{2}$ and geophysical techniques have long been employed to characterize and monitor these units. Most of these developments are focused on seismic exploration and monitoring techniques, and hence not the focus of this chapter. But some studies have used multiple geophysical techniques to provide, e.g., structural constraints to the inversion of another technique, or geophysical data has been coupled with process models to provide improved estimates of the reservoir properties. These developments are often based on $\mathrm{CO}_{2}$-induced changes in seismic and electrical properties, where usually an increase in $\mathrm{CO}_{2}$ saturation relates to a decrease in seismic velocities and an increase in the electrical resistivity (Kim et al., 2013; Carcione et al., 2012).

\section{Structurally-constrained inversion}

Based on data from the Ketzin Pilot site for $\mathrm{CO}_{2}$ storage, Bergmann et al. (2014) investigate the potential of including structural constraints obtained from seismic reflection data into the inversion of surface-downhole ERT data. They show that by incorporating the seismic constraints, the inverted ERT data reflects more closely independent observations of the geological boundary, i.e., the location of the reservoir-caprock boundary, but also provides better estimates of the $\mathrm{CO}_{2}$ migration patterns. Through a thorough sensitivity study, Bergmann et al. (2014) also show that incorporating the seismic constraints helps to reduce the data misfit for the ERT inversion, providing models that are in better agreement with the observed data. The surface-downhole ERT measurement layout of this study, although providing ease in logistics for repeated measurements, has some limitations in terms of sensitivity and resolution. Therefore, adding the constraints from the seismic and wellbore data clearly aids in providing more detailed electrical information by reducing the number of degrees of freedom.

\section{Process-based inversion}

At the Cranfield $\mathrm{CO}_{2}$ storage site in Mississippi, various geophysical monitoring methods have been employed (e.g., Zhou et al., 2020). Doetsch et al. (2013) link time-lapse crosshole ERT measurements in an uncoupled process-based inversion, together with gas composition data, 
to a process model describing $\mathrm{CO}_{2}$ migration in the reservoir. Due to data quality limitations, the authors report that it was critical to invert the ERT data first using structural constraints derived from borehole logs. This demonstrates that uncoupled process-based inversions can be combined with other multimethod inversion approaches discussed in this chapter. The authors use the ERT-derived changes in $\mathrm{CO}_{2}$ saturation along with gas composition data to estimate reservoir permeability and effective reservoir width of their model. In doing so, they test several conceptual models and found that the reservoir response is inadequately captured by a radial model. A three-layer model with horizontal layers, whose widths and permeability values are obtained from the process-based inversion, is able to explain the observations and the estimated permeability values are in agreement with those obtained from laboratory measurements on rock cores. The authors conclude that fully-coupled inversion of time-lapse ERT data would be an important extension of their work.

Building upon the geophysical characterization and monitoring of the Ketzin $\mathrm{CO}_{2}$ storage site Bergmann et al. (2016), a fully-coupled process-based inversion approach has been developed (Wagner and Wiese, 2018; Wiese et al., 2018). Combining commercial reservoir modeling codes to simulate the hydrology and $\mathrm{CO}_{2}$ migration within the reservoir and surrounding with geoelectrical forward modeling, Wiese et al. (2018) show that these models can be integrated into a fully-coupled inversion approach that fits both hydrological and geophysical observations. To reduce the dimensionality of this complex problem, Wiese et al. (2018) make use of so-called superparameters, which are factors that link a subset of eigenvectors to the actual model parameters. Through this approach, the full Jacobian, including both hydrological and geophysical sensitivities, only needs to be calculated once at the beginning of the inversion, and following iterations calculate the sensitivity for these superparameters only. This is shown to reduce the computational time by a factor of at least four. This process-based, fully-coupled inversion scheme is shown to be able to fit the observed data, with smaller errors for the hydraulic data than for the resistivity data. Applied to actual data from the Ketzin test site, Wagner and Wiese (2018) show that this model also accurately predicts acquired field data, particularly the gas pressures and $\mathrm{CO}_{2}$ migration patterns, thereby confirming the accuracy of the estimated permeability field.

These studies show that multimethod imaging aids to provide a better understanding of subsurface storage units, as shown here for $\mathrm{CO}_{2}$ storage applications, but also for, e.g., shallow geothermal applications (e.g., Lesparre et al., 2019). While most studies combine seismic and ERT methods, also crosshole EM and GPR should provide valuable information, particularly in the area of enhanced geothermal systems, where fracture zones may need to be characterized. 


\section{Remaining challenges and new frontiers}

We have reviewed the theory and applications of several multimethod imaging approaches in environmental geophysics. In the following discussion, we highlight some considerations and potential pitfalls in the use of these approaches and discuss areas, where we anticipate particular research potential in the near future.

\subsection{Potential pitfalls in multimethod geophysical imaging}

\subsubsection{Structurally-constrained inversion}

Structurally-constrained inversions disconnect spatial regularization across predefined subsurface boundaries. The effect of this can be striking (e.g., Fig. 3C) and has shown to provide clearer differentiation of subsurface units, stronger contrasts between properties, and more reliably deduced petrophysical parameters (e.g., Jiang et al., 2020). However, the obvious pitfall lies in possible uncertainties in the locations of the prescribed interfaces. Binley and Slater (2020) hence emphasize that prescribed structural constraints should always be evidence-based and used with caution. Even if the position of a particular subsurface boundary is known, another choice has to be made with regard to the degree of decoupling, i.e., a locally downweighted or fully-disconnected regularization. As both the presence and strength of the structural constraints do not solely influence the structure, but also the amplitudes of the retrieved geophysical properties, they can also impact the subsequent quantification of petrophysical properties (e.g., Steiner et al., 2021). We recommend to follow a procedure as described by Bergmann et al. (2014), in which the interplay of the coupling parameter (e.g., $\beta$ in Fig. 3E) and the overall regularization strength ( $\lambda$ in Eq. 1 ) is investigated over a range of values in light of data misfit and model misfit. If the position (or presence) of subsurface boundaries is not clear, a safer and less subjective alternative is presented by structural joint inversion approaches, which circumvent the prior prescription of expected subsurface boundaries.

\subsubsection{Structural joint inversion}

Structural joint inversions promote structural similarity in the parameter distributions of different methods, given that this similarity is supported by the observations. Yet, structural similarity between different rock properties may not necessarily exist. Structural joint inversion approaches are therefore only recommended if individual inversions of the involved methods exhibit structural similarity or if such similarity can be expected on the basis of petrophysical considerations (Linde et al., 2008). 
Practitioners may also wonder whether a coupled or cooperative joint inversion approach is more suited for their data. Linde and Doetsch (2016) point out that the advantages and disadvantages of the SCCI approach compared to the structurally-coupled joint inversion based on cross-gradients remain to be demonstrated. While we fully agree, a few differences can already be outlined that may support a case-specific decision. Structurally-coupled joint inversion based on cross-gradients uses the cross product, which is defined for two vectors in a 3D Euclidean space. This has two consequences. First, while the third dimension can be set to zero for the application of cross-gradients in 2D, it cannot be applied to 1D data (e.g., electromagnetic soundings), which is not the case for the SCCI approach, where structural information is only exchanged between two otherwise independent inversions (e.g., Skibbe et al., 2018). However, a potential pitfall of the SCCI approach lies in the appropriate choice of the coupling parameters (i.e., a and b in Eq. 5) as discussed in more detail by Skibbe et al. (2021). Second, joint inversion based on cross-gradients is particularly suited for structured rectilinear grids. In such regular discretizations where cell boundaries are either vertically or horizontally oriented, the functional can be readily computed. Its translation to unstructured meshes, however, is not straightforward. Jordi et al. (2020) present an extension of the cross-gradient method, which calculates the cross-gradient operator on the basis of a correlation model allowing to define physical length scales. This strongly reduces its dependency on the model discretization, which is particularly beneficial for unstructured meshes with varying cell sizes.

Inversions of different geophysical methods may strongly differ with regard to model discretizations, forward modeling approaches, and used inversion algorithms. Coupling these into a single objective function and inversion algorithm can thus be challenging. Based on the work of Um et al. (2014) and Gao and Zhang (2018), approaches are emerging, where the crossgradient constraint is also used in a cooperative manner to better account for varying sensitivity magnitudes and different data coverages of the methods involved.

\subsubsection{Petrophysical joint inversion}

In comparison to structural joint inversions, where the only assumption is structural similarity between multiple geophysical properties, petrophysical joint inversions require knowledge of the petrophysical relationships between the geophysical properties and the parameters of interest. These relationships are most often defined on the representative elementary volume (REV), whereas their use in coupled inversions operates at a much larger scale, which is ultimately dictated by the resolutions of the methods involved. Linde and Doetsch (2016) point out that there are few reasons to believe that the chosen parameters are applicable to both scales. Additionally, the spatial and temporal distributions of petrophysical parameters are often as- 
sumed to be constant. If practitioners encounter convergence problems in petrophysical joint inversions, which do not occur in individual inversions of their data, this is often an indication for a discrepancy in the underlying petrophysical model and/or its parameters.

Petrophysical coupling approaches can increase in robustness when applied in a monitoring context, if selected petrophysical parameters can assumed to be constant over the investigated time period (e.g., Klahold et al., 2021). Aside from time-lapse joint inversion, an interesting research avenue is also represented by a combination of structural and petrophysical coupling approaches. This may allow to produce models, which switch to qualitative structural agreement, if quantitative petrophysical agreement is not possible.

\subsubsection{Process-based inversion}

Coupled process-based inversions use a single process-based forward simulation and inversion, while in uncoupled process-based inversions, the geophysical data sets are inverted conventionally before they are linked to the dynamic subsurface process. While the former may seem more elegant and is often believed to be superior, Camporese et al. (2015) highlight that this is casedependent and uncoupled inversions can be more robust. If the overall computational time allows for it, the authors recommend to always conduct an uncoupled inversion prior to the coupled one. The uncoupled approach also provides more flexibility with respect to the type of geophysical inversion, e.g., a structural joint inversion of two geophysical methods could serve as the basis for an uncoupled process-based inversion. The indisputable advantage of the coupled approach is that the geophysical predictions are based on the physical process. While this is often interpreted as a quasi-regularization, Commer et al. (2020) argue that this can be misleading, since every ill-posed problem requires regularization and as such, coupled inversions may also require spatial smoothing of the process parameters. Previously discussed pitfalls in petrophysical joint inversions such as upscaling issues of petrophysical models or unjustified homogeneity of petrophysical parameters are equally valid for process-based inversions. In addition, inappropriate conceptual decisions made for the process model (e.g., boundary conditions) may lead to convergence problems and misinterpretations in process-based inversions of geophysical data.

\subsection{Optimal experimental design}

The discussed applications have demonstrated how geophysical methods are being used to jointly image the subsurface. In addition to the physical limitations of the methods involved, the field survey design ultimately dictates their data quality and the overall survey benefit. While considerable research effort is directed towards novel geophysical processing and inver- 
sion schemes, comparably less attention is paid to optimized geophysical experimental design. Maurer et al. (2010) highlight advances in the field of optimized geophysical survey design including examples from geoelectrical, crosshole and surface seismic, as well as microseismic monitoring methods. In electrical resistivity imaging for example, optimized experimental design approaches have been developed to identify optimal four-point measurements (Stummer et al., 2004; Wilkinson et al., 2006), optimal electrode positions for permanent monitoring (Wagner et al., 2015), as well as both simultaneously (Uhlemann et al., 2018) that are shown to improve the resolution of ERT imaging. Yet, these studies optimize electrical resistivity measurements independent of their use in integrated multimethod imaging campaigns.

A question with considerable research potential is hence: How do the sensors of various geophysical methods have to be arranged in the field to optimally complement each other? This optimality may differ if the methods are sought to be combined petrophysically or structurally. Furthermore, the trend of geophysical inquiry of dynamic subsurface processes with the aim to quantify process-relevant parameters may give rise to process-based geophysical survey design, i.e., optimal experimental design algorithms, which simultaneously optimize the positions and depths of boreholes for fluid sampling and temperature monitoring as well as those of geophysical sensors for example. Such interdisciplinary optimized experimental design approaches will have an impact on the advancement of multimethod geophysical imaging and will benefit from the increasing availability of high-performance computing systems.

\subsection{Incorporation of geological realism}

While the ill-posed inverse problem can be efficiently tamed through the use of spatial smoothness regularization, the resulting images are often hard to interpret as potentially sharp geologically boundaries tend to be smeared. A large body of literature is addressing this problem through advanced regularization strategies. Based on the minimum-gradient support for example (Portniaguine and Zhdanov, 1999), sharp changes can be allowed in the tomogram if needed (e.g., Blaschek et al., 2008; Grombacher et al., 2017). The choice of the additional regularization parameters is not straightforward and often arbitrary, but may be estimated objectively from time-lapse data (Nguyen et al., 2016). With a similar goal, but a completely different approach, Deleersnyder et al. (2021) present a regularization method, which transforms the model into the wavelet domain. This novel scale-dependent regularization term can favor both blocky and smooth models, as well as high-amplitude features embedded in an otherwise smooth model domain. Jordi et al. (2018) incorporate prior geological information through geostatistical regularization operators into 3D geophysical inversion on unstructured meshes, which lead to models in good accordance with the expected geology and improved interpretabil- 
ity, in particular for layered structures. A thorough comparison of the different regularization approaches and their benefits and limitations in the context of multimethod geophysical imaging remains to be addressed.

Incorporating known interfaces in structurally-constrained inversions can help to improve the geological realism of the resulting models. Zhou et al. (2014) for example apply image processing techniques to a guiding image in order to extract edges, which are subsequently exempt from spatial smoothness regularization promoting layer-internal consistency and sharp boundaries in-between. The guiding image could stem from a high-resolution seismic or GPR survey or a cross-section drawn by a geologist. As for other structurally-constrained inversions, where the roughness operator is only manipulated once, this static approach is dependent of the validity of the guiding image. Alternatively, the position of a sharp interface may be estimated during the joint inversion, as demonstrated in the context of bedrock detection by means of probabilistic joint inversion of electrical resistivity and seismic refraction data (de Pasquale et al., 2019). We expect that the recent availability of open and versatile geological modeling tools (e.g., de la Varga et al., 2019) will pave the way for an improved amalgamation of geophysical and geological data in joint structure-based inversion frameworks (e.g., Güdük et al., 2021; Förderer et al., 2021).

\subsection{Uncertainty quantification}

In this chapter, we have shown that the use of multiple geophysical techniques, and their coupling to process models usually result in an increased resolution enabling more detailed imaging of structural characteristics and dynamic processes. Although this suggests that joint interpretation and inversion approaches reduce the ambiguity of geophysical imaging, a detailed uncertainty quantification is often omitted, yet required to communicate limitations of geophysical parameter estimates (Linde, 2014). This may have several reasons: uncertainty quantification, particularly for multimethod investigations may (1) require a complex theoretical framework (e.g., joint posterior sampling), and (2) likely requires considerable computational resources to determine posterior parameter distributions (Linde et al., 2017). Especially for problems with a large number of parameters, such as in fully-coupled process-based inversion approaches, such analysis can become computationally prohibitive. Linde et al. (2017) highlight recent advances in the field of geophysical uncertainty quantification, noting that although uncertainty can meanwhile relatively easily be addressed in forward modeling approaches, more research is required to fully address uncertainty of measurements and petrophysical relationships, particularly for process-based modeling and inversion approaches. For more details on recent 
developments in uncertainty quantification in geophysical problems, the reader is referred to the review by Linde et al. (2017).

Highlighted by Linde et al. (2017) as an important contribution to the overall uncertainty of geophysical parameter estimation, the uncertainty in petrophysical relationships has been addressed by Tso et al. (2020). Using an ensemble-based data assimilation framework, they show that for a synthetic case the posterior distribution of petrophysical parameter estimates can be very narrow, in a real data example, the posterior distribution, and hence the uncertainty, remained wide and therefore large. Within their framework, Tso et al. (2020) estimate petrophysical parameters, yet in many other process-based or petrophysical joint inversion approaches, the petrophysical parameters are defined. Assessing the uncertainty that those assumptions introduce into the inversion remains to be addressed.

Due to the increasing complexity and the expanding range of scales investigated using modern geophysical methods, inevitably advanced numerical techniques are required to perform well on large parameter and high-dimensional spaces. Since a thorough uncertainty quantification is required to fully exploit the opportunities multimethod geophysical imaging can provide to Earth system modeling, and the use of novel machine learning approaches within the field of geophysics is rapidly increasing, we envisage that this field of research will see many advances in the near future.

\subsection{Machine learning}

Recent developments in machine learning and artificial intelligence algorithms have shown to be valuable tools in the interpretation and inversion of geophysical data (e.g., Araya-Polo et al., 2018; Delforge et al., 2021; Brillante et al., 2016). These algorithms provide the opportunity to jointly analyze multiple data streams, ranging from hydrological and geophysical to remote sensing data, while exploiting co-variability that may exist between the various parameters. This has been highlighted as an emerging technology, particularly in multi-disciplinary research, such as watershed science (Hubbard et al., 2020).

Machine learning, and classification in particular, has been used quite extensively to map above/below ground variability across multiple scales. Hubbard et al. (2013) studied an Arctic permafrost environment and applied clustering approaches to both remote sensing and geophysical data independently and observed a strong co-variability of the spatial distribution of the two sets of clusters. This co-variability indicates a strong linkage between surface properties, i.e., microtopography, and subsurface properties, i.e., active layer thickness and permafrost distribution. 
By exploiting these links, Wainwright et al. (2015) used an unsupervised clustering approach to jointly analyse remote sensing and surface geophysical data to identify zones that provide the most unique spatial grouping of above and below ground observations. The co-variability of vegetation distribution, elevation, permafrost and hydraulic properties, as imaged by the geophysical methods, allowed them to automatically classify the landscape into various Arctic landforms, such as high- or low-centered polygons, and their surrounding drainage areas.

Similarly, Falco et al. (2019) use a support vector machine to estimate the spatial distribution of key plant communities using remote sensing, geophysical, and soil sampling data and show that by including information on the soil structure, the classification of particularly meadow plants can be significantly refined. Making use of a random forest regression model, Falco et al. (2019) also predict the spatial variability of the soil electrical properties from key topographic indices, such as slope, curvature and topographic wetness index. They achieve a Pearson's correlation of 0.93 between the measured and predicted data and show that for their analysed hillslope, the slope is the most important predictor of soil electrical properties.

A similar approach was also followed by Terry et al. (2019), which map the discharge of a contaminant plume into surface water at a crude oil spill site using EMI, GPR, and specific conductance and surface observations of the spill through linear and logistic regression approaches. They compare their machine learning-based classification results with conventional inversion approaches and show that the machine learning approach was less sensitive to variations in the pore water conductivity, that may obscure electrical changes caused by the oil spill. Although these studies were applied to comparably small domains (i.e., hillslope and site scales), it shows that such approaches, both in terms of classification but also prediction, are viable tools to do similar analysis on much larger scales, such as watersheds or basins, at which remote sensing data is readily available, and geophysical data is becoming available (e.g., Zamudio et al., 2021; Minsley et al., 2021).

Recent developments aim particularly at analysing large data sets, such as those produced by distributed acoustic sensing (DAS) technologies, which are increasingly being used for environmental applications (e.g., Rodríguez Tribaldos and Ajo-Franklin, 2021), where conventional data analysis tools are either too time or memory consuming. For instance, Dumont et al. (2020) present a deep learning approach that, based on image recognition methods, assesses the likelihood of a DAS recording to contain surface wave energy. Given the vast amount of data that can be recorded by DAS (e.g., Lindsey and Martin, 2021), such approaches are very valuable, as they allow for an automated, focused analysis of subsets of the data that actually contain the information needed for, e.g., time-lapse imaging of near-surface dynamics. Although most of these recent developments are focused on seismological studies, similar approaches, particu- 
larly with regards to parameter estimation, are also emerging for electrical and electromagnetic methods (e.g., Moghadas, 2020).

Machine learning and artificial intelligence techniques may path the way for novel analysis strategies and applications of geophysical data to provide direct estimates of parameters required by, e.g., hydrological or geomechanical models, and may aid in linking various, independent observations into mutually agreeing observations of key subsurface parameters, critical for a range of environmental problems, such as groundwater management, early warning of natural hazards, or precision agriculture. Hence, machine learning approaches are likely becoming a standard tool in the analysis of multimethod geophysical investigations, as shown by the increasing number of studies already implementing them.

\subsection{Opportunities through open-source software developments}

The reviewed joint and process-based inversion approaches implicate considerable technical challenges, since they require coupling of different geophysical forward models, petrophysical relations, and process simulations within single inversion frameworks. This represents an obstacle for many practitioners and particularly novices in the field. Even technically versatile users often build customized solutions by coupling different and potentially proprietary forward simulators impeding scientific reproducibility.

Fortunately in recent years, many open-source software packages for different geophysical methods have been developed. Some of these allow to simulate different geophysical methods as well as subsurface processes and hence offer opportunities to realize joint and process-based inversions (e.g., Cockett et al., 2015; Johnson et al., 2017; Rücker et al., 2017). Increased usage and collaborative community-driven development of these tools have the potential to accelerate progress in multimethod geophysical imaging, while ensuring its transparency and reproducibility. Since many of these codes are either written in or readily linked to popular programming languages like Python, which also see rapid developments in novel aspects such as deep learning, this will further facilitate the development and combination of various approaches for integrated geophysical imaging. This integration is likely allowing for exciting new developments in the field of near-surface geophysics, such as parameter estimation, feature extraction, and complex process-based geophysical analysis, supported by, e.g., physics-informed machine learning approaches. 


\section{Concluding remarks}

A considerable set of approaches to combine geophysical and non-geophysical observations for high-resolution and quantitative subsurface imaging has been developed in recent years. Structurally-constrained and structural joint inversions are widely used and have matured to robust imaging methods. Their robustness can be largely attributed to the limited amount of necessary prior information when compared to petrophysically-coupled or process-based inversions, for which representative rock-physics and process models are inevitable. While structural coupling based on cross-gradients is the prevailing type of joint inversion, a detailed comparison of different structural coupling approaches remains to be addressed. An additional benefit of structural joint inversions (both coupled and cooperative), is that the structures are not prescribed as in structurally-constrained inversions. Moreover, the advent of versatile opensource geological modeling tools offers new possibilities for structure-based joint inversions of geological and geophysical observations for models with improved geological plausibility.

Several recent studies have demonstrated the applicability of multi-parameter petrophysical joint inversions. Ultimately limited by the goodness of the underlying petrophysical relation, their benefit will also depend on robust means to quantify the contributions of petrophysical and geophysical data uncertainties within the overall parameter estimation. Such thorough uncertainty assessment is required to provide meaningful estimates of parameter distributions and dynamics, and should be included as a standard part of multimethod geophysical imaging approaches.

Process-based inversion has been widely adopted in many fields in environmental geophysics and the coupled approach is perhaps the most prevailing. The increased computational cost due to the involved process model is one reason why process-based inversion is still widely used in a deterministic manner lacking a full probabilistic description and quantification of parameter uncertainties. While the use of physics-informed surrogate models and new approaches from machine learning in general can help to improve computational efficiency, the uncertainty introduced by surrogate models also requires careful treatment.

We reviewed the use and potentials of multimethod imaging approaches in critical zone and groundwater investigations, natural hazards, permafrost degradation, and geological $\mathrm{CO}_{2}$ storage. While many sophisticated petrophysical models as well as flow and transport simulation codes exist within the scope of the saturated and vadose zone, the numerical description of, e.g., freeze and thaw processes and their effect on geophysical properties is still insufficiently understood. Consequently, petrophysical and process-based inversions in cryospheric applications are only starting to emerge. Similar limitations also exist for the application to natural 
hazards, where geophysical properties often need to be linked to geotechnical parameters. Recent developments in this field show great potential, but the link to, e.g., open-source slope stability models (in the case of landslides) is still mostly rudimentary.

Future research avenues of interest for multimethod geophysical imaging in all applications include experimental design optimized for multiple methods and process monitoring, the use of surrogate models and other machine learning approaches, and the incorporation of geological observations and realism leveraging upon community-driven open-source software to ensure transparency, reproducibility and more rapid development in the interdisciplinary and exciting field of multimethod geophysical imaging.

\section{Acknowledgements}

The authors gratefully acknowledge Andy Binley for his careful and knowledgeable review as well as editor Cédric Schmelzbach for the fruitful discussions throughout the writing phase. The original manuscript further benefited from the thorough proofreading and constructive comments by Maximilian Weigand, Andrea Balza Morales, and Nico Skibbe.

The contribution of Florian Wagner was supported the Dr. Erich Ritter foundation in cooperation with the Water Science Alliance, which allowed the original idea for this chapter to be developed during a research visit at Lawrence Berkeley National Laboratory.

The contribution of Sebastian Uhlemann was supported by the Watershed Function Scientific Focus Area funded by the U.S. Department of Energy, Office of Science, Office of Biological and Environmental Research under Award no. DE-AC02-05CH11231, as well as a Laboratory Directed Research and Development Grant awarded to Sebastian Uhlemann. 


\section{References}

Aines, R., et al. (2002). The Stochastic Engine Initiative: Improving Prediction of Behavior in Geologic Environments We Cannot Directly Observe. Technical report, Lawrence Livermore National Lab., CA (US). UCRL-ID-148221.

Araya-Polo, M., Jennings, J., Adler, A., \& Dahlke, T. (2018). Deep-learning tomography. The Leading Edge, 37(1), 58-66, https://doi.org/10.1190/tle37010058.1.

Aster, R. C., Borchers, B., \& Thurber, C. H. (2013). Chapter nine - nonlinear regression. In R. C. Aster, B. Borchers, \& C. H. Thurber (Eds.), Parameter Estimation and Inverse Problems (Second Edition) (pp. 217-238). Boston: Academic Press, second edition edition.

Banerjee, B. \& Gupta, S. K. (1975). Hidden layer problem in seismic refraction work*. Geophysical Prospecting, 23(4), 642-652, https://doi.org/10.1111/j.1365-2478.1975.tb01550.x.

Bekler, T., Ekinci, Y. L., Demirci, A., Erginal, A. E., \& Ertekin, C. (2011). Characterization of a landslide using seismic refraction, electrical resistivity and hydrometer methods, Adatepe - Çanakkale, NW Turkey. Journal of Environmental and Engineering Geophysics, 16(3), 115-126, https://doi.org/10.2113/jeeg16.3.115.

Bergmann, P., et al. (2016). Review on geophysical monitoring of $\mathrm{CO}_{2}$ injection at Ketzin, Germany. Journal of Petroleum Science and Engineering, 139, 112-136, https://doi.org/ 10.1016/j.petrol.2015.12.007.

Bergmann, P., et al. (2014). Combination of seismic reflection and constrained resistivity inversion with an application to 4D imaging of the $\mathrm{CO}_{2}$ storage site, Ketzin, Germany. GEOPHYSICS, 79(2), B37-B50, https://doi.org/10.1190/geo2013-0131.1.

Bichler, A., Bobrowsky, P., Best, M., Douma, M., Hunter, J., Calvert, T., \& Burns, R. (2004). Three-dimensional mapping of a landslide using a multi-geophysical approach: the Quesnel Forks landslide. Landslides, 1(1), 29-40, https://doi.org/10.1007/ s10346-003-0008-7.

Bièvre, G., Jongmans, D., Winiarski, T., \& Zumbo, V. (2012). Application of geophysical measurements for assessing the role of fissures in water infiltration within a clay landslide (Trièves area, French Alps). Hydrological Processes, 26, 2128-2142, https://doi.org/10. 1002/hyp.7986.

Binley, A., Hubbard, S. S., Huisman, J. A., Revil, A., Robinson, D. A., Singha, K., \& Slater, L. D. (2015). The emergence of hydrogeophysics for improved understanding of subsurface processes over multiple scales. Water Resources Research, 51(6), 3837-3866, https://doi. org/10.1002/2015WR017016.

Binley, A. \& Slater, L. (2020). Resistivity and Induced Polarization: Theory and Applications to the Near-Surface Earth. Cambridge University Press.

Blaschek, R., Hördt, A., \& Kemna, A. (2008). A new sensitivity-controlled focusing regularization scheme for the inversion of induced polarization data based on the minimum gradient support. GEOPHYSICS, 73(2), F45-F54, https://doi.org/10.1190/1.2824820. 
Blazevic, L., Bodet, L., Pasquet, S., Linde, N., Jougnot, D., \& Longuevergne, L. (2020). TimeLapse Seismic and Electrical Monitoring of the Vadose Zone during a Controlled Infiltration Experiment at the Ploemeur Hydrological Observatory, France. Water, 12(5), 1230, https://doi.org/10.3390/w12051230.

Blöschl, G., et al. (2019). Twenty-three unsolved problems in hydrology (UPH)-a community perspective. Hydrological Sciences Journal, 64(10), 1141-1158, https:/ / doi.org/10.1080/ 02626667.2019.1620507.

Bouchedda, A., Chouteau, M., Binley, A., \& Giroux, B. (2012). 2-D joint structural inversion of cross-hole electrical resistance and ground penetrating radar data. Journal of Applied Geophysics, 78, 52-67, https://doi.org/10.1016/j.jappgeo.2011.10.009.

Boucher, M., et al. (2009). Contribution of geophysical surveys to groundwater modelling of a porous aquifer in semiarid Niger: An overview. Comptes Rendus Geoscience, 341 (10-11), 800-809, https://doi.org/10.1016/j.crte.2009.07.008.

Brantley, S., et al. (2006). Frontiers in Exploration of the Critical Zone: Report of a workshop sponsored by the National Science Foundation (NSF). Technical report, Newark, DE.

Brillante, L., Bois, B., Mathieu, O., \& Lévêque, J. (2016). Electrical imaging of soil water availability to grapevine: a benchmark experiment of several machine-learning techniques. Precision Agriculture, 17(6), 637-658, https://doi.org/10.1007/s11119-016-9441-1.

Buchli, T., Merz, K., Zhou, X., Kinzelbach, W., \& Springman, S. M. (2013). Characterization and Monitoring of the Furggwanghorn Rock Glacier, Turtmann Valley, Switzerland: Results from 2010 to 2012. Vadose Zone Journal, 12(1), vzj2012.0067, https:/ /doi.org/10.2136/ vzj2012.0067.

Busato, L., Boaga, J., Perri, M. T., Majone, B., Bellin, A., \& Cassiani, G. (2019). Hydrogeophysical characterization and monitoring of the hyporheic and riparian zones: The Vermigliana Creek case study. Science of The Total Environment, 648, 1105-1120, https: //doi.org/10.1016/j.scitotenv.2018.08.179.

Busch, S., Weihermüller, L., Huisman, J. A., Steelman, C. M., Endres, A. L., Vereecken, H., \& van der Kruk, J. (2013). Coupled hydrogeophysical inversion of time-lapse surface GPR data to estimate hydraulic properties of a layered subsurface. Water Resources Research, 49, 8480-8494, https://doi.org/10.1002/2013WR013992.

Campbell, S., Affleck, R. T., \& Sinclair, S. (2018). Ground-penetrating radar studies of permafrost, periglacial, and near-surface geology at McMurdo Station, Antarctica. Cold Regions Science and Technology, 148, 38-49, https://doi.org/10.1016/j.coldregions.2017. 12.008 .

Camporese, M., Cassiani, G., Deiana, R., Salandin, P., \& Binley, A. (2015). Coupled and uncoupled hydrogeophysical inversions using ensemble Kalman filter assimilation of ERTmonitored tracer test data. Water Resources Research, 51 (5), 3277-3291, https://doi.org/ 10.1002/2014WR016017. 
Capizzi, P. \& Martorana, R. (2014). Integration of constrained electrical and seismic tomographies to study the landslide affecting the cathedral of Agrigento. Journal of Geophysics and Engineering, 11(4), 045009, https://doi.org/10.1088/1742-2132/11/4/045009.

Carbonel, D., et al. (2014). Evaluation of trenching, ground penetrating radar (GPR) and electrical resistivity tomography (ERT) for sinkhole characterization. Earth Surface Processes and Landforms, 39(2), 214-227, https://doi.org/10.1002/esp.3440.

Carcione, J. M., Gei, D., Picotti, S., \& Michelini, A. (2012). Cross-hole electromagnetic and seismic modeling for $\mathrm{CO}_{2}$ detection and monitoring in a saline aquifer. Journal of Petroleum Science and Engineering, 100, 162-172, https://doi.org/10.1016/j.petrol.2012.03.018.

Carey, A. M., Paige, G. B., Carr, B. J., Holbrook, W. S., \& Miller, S. N. (2019). Characterizing hydrological processes in a semiarid rangeland watershed: A hydrogeophysical approach. Hydrological Processes, 33(5), 759-774, https://doi.org/10.1002/hyp.13361.

Claerbout, J. F. \& Muir, F. (1973). Robust modeling with erratic data. GEOPHYSICS, 38(5), 826-844, https://doi.org/10.1190/1.1440378.

Cockett, R., Kang, S., Heagy, L. J., Pidlisecky, A., \& Oldenburg, D. W. (2015). SimPEG: An open source framework for simulation and gradient based parameter estimation in geophysical applications. Computers \& Geosciences, 85, 142-154, https://doi.org/10.1016/j.cageo. 2015.09.015.

Commer, M., Pride, S. R., Vasco, D. W., Finsterle, S., \& Kowalsky, M. B. (2020). Imaging of a fluid injection process using geophysical data - A didactic example. GEOPHYSICS, 85(2), W1-W16, https://doi.org/10.1190/geo2018-0787.1.

Coon, E., et al. (2020). Advanced Terrestrial Simulator. Technical report, U.S. Department of Energy, USA.

Crawford, M. M. \& Bryson, L. S. (2018). Assessment of active landslides using field electrical measurements. Engineering Geology, 233, 146-159, https://doi.org/10.1016/j.enggeo. 2017.11.012.

Crook, N., Binley, A., Knight, R., Robinson, D. A., Zarnetske, J., \& Haggerty, R. (2008). Electrical resistivity imaging of the architecture of substream sediments. Water Resources Research, 46(4), W00D13, https://doi.org/10.1029/2008WR006968.

Dafflon, B., Hubbard, S., Ulrich, C., Peterson, J., Wu, Y., Wainwright, H., \& Kneafsey, T. J. (2016). Geophysical estimation of shallow permafrost distribution and properties in an ice-wedge polygon-dominated arctic tundra region. GEOPHYSICS, 81(1), WA247WA263, https://doi.org/10.1190/geo2015-0175.1.

Dafflon, B., Oktem, R., Peterson, J., Ulrich, C., Tran, A. P., Romanovsky, V., \& Hubbard, S. S. (2017). Coincident aboveground and belowground autonomous monitoring to quantify covariability in permafrost, soil, and vegetation properties in Arctic tundra. Journal of Geophysical Research: Biogeosciences, 122(6), 1321-1342, https://doi.org/10.1002/ 2016JG003724. 
de la Varga, M., Schaaf, A., \& Wellmann, F. (2019). GemPy 1.0: open-source stochastic geological modeling and inversion. Geoscientific Model Development, 12(1), 1-32, https://doi.org/10.5194/gmd-12-1-2019.

de Pasquale, G., Linde, N., \& Greenwood, A. (2019). Joint probabilistic inversion of DC resistivity and seismic refraction data applied to bedrock/regolith interface delineation. Journal of Applied Geophysics, 170, 103839, https://doi.org/10.1016/j.jappgeo.2019.103839.

deGroot Hedlin, C. \& Constable, S. (1990). Occam's inversion to generate smooth, twodimensional models from magnetotelluric data. GEOPHYSICS, 55(12), 1613-1624, https: //doi.org/10.1190/1.1442813.

Deleersnyder, W., Maveau, B., Hermans, T., \& Dudal, D. (2021). Inversion of electromagnetic induction data using a novel wavelet-based and scale-dependent regularization term. Geophysical Journal International, 226(3), 1715-1729, https://doi.org/10.1093/ gji/ggab182.

Delforge, D., Watlet, A., Kaufmann, O., Van Camp, M., \& Vanclooster, M. (2021). Time-series clustering approaches for subsurface zonation and hydrofacies detection using a real timelapse electrical resistivity dataset. Journal of Applied Geophysics, 184, 104203, https: //doi.org/10.1016/j.jappgeo.2020.104203.

Delouis, B., Giardini, D., Lundgren, P., \& Salichon, J. (2002). Joint Inversion of InSAR, GPS, Teleseismic, and Strong-Motion Data for the Spatial and Temporal Distribution of Earthquake Slip: Application to the 1999 Izmit Mainshock. Bulletin of the Seismological Society of America, 92(1), 278-299, https://doi.org/10.1785/0120000806.

Doetsch, J., et al. (2013). Constraining $\mathrm{CO}_{2}$ simulations by coupled modeling and inversion of electrical resistance and gas composition data. International Journal of Greenhouse Gas Control, 18, 510-522, https://doi.org/10.1016/j.ijggc.2013.04.011.

Doetsch, J., Linde, N., \& Binley, A. (2010). Structural joint inversion of time-lapse crosshole ERT and GPR traveltime data. Geophysical Research Letters, 37(24), 1-6, https://doi.org/ 10.1029/2010GL045482.

Doetsch, J., Linde, N., Pessognelli, M., Green, A. G., \& Günther, T. (2012a). Constraining 3-D electrical resistance tomography with GPR reflection data for improved aquifer characterization. Journal of Applied Geophysics, 78, 68-76, https://doi.org/10.1016/j.jappgeo. 2011.04.008.

Doetsch, J., Linde, N., Vogt, T., Binley, A., \& Green, A. G. (2012b). Imaging and quantifying salt-tracer transport in a riparian groundwater system by means of 3D ERT monitoring. GEOPHYSICS, 77(5), B207-B218, https://doi.org/10.1190/geo2012-0046.1.

Domenzain, D., Bradford, J., \& Mead, J. (2020a). Joint inversion of full-waveform groundpenetrating radar and electrical resistivity data: Part 1. GEOPHYSICS, 85(6), H97-H113, https://doi.org/10.1190/geo2019-0754.1.

Domenzain, D., Bradford, J., \& Mead, J. (2020b). Joint inversion of full-waveform groundpenetrating radar and electrical resistivity data — Part 2: Enhancing low frequencies with 
the envelope transform and cross gradients. GEOPHYSICS, 85(6), H115-H132, https: //doi.org/10.1190/geo2019-0755.1.

Dou, S., Nakagawa, S., Dreger, D., \& Ajo-Franklin, J. (2016). A rock-physics investigation of unconsolidated saline permafrost: P-wave properties from laboratory ultrasonic measurements. GEOPHYSICS, 81(1), WA233-WA245, https://doi.org/10.1190/geo2015-0176.1.

Dumont, V., Tribaldos, V. R., Ajo-Franklin, J., \& Wu, K. (2020). Deep Learning for Surface Wave Identification in Distributed Acoustic Sensing Data. In 2020 IEEE International Conference on Big Data (Big Data) (pp. 1293-1300).: IEEE.

Emmert, A. \& Kneisel, C. (2021). Internal structure and palsa development at Orravatnsrústir Palsa Site (Central Iceland), investigated by means of integrated resistivity and groundpenetrating radar methods. Permafrost and Periglacial Processes, (November 2020), https: //doi.org/10.1002/ppp.2106.

Falco, N., et al. (2019). Investigating microtopographic and soil controls on a mountainous meadow plant community using high-resolution remote sensing and surface geophysical data. Journal of Geophysical Research: Biogeosciences, 124, 1618-1636, https://doi.org/ 10.1029/2018JG004394.

Fan, Y., et al. (2019). Hillslope Hydrology in Global Change Research and Earth System Modeling. Water Resources Research, 55(2), 1737-1772, https://doi.org/10.1029/ 2018 WR023903.

Farzamian, M., et al. (2020). Detailed detection of active layer freeze-thaw dynamics using quasi-continuous electrical resistivity tomography (Deception Island, Antarctica). Cryosphere, 14(3), 1105-1120, https://doi.org/10.5194/tc-14-1105-2020.

Ferré, T., et al. (2009). Critical Steps for the Continuing Advancement of Hydrogeophysics. Eos, Transactions American Geophysical Union, 90(23), 200, https://doi.org/10.1029/ 2009EO230004.

Finn, C. A., Deszcz-Pan, M., Ball, J. L., Bloss, B. J., \& Minsley, B. J. (2018). Three-dimensional geophysical mapping of shallow water saturated altered rocks at Mount Baker, Washington: Implications for slope stability. Journal of Volcanology and Geothermal Research, 357, 261-275, https://doi.org/10.1016/j.jvolgeores.2018.04.013.

Finsterle, S. \& Kowalsky, M. B. (2008). Joint Hydrological-Geophysical Inversion for Soil Structure Identification. Vadose Zone Journal, 7(1), 287-293, https://doi.org/10.2136/ vzj2006.0078.

Förderer, A., Wellmann, F., \& Wagner, F. M. (2021). Geoelectrical imaging of subsurface discontinuities and heterogeneities using low-dimensional parameterizations. In EGU General Assembly 2021, online, 19-30 Apr 2021.

Gallardo, L. A. (2004). Joint two-dimensional DC resistivity and seismic travel time inversion with cross-gradients constraints. Journal of Geophysical Research, 109(B3), B03311, https: //doi.org/10.1029/2003JB002716.

Gallardo, L. A. (2007). Multiple cross-gradient joint inversion for geospectral imaging. Geophysical Research Letters, 34(19), L19301, https://doi.org/10.1029/2007GL030409. 
Gallardo, L. A. \& Meju, M. A. (2003). Characterization of heterogeneous near-surface materials by joint 2D inversion of dc resistivity and seismic data. Geophysical Research Letters, 30(13), https://doi.org/10.1029/2003GL017370.

Gallardo, L. A. \& Meju, M. A. (2011). Structure-coupled multiphysics imaging in geophysical sciences. Reviews of Geophysics, 49(1), RG1003, https://doi.org/10.1029/2010RG000330.

Gao, J. \& Zhang, H. (2018). An efficient sequential strategy for realizing cross-gradient joint inversion: method and its application to 2-d cross borehole seismic traveltime and DC resistivity tomography. Geophysical Journal International, 213(2), 1044-1055, https:// doi.org/10.1093/gji/ggy026.

Gómez-Ortiz, D. \& Martín-Crespo, T. (2012). Assessing the risk of subsidence of a sinkhole collapse using ground penetrating radar and electrical resistivity tomography. Engineering Geology, 149-150, 1-12, https://doi.org/10.1016/j.enggeo.2012.07.022.

Grant, R. F. \& Roulet, N. T. (2002). Methane efflux from boreal wetlands: Theory and testing of the ecosystem model Ecosys with chamber and tower flux measurements. Global Biogeochemical Cycles, 16(4), 1054, https://doi.org/10.1029/2001GB001702.

Grombacher, D., Fiandaca, G., Behroozmand, A. A., \& Auken, E. (2017). Comparison of stabiliser functions for surface NMR inversions. Near Surface Geophysics, 15(5), 533-544, https://doi.org/10.3997/1873-0604.2017027.

Güdük, N., de la Varga, M., Kaukolinna, J., \& Wellmann, F. (2021). Model-based probabilistic inversion using magnetic data: A case study on the kevitsa deposit. Geosciences, 11(4), 150, https://doi.org/10.3390/geosciences11040150.

Günther, T., Dlugosch, R., Holland, R., \& Yaramanci, U. (2010). Aquifer characterization using coupled inversion of DC/IP and mrs data on a hydrogeophysical test-site. In Symposium on the Application of Geophysics to Engineering and Environmental Problems 2010: Environment and Engineering Geophysical Society.

Günther, T. \& Müller-Petke, M. (2012). Hydraulic properties at the North Sea island of Borkum derived from joint inversion of magnetic resonance and electrical resistivity soundings. Hydrology and Earth System Sciences, 16(9), 3279-3291, https://doi.org/ 10.5194/hess-16-3279-2012.

Günther, T. \& Rücker, C. (2006). A General Approach for Introducing Information into Inversion and Examples from DC Resistivity Inversion. In Near Surface 2006 - 12th EAGE European Meeting of Environmental and Engineering Geophysics Helsinki, Finland,: European Association of Geoscientists \& Engineers.

Günther, T. \& Rücker, C. (2008). A New Joint Inversion Approach Applied to the Combined Tomography of DC Resistivity and Seismic Refraction Data, (pp. 1196-1202).

Haber, E. \& Oldenburg, D. (1997). Joint inversion: A structural approach. Inverse Problems, 13(1), 63-77, https://doi.org/10.1088/0266-5611/13/1/006.

Hauck, C., Böttcher, M., \& Maurer, H. (2011). A new model for estimating subsurface ice content based on combined electrical and seismic data sets. The Cryosphere, 5(2), 453468, https://doi.org/10.5194/tc-5-453-2011. 
Hausmann, J., Steinel, H., Kreck, M., Werban, U., Vienken, T., \& Dietrich, P. (2013). Twodimensional geomorphological characterization of a filled abandoned meander using geophysical methods and soil sampling. Geomorphology, 201, 335-343, https://doi.org/10. 1016/j.geomorph.2013.07.009.

Hayes, J. L., Riebe, C. S., Steven Holbrook, W., Flinchum, B. A., \& Hartsough, P. C. (2019). Porosity production in weathered rock: Where volumetric strain dominates over chemical mass loss. Science Advances, 5(9), 1-12, https://doi.org/10.1126/sciadv.aao0834.

Heincke, B., Günther, T., Dalsegg, E., Rønning, J. S., Ganerød, G. V., \& Elvebakk, H. (2010). Combined three-dimensional electric and seismic tomography study on the Åknes rockslide in western Norway. Journal of Applied Geophysics, 70(4), 292-306, https://doi.org/ 10.1016/j.jappgeo.2009.12.004.

Hellman, K., Ronczka, M., Günther, T., Wennermark, M., Rücker, C., \& Dahlin, T. (2017). Structurally coupled inversion of ERT and refraction seismic data combined with clusterbased model integration. Journal of Applied Geophysics, 143, 169-181, https://doi.org/ 10.1016/j.jappgeo.2017.06.008.

Hilbich, C. (2010). Time-lapse refraction seismic tomography for the detection of ground ice degradation. The Cryosphere, 4(3), 243-259, https://doi.org/10.5194/tc-4-243-2010.

Hinnell, A. C., Ferré, T. P. A., Vrugt, J. A., Huisman, J. A., Moysey, S., Rings, J., \& Kowalsky, M. B. (2010). Improved extraction of hydrologic information from geophysical data through coupled hydrogeophysical inversion. Water Resources Research, 46(4), W00D40, https: //doi.org/10.1029/2008WR007060.

Holbrook, W. S., et al. (2014). Geophysical constraints on deep weathering and water storage potential in the Southern Sierra Critical Zone Observatory. Earth Surface Processes and Landforms, 39, 366-380, https://doi.org/10.1002/esp.3502.

Hubbard, S. S., et al. (2001). Hydrogeological characterization of the south oyster bacterial transport site using geophysical data. Water Resources Research, 37(10), 2431-2456, https://doi.org/10.1029/2001WR000279.

Hubbard, S. S., et al. (2013). Quantifying and relating land-surface and subsurface variability in permafrost environments using LiDAR and surface geophysical datasets. Hydrogeology Journal, 21(1), 149-169, https://doi.org/10.1007/s10040-012-0939-y.

Hubbard, S. S., Varadharajan, C., Wu, Y., Wainwright, H., \& Dwivedi, D. (2020). Emerging technologies and radical collaboration to advance predictive understanding of watershed hydrobiogeochemistry. Hydrological Processes, 34(15), 3175-3182, https://doi.org/10. 1002/hyp.13807.

Huggel, C., Clague, J. J., \& Korup, O. (2011). Is climate change responsible for changing landslide activity in high mountains? Earth Surface Processes and Landforms, 37(1), 7791, https://doi.org/10.1002/esp.2223.

Jafarov, E. E., Coon, E. T., Harp, D. R., Wilson, C. J., Painter, S. L., Atchley, A. L., \& Romanovsky, V. E. (2018). Modeling the role of preferential snow accumulation in through talik devel- 
opment and hillslope groundwater flow in a transitional permafrost landscape. Environmental Research Letters, 13(10), 105006, https://doi.org/10.1088/1748-9326/aadd30.

Jafarov, E. E., et al. (2020). Estimation of subsurface porosities and thermal conductivities of polygonal tundra by coupled inversion of electrical resistivity, temperature, and moisture content data. The Cryosphere, 14(1), 77-91, https://doi.org/10.5194/tc-14-77-2020.

Jardani, A., Revil, A., Santos, F., Fauchard, C., \& Dupont, J. P. (2007). Detection of preferential infiltration pathways in sinkholes using joint inversion of self-potential and EM-34 conductivity data. Geophysical Prospecting, 55(5), 749-760, https://doi.org/10.1111/j. 1365-2478.2007.00638.x.

Jiang, C., et al. (2020). Magnetic resonance tomography constrained by ground-penetrating radar for improved hydrogeophysical characterization. GEOPHYSICS, 85(6), JM13-JM26, https://doi.org/10.1190/geo2020-0052.1.

Johnson, T. C., Hammond, G. E., \& Chen, X. (2017). PFLOTRAN-e4d: A parallel open source PFLOTRAN module for simulating time-lapse electrical resistivity data. Computers \& Geosciences, 99, 72-80, https://doi.org/10.1016/j.cageo.2016.09.006.

Johnson, T. C., Versteeg, R. J., Huang, H., \& Routh, P. S. (2009). Data-domain correlation approach for joint hydrogeologic inversion of time-lapse hydrogeologic and geophysical data. GEOPHYSICS, 74(6), F127-F140, https://doi.org/10.1190/1.3237087.

Jongmans, D. \& Garambois, S. (2007). Geophysical investigation of landslides: a review. Bulletin de la Société géologique de France, 33(1), 101-112.

Jordi, C., Doetsch, J., Günther, T., Schmelzbach, C., Maurer, H., \& Robertsson, J. O. A. (2020). Structural joint inversion on irregular meshes. Geophysical Journal International, 220(3), 1995-2008, https://doi.org/10.1093/gji/ggz550.

Jordi, C., Doetsch, J., Günther, T., Schmelzbach, C., \& Robertsson, J. O. (2018). Geostatistical regularization operators for geophysical inverse problems on irregular meshes. Geophysical Journal International, 213(2), 1374-1386, https://doi.org/10.1093/gji/ggy055.

Khan, M. Y., et al. (2021). Investigation of coseismic liquefaction-induced ground deformation associated with the $2019 \mathrm{M}_{\mathrm{W}}$ 5.8 Mirpur, Pakistan, earthquake using near-surface electrical resistivity tomography and geological data. Near Surface Geophysics, 19(2), 169-182, https://doi.org/10.1002/nsg.12148.

Kim, J., Nam, M. J., \& Matsuoka, T. (2013). Estimation of $\mathrm{CO}_{2}$ saturation during both $\mathrm{CO}_{2}$ drainage and imbibition processes based on both seismic velocity and electrical resistivity measurements. Geophysical Journal International, 195(1), 292-300, https://doi.org/10. 1093/gji/ggt232.

Klahold, J., Hauck, C., \& Wagner, F. M. (2021). Ice or rock matrix? Improved quantitative imaging of Alpine permafrost evolution through time-lapse petrophysical joint inversion. In EGU General Assembly 2021, online, 19-30 Apr 2021.

Kneisel, C., Hauck, C., Fortier, R., \& Moorman, B. (2008). Advances in geophysical methods for permafrost investigations. Permafrost and Periglacial Processes, 19(2), 157-178, https: //doi.org/10.1002/ppp.616. 
Knödel, K., Lange, G., \& Voigt, H.-J. (2007). Environmental Geology. Berlin, Heidelberg: Springer Berlin Heidelberg.

Kowalsky, M. B., Chen, J., \& Hubbard, S. S. (2006). Joint inversion of geophysical and hydrological data for improved subsurface characterization. The Leading Edge, 25(6), 730-734, https://doi.org/10.1190/1.2210057.

Kowalsky, M. B., et al. (2005). Estimation of field-scale soil hydraulic and dielectric parameters through joint inversion of GPR and hydrological data. Water Resources Research, 41(11), W11425, https://doi.org/10.1029/2005WR004237.

Kuhl, A. S., Kendall, A. D., Van Dam, R. L., \& Hyndman, D. W. (2018). Quantifying soil water and root dynamics using a coupled hydrogeophysical inversion. Vadose Zone Journal, 17, 170154, https://doi.org/10.2136/vzj2017.08.0154.

Lawrence, D. M., et al. (2019). The Community Land Model Version 5: Description of New Features, Benchmarking, and Impact of Forcing Uncertainty. Journal of Advances in Modeling Earth Systems, 11(12), 4245-4287, https://doi.org/10.1029/2018MS001583.

Lesparre, N., Robert, T., Nguyen, F., Boyle, A., \& Hermans, T. (2019). 4D electrical resistivity tomography (ERT) for aquifer thermal energy storage monitoring. Geothermics, 77, 368382, https://doi.org/10.1016/j.geothermics.2018.10.011.

Linde, N. (2014). Falsification and corroboration of conceptual hydrological models using geophysical data. Wiley Interdisciplinary Reviews: Water, 1(2), 151-171, https://doi.org/10. 1002/wat2.1011.

Linde, N., Binley, A., Tryggvason, A., Pedersen, L. B., \& Revil, A. (2006). Improved hydrogeophysical characterization using joint inversion of cross-hole electrical resistance and ground-penetrating radar traveltime data. Water Resources Research, 42(12), W12404, https://doi.org/10.1029/2006WR005131.

Linde, N. \& Doetsch, J. (2016). Joint Inversion in Hydrogeophysics and Near-Surface Geophysics. In M. Moorkamp, P. G. Lelièvre, N. Linde, \& A. Khan (Eds.), Integrated Imaging of the Earth: Theory and Applications (pp. 117-135). Hoboken, NJ: John Wiley \& Sons, Inc.

Linde, N., Ginsbourger, D., Irving, J., Nobile, F., \& Doucet, A. (2017). On uncertainty quantification in hydrogeology and hydrogeophysics. Advances in Water Resources, 110, 166-181, https://doi.org/10.1016/j.advwatres.2017.10.014.

Linde, N., Tryggvason, A., Peterson, J. E., \& Hubbard, S. S. (2008). Joint inversion of crosshole radar and seismic traveltimes acquired at the South Oyster Bacterial Transport Site. GEOPHYSICS, 73(4), G29-G37, https://doi.org/10.1190/1.2937467.

Lindsey, N. J. \& Martin, E. R. (2021). Fiber-Optic Seismology. Annual Review of Earth and Planetary Sciences, 49(1), 309-336, https://doi.org/10.1146/annurev-earth-072420-065213.

Lochbühler, T., Doetsch, J., Brauchler, R., \& Linde, N. (2013). Structure-coupled joint inversion of geophysical and hydrological data. GEOPHYSICS, 78(3), ID1-ID14, https://doi.org/ 10.1190/geo2012-0460.1. 
Looms, M. C., Jensen, K. H., Binley, A., \& Nielsen, L. (2008). Monitoring Unsaturated Flow and Transport Using Cross-Borehole Geophysical Methods. Vadose Zone Journal, 7(1), 227-237, https://doi.org/10.2136/vzj2006.0129.

MacDonald, A. M., et al. (2021). Mapping groundwater recharge in Africa from ground observations and implications for water security. Environmental Research Letters, 16(3), 034012, https://doi.org/10.1088/1748-9326/abd661.

Malehmir, A., Bastani, M., Krawczyk, C. M., Gurk, M., Ismail, N., Polom, U., \& Persson, L. (2013). Geophysical assessment and geotechnical investigation of quick-clay landslides - A Swedish case study. Near Surface Geophysics, 11(3), 341-350, https://doi.org/10. 3997/1873-0604.2013010.

Mary, B., et al. (2020). Time-lapse monitoring of root water uptake using electrical resistivity tomography and mise-à-la-masse: a vineyard infiltration experiment. SOIL, 6(1), 95-114, https://doi.org/10.5194/soil-6-95-2020.

Maurer, H., Curtis, A., \& Boerner, D. E. (2010). Recent advances in optimized geophysical survey design. GEOPHYSICS, 75(5), 75A177-75A194, https://doi.org/10.1190/1.3484194.

Mawer, C., Parsekian, A., Pidlisecky, A., \& Knight, R. (2016). Characterizing Heterogeneity in Infiltration Rates During Managed Aquifer Recharge. Groundwater, 54(6), 818-829, https://doi.org/10.1111/gwat.12423.

McClymont, A. F., Roy, J. W., Hayashi, M., Bentley, L. R., Maurer, H., \& Langston, G. (2011). Investigating groundwater flow paths within proglacial moraine using multiple geophysical methods. Journal of Hydrology, 399(1-2), 57-69, https://doi.org/10.1016/j.jhydrol. 2010.12.036.

McGuire, A. D., et al. (2018). Dependence of the evolution of carbon dynamics in the northern permafrost region on the trajectory of climate change. Proceedings of the National Academy of Sciences, 115(15), 3882-3887, https://doi.org/10.1073/pnas.1719903115.

Mekonnen, Z. A., Riley, W. J., Grant, R. F., \& Romanovsky, V. E. (2021). Changes in precipitation and air temperature contribute comparably to permafrost degradation in a warmer climate. Environmental Research Letters, 16(2), 024008, https://doi.org/10. 1088/1748-9326/abc444.

Merritt, A. J., et al. (2014). 3D ground model development for an active landslide in Lias mudrocks using geophysical, remote sensing and geotechnical methods. Landslides, 11(4), 537-550, https://doi.org/10.1007/s10346-013-0409-1.

Minsley, B., et al. (2021). Airborne geophysical surveys demonstrate new capability for mapping system-scale subsurface architecture of the lower Mississippi Valley. Communications Earth \& Environment, 2, 131.

Minsley, B. J., et al. (2012). Airborne electromagnetic imaging of discontinuous permafrost. Geophysical Research Letters, 39(2), 1-8, https://doi.org/10.1029/2011GL050079.

Moghadas, D. (2020). One-dimensional deep learning inversion of electromagnetic induction data using convolutional neural network. Geophysical Journal International, 222(1), 247259, https://doi.org/10.1093/gji/ggaa161. 
Mohammadi Vizheh, M., Oskooi, B., Bastani, M., \& Kalscheuer, T. (2020). Using GPR Data as Constraints in RMT Data Inversion for Water Content Estimation: A Case Study in Heby, Sweden. Pure and Applied Geophysics, 177(6), 2903-2929, https://doi.org/10. 1007/s00024-019-02391-1.

Mollaret, C., Wagner, F. M., Hilbich, C., Scapozza, C., \& Hauck, C. (2020). Petrophysical joint inversion applied to alpine permafrost field sites to image subsurface ice, water, air and rock contents. Front. Earth Sci., 8, 85, https://doi.org/10.3389/feart.2020.00085.

Moorkamp, M., Lelièvre, P. G., Linde, N., \& Khan, A., Eds. (2016a). Integrated Imaging of the Earth. John Wiley \& Sons, Inc.

Moorkamp, M., Lelièvre, P. G., Linde, N., \& Khan, A. (2016b). Introduction. In M. Moorkamp, P. G. Lelièvre, N. Linde, \& A. Khan (Eds.), Integrated Imaging of the Earth: Theory and Applications (pp. 1-6). Hoboken, NJ: John Wiley \& Sons, Inc.

Moravec, B., et al. (2020). Resolving deep critical zone architecture in complex volcanic terrain. Journal of Geophysical Research: Earth Surface, 125(2019), e2019JF005189, https://doi. org/10.1029/2019jf005189.

Nguyen, F., Kemna, A., Robert, T., \& Hermans, T. (2016). Data-driven selection of the minimumgradient support parameter in time-lapse focused electric imaging. GEOPHYSICS, 81(1), A1-A5, https://doi.org/10.1190/geo2015-0226.1.

Oldenburg, D. W., McGillivray, P. R., \& Ellis, R. G. (1993). Generalized Subspace Methods For Large-Scale Inverse Problems. Geophysical Journal International, 114(1), 12-20, https: //doi.org/10.1111/j.1365-246X.1993.tb01462.x.

Parsekian, A. D., Creighton, A. L., Jones, B. M., \& Arp, C. D. (2019). Surface nuclear magnetic resonance observations of permafrost thaw below floating, bedfast, and transitional ice lakes. Geophysics, 84(3), EN33-EN45, https://doi.org/10.1190/geo2018-0563.1.

Parsekian, A. D., Singha, K., Minsley, B. J., Holbrook, W. S., \& Slater, L. (2015). Multiscale geophysical imaging of the critical zone. Reviews of Geophysics, 53, 1-26, https://doi. org/10.1002/2014RG000465.

Peterson, D. E., Finn, C. A., \& Bedrosian, P. A. (2021). Airborne Geophysical Imaging of Weak Zones on Iliamna Volcano, Alaska: Implications for Slope Stability. Journal of Geophysical Research: Solid Earth, 126(3), 1-21, https://doi.org/10.1029/2020JB020807.

Portniaguine, O. \& Zhdanov, M. S. (1999). Focusing geophysical inversion images. GEOPHYSICS, 64(3), 874-887, https://doi.org/10.1190/1.1444596.

Reynolds, J. M. (2011). An Introduction to Applied and Environmental Geophysics. John Wiley \& Sons, Ltd., 2nd editio edition.

Rittgers, J. B., Revil, A., Mooney, M. A., Karaoulis, M., Wodajo, L., \& Hickey, C. J. (2016). Timelapse joint inversion of geophysical data with automatic joint constraints and dynamic attributes. Geophysical Journal International, 207(3), 1401-1419, https://doi.org/10. 1093 /gji/ggw346.

Rodríguez Tribaldos, V. \& Ajo-Franklin, J. B. (2021). Aquifer Monitoring Using Ambient Seismic Noise Recorded With Distributed Acoustic Sensing (DAS) Deployed on Dark Fiber. 
Journal of Geophysical Research: Solid Earth, 126(4), 1-20, https://doi.org/10.1029/ 2020JB021004.

Ronczka, M., Hellman, K., Günther, T., Wisén, R., \& Dahlin, T. (2017). Electric resistivity and seismic refraction tomography: A challenging joint underwater survey at Äspö Hard Rock Laboratory. Solid Earth, 8(3), 671-682, https://doi.org/10.5194/se-8-671-2017.

Rücker, C., Günther, T., \& Spitzer, K. (2006). Three-dimensional modelling and inversion of dc resistivity data incorporating topography - I. Modelling. Geophysical Journal International, 166(2), 495-505, https://doi.org/10.1111/j.1365-246X.2006.03010.x.

Rücker, C., Günther, T., \& Wagner, F. M. (2017). pyGIMLi: An open-source library for modelling and inversion in geophysics. Computers \& Geosciences, 109, 106-123, https://doi.org/10. 1016/j.cageo.2017.07.011.

Samyn, K., Mathieu, F., Bitri, A., Nachbaur, A., \& Closset, L. (2014). Integrated geophysical approach in assessing karst presence and sinkhole susceptibility along flood-protection dykes of the Loire River, Orléans, France. Engineering Geology, 183, 170-184, https: //doi.org/10.1016/j.enggeo.2014.10.013.

Sass, O., Bell, R., \& Glade, T. (2008). Comparison of GPR, 2D-resistivity and traditional techniques for the subsurface exploration of the Öschingen landslide, Swabian Alb (Germany). Geomorphology, 93, 89-103, https://doi.org/10.1016/j.geomorph.2006.12.019.

Sauvin, S., Lecomte, I., Bazin, S., L'Heureux, J.-S., Vanneste, M., Solberg, I.-L., \& Dalsegg, E. (2013). Towards geophysical and geotechnical integration for quick-clay mapping in Norway. Near Surface Geophysics, 11, 613-623, https://doi.org/10.3997/1873-0604. 2012064.

Scandroglio, R., Draebing, D., Offer, M., \& Krautblatter, M. (2021). 4D quantification of alpine permafrost degradation in steep rock walls using a laboratory-calibrated electrical resistivity tomography approach. Near Surface Geophysics, 19(2), 241-260, https: //doi.org/10.1002/nsg.12149.

Scanlon, B. R., Faunt, C. C., Longuevergne, L., Reedy, R. C., Alley, W. M., McGuire, V. L., \& McMahon, P. B. (2012). Groundwater depletion and sustainability of irrigation in the US High Plains and Central Valley. Proceedings of the National Academy of Sciences, 109(24), 9320-9325, https://doi.org/10.1073/pnas.1200311109.

Scheibe, T. D. \& Chien, Y.-J. (2003). An Evaluation of Conditioning Data for Solute Transport Prediction. Ground Water, 41 (2), 128-141, https://doi.org/10.1111/j.1745-6584.2003. tb02577.x.

Schmutz, M., Guérin, R., Andrieux, P., \& Maquaire, O. (2009). Determination of the 3D structure of an earthflow by geophysical methods. Journal of Applied Geophysics, 68(4), 500-507, https://doi.org/10.1016/j.jappgeo.2008.12.004.

Schuur, E. A. G., et al. (2015). Climate change and the permafrost carbon feedback. Nature, 520(7546), 171-179, https://doi.org/10.1038/nature14338.

Shailaja, G., Kadam, A. K., Gupta, G., Umrikar, B. N., \& Pawar, N. J. (2019). Integrated geophysical, geospatial and multiple-criteria decision analysis techniques for delineation of 
groundwater potential zones in a semi-arid hard-rock aquifer in Maharashtra, India. Hydrogeology Journal, 27(2), 639-654, https://doi.org/10.1007/s10040-018-1883-2.

Skibbe, N., Günther, T., \& Müller-Petke, M. (2018). Structurally coupled cooperative inversion of magnetic resonance with resistivity soundings. GEOPHYSICS, 83(6), JM51-JM63, https://doi.org/10.1190/geo2018-0046.1.

Skibbe, N., Günther, T., \& Müller-Petke, M. (2021). Improved hydrogeophysical imaging by structural coupling of two-dimensional magnetic resonance and electrical resistivity tomography. GEOPHYSICS, 86(5), WB135-WB146, https://doi.org/10.1190/ geo2020-0593.1.

Socco, L. V., Jongmans, D., Boiero, D., Stocco, S., Maraschini, M., Tokeshi, K., \& Hantz, D. (2010). Geophysical investigation of the Sandalp rock avalanche deposits. Journal of Applied Geophysics, 70(4), 277-291, https://doi.org/10.1016/j.jappgeo.2009.12.005.

Steelman, C. M., Klazinga, D. R., Cahill, A. G., Endres, A. L., \& Parker, B. L. (2017). Monitoring the evolution and migration of a methane gas plume in an unconfined sandy aquifer using time-lapse GPR and ERT. Journal of Contaminant Hydrology, 205, 12-24, https: //doi.org/10.1016/j.jconhyd.2017.08.011.

Steiner, M., Wagner, F. M., Maierhofer, T., \& Schöner, W. Flores Orozco, A. (2021). Improved estimation of ice and water contents in Alpine permafrost through constrained petrophysical joint inversion: The Hoher Sonnblick case study. GEOPHYSICS, 86(5), WB119-WB133, https://doi.org/10.1190/geo2020-0592.1.

Steklova, K. \& Haber, E. (2017). Joint hydrogeophysical inversion: state estimation for seawater intrusion models in 3D. Computational Geosciences, 21(1), 75-94, https://doi.org/10. 1007/s10596-016-9595-y.

Stummer, P., Maurer, H., \& Green, A. G. (2004). Experimental design: Electrical resistivity data sets that provide optimum subsurface information. GEOPHYSICS, 69(1), 120-139, https://doi.org/10.1190/1.1649381.

Telford, W., Geldart, L., \& Sheriff, R. (1990). Applied Geophysics. Cambridge, UK: Cambridge University Press, second edi edition.

Terry, N., Day-Lewis, F. D., Lane, J. W., Trost, J. J., \& Bekins, B. A. (2019). Geophysical mapping of plume discharge to surface water at a crude oil spill site: Inversion versus machine learning. GEOPHYSICS, 84(5), EN67-EN80, https://doi.org/10.1190/geo2018-0690.1.

Thayer, D., et al. (2018). Geophysical Measurements to Determine the Hydrologic Partitioning of Snowmelt on a Snow-Dominated Subalpine Hillslope. Water Resources Research, 54(6), 3788-3808, https://doi.org/10.1029/2017WR021324.

Tran, A. P., Dafflon, B., Hubbard, S. S., Kowalsky, M. B., Long, P., Tokunaga, T. K., \& Williams, K. H. (2016). Quantifying shallow subsurface water and heat dynamics using coupled hydrological-thermal-geophysical inversion. Hydrology and Earth System Sciences, 20(9), 3477-3491, https://doi.org/10.5194/hess-20-3477-2016. 
Tso, C.-H. M., et al. (2020). Integrated hydrogeophysical modelling and data assimilation for geoelectrical leak detection. Journal of Contaminant Hydrology, 234, 103679, https: //doi.org/10.1016/j.jconhyd.2020.103679.

Uhlemann, S., Chambers, J., Meldrum, P., McClure, P., \& Dafflon, B. (2021a). Geophysical Monitoring of Landslides-A Step Closer Towards Predictive Understanding? In Z. Arbanas (Ed.), Understanding and Reducing Landslide Disaster Risk chapter Volume 3 - Monitoring and Early Warning, (pp. 85-91). Kyoto, Japan: World Landslide Forum.

Uhlemann, S., Dafflon, B., Peterson, J., Ulrich, C., Shirley, I., Michail, S., \& Hubbard, S. S. (2021b). Geophysical Monitoring Shows that Spatial Heterogeneity in Thermohydrological Dynamics Reshapes a Transitional Permafrost System. Geophysical Research Letters, 48(6), e2020GL091149, https://doi.org/10.1029/2020GL091149.

Uhlemann, S., Kuras, O., Richards, L. A., Naden, E., \& Polya, D. A. (2017). Electrical resistivity tomography determines the spatial distribution of clay layer thickness and aquifer vulnerability, Kandal Province, Cambodia. Journal of Asian Earth Sciences, 147, 402-414, https://doi.org/10.1016/j.jseaes.2017.07.043.

Uhlemann, S., Wilkinson, P. B., Maurer, H., Wagner, F. M., Johnson, T. C., \& Chambers, J. E. (2018). Optimized survey design for electrical resistivity tomography: combined optimization of measurement configuration and electrode placement. Geophysical Journal International, 214(1), 108-121, https://doi.org/10.1093/gji/ggy128.

Um, E. S., Commer, M., \& Newman, G. A. (2014). A strategy for coupled 3d imaging of largescale seismic and electromagnetic data sets: Application to subsalt imaging. GEOPHYSICS, 79(3), ID1-ID13, https://doi.org/10.1190/geo2013-0053.1.

von Hebel, C., et al. (2018). Understanding soil and plant interaction by combining groundbased quantitative electromagnetic induction and airborne hyperspectral data. Geophysical Research Letters, 45(15), 7571-7579, https://doi.org/10.1029/2018GL078658.

Vouillamoz, J. M., Hoareau, J., Grammare, M., Caron, D., Nandagiri, L., \& Legchenko, A. (2012). Quantifying aquifer properties and freshwater resource in coastal barriers: A hydrogeophysical approach applied at Sasihithlu (Karnataka state, India). Hydrology and Earth System Sciences, 16(11), 4387-4400, https://doi.org/10.5194/ hess-16-4387-2012.

Wagner, F. M., Günther, T., Schmidt-Hattenberger, C., \& Maurer, H. (2015). Constructive optimization of electrode locations for target-focused resistivity monitoring. GEOPHYSICS, 80(2), E29-E40, https://doi.org/10.1190/geo2014-0214.1.

Wagner, F. M., Mollaret, C., Günther, T., Kemna, A., \& Hauck, C. (2019). Quantitative imaging of water, ice and air in permafrost systems through petrophysical joint inversion of seismic refraction and electrical resistivity data. Geophysical Journal International, 219(3), 18661875, https://doi.org/10.1093/gji/ggz402.

Wagner, F. M. \& Wiese, B. U. (2018). Fully coupled inversion on a multi-physical reservoir model - Part II: The Ketzin $\mathrm{CO}_{2}$ storage reservoir. International Journal of Greenhouse Gas Control, 75, 273-281, https://doi.org/10.1016/j.ijggc.2018.04.009. 
Wainwright, H. M., et al. (2015). Identifying multiscale zonation and assessing the relative importance of polygon geomorphology on carbon fluxes in an Arctic tundra ecosystem. Journal of Geophysical Research: Biogeosciences, 120(4), 788-808, https://doi.org/10. 1002/2014JG002799.

Werban, U., al Hagrey, S. A., \& Rabbel, W. (2008). Monitoring of root-zone water content in the laboratory by 2D geoelectrical tomography. Journal of Plant Nutrition and Soil Science, 171(6), 927-935, https://doi.org/10.1002/jpln.200700145.

Wiese, B. U., Wagner, F. M., Norden, B., Maurer, H., \& Schmidt-Hattenberger, C. (2018). Fully coupled inversion on a multi-physical reservoir model - Part I: Theory and concept. International Journal of Greenhouse Gas Control, 75, 262-272, https://doi.org/10.1016/j. ijggc.2018.05.013.

Wilkinson, P. B., Meldrum, P. I., Chambers, J. E., Kuras, O., \& Ogilvy, R. D. (2006). Improved strategies for the automatic selection of optimized sets of electrical resistivity tomography measurement configurations. Geophysical Journal International, 167(3), 1119-1126, https://doi.org/10.1111/j.1365-246x.2006.03196.x.

Wu, Y., Nakagawa, S., Kneafsey, T. J., Dafflon, B., \& Hubbard, S. (2017). Electrical and seismic response of saline permafrost soil during freeze - Thaw transition. Journal of Applied Geophysics, 146, 16-26, https://doi.org/10.1016/j.jappgeo.2017.08.008.

Yamakawa, Y., Kosugi, K., Masaoka, N., Sumida, J., Tani, M., \& Mizuyama, T. (2012). Combined geophysical methods for detecting soil thickness distribution on a weathered granitic hillslope. Geomorphology, 145-146, 56-69, https://doi.org/10.1016/j.geomorph.2011.12. 035.

Zamudio, K., Minsley, B., \& Ball, L. (2021). Airborne electromagnetic, magnetic, and radiometric survey, upper East River and surrounding watersheds near Crested Butte, Colorado, 2017. Technical report, U.S. Geological Survey.

Zarroca, M., Linares, R., Roqué, C., Rosell, J., \& Gutiérrez, F. (2014). Integrated geophysical and morphostratigraphic approach to investigate a coseismic (?) translational slide responsible for the destruction of the Montclús village (Spanish Pyrenees). Landslides, 11(4), 655-671, https://doi.org/10.1007/s10346-013-0427-z.

Zhou, J., Revil, A., Karaoulis, M., Hale, D., Doetsch, J., \& Cuttler, S. (2014). Image-guided inversion of electrical resistivity data. Geophysical Journal International, 197(1), 292309, https://doi.org/10.1093/gji/ggu001.

Zhou, Q., et al. (2020). Dynamic processes of $\mathrm{CO}_{2}$ storage in the field: 1 . Multiscale and multipath channeling of $\mathrm{CO}_{2}$ flow in the hierarchical fluvial reservoir at Cranfield, Mississippi. Water Resources Research, 56(2), e2019EF001360, https://doi.org/10.1029/ 2019 wr025688. 